Portland State University

PDXScholar

Winter 4-22-2019

\title{
A Characterization of Structures Across the Hurricane Ridge Fault in the Southeastern Olympic Peninsula, WA, Hamma Hamma River Transect
}

Veronica Catherine Biesiada

Portland State University

Follow this and additional works at: https://pdxscholar.library.pdx.edu/open_access_etds

Part of the Geology Commons

Let us know how access to this document benefits you.

\section{Recommended Citation}

Biesiada, Veronica Catherine, "A Characterization of Structures Across the Hurricane Ridge Fault in the Southeastern Olympic Peninsula, WA, Hamma Hamma River Transect" (2019). Dissertations and Theses. Paper 4883.

https://doi.org/10.15760/etd.6759

This Thesis is brought to you for free and open access. It has been accepted for inclusion in Dissertations and Theses by an authorized administrator of PDXScholar. Please contact us if we can make this document more accessible: pdxscholar@pdx.edu. 
A Characterization of Structures across the Hurricane Ridge Fault in the Southeastern Olympic Peninsula, WA, Hamma Hamma River Transect

\title{
by
}

Veronica Catherine Biesiada

A thesis submitted in partial fulfillment of the requirements for the degree of

\author{
Master of Science \\ in \\ Geology
}

Thesis Committee:

Dr. Nancy Price

Dr. Ray Wells

Dr. Martin Streck

Portland State University

2019 
(C) 2019 Veronica Catherine Biesiada 


\begin{abstract}
The Olympic Mountains in northwestern Washington, USA are defined by the arcuate shape of the basaltic Crescent Formation (Fm.) that wraps a faulted and folded metasedimentary core. This area was developed through accretion and exhumation by subduction-related processes, but how this relates to the deformational history of the area is not fully understood. The region has been mapped geologically, however little focus has been placed on interpreting meso-scale structures. This study investigates structures along a transect where the Hamma Hamma River crosses the Hurricane Ridge Fault, which juxtaposes the meta-sedimentary core (west) and the basaltic Crescent Fm. (east). In the study area, the meta-sedimentary unit is characterized by outcrop scale folding with a calculated fold axis of $69 \rightarrow 342$ and a penetrative foliation with a representative orientation of $(178,75)$. The folds and foliation are crosscut by two fracture populations with representative orientations of $(115,61)$ and $(303,76)$. The pillow basalts of the Crescent Fm. are near vertical, N-S striking beds that are cut by four fault groups. Fault Groups A and B have representative orientations of $(304,37)$ and $(207,59)$, respectively, and are associated with similarly oriented fracture populations. Fault Group C crosscuts Groups A and B and has a representative orientation of $(031,61)$. Fault Group D runs subparallel to the outcrop, cuts all other faults, and has a representative orientation of $(087,50)$. From an interpretation of this data, a deformation model is presented that proposes three distinct periods of deformation under three different states of stress. The first period was dominated by E-W or ENE-WSW oriented compression, followed by a period of N-S or NNW-SSE oriented compression, followed by vertical compression.
\end{abstract}




\section{Acknowledgements}

The writing of this thesis would not have been possible without the support of several individuals.

First, I would like to thank my research group, led by our adviser, Dr. Nancy Price, and includes Christine Maher, Eleanor Lahart, Alex Dill, and Alyssa Orr. These people have listened to hours of me talking about my research and have provided critical feedback and direction. Nancy has not only helped me grow as a geologist, but also as a person. She has taught me many life lessons and has given me great advice and I truly look up to her. Christine and I have also become very close throughout this process since we share an office and have similar research interests. I deeply value our friendship and am excited to see her complete her thesis work.

I would also like to thank the other members of my committee, Dr. Martin Streck and Dr. Ray Wells. Martin has been very supportive and always has a positive attitude when it comes to my thesis. I have been a big fan of Ray's since before I even started on this thesis. I was first introduced to Ray's work as an undergraduate at Indiana University while writing a paper for my plate tectonics class. I was fascinated by the clockwise rotation model of Siletzia and thought the figures in his papers did such a great job of explaining it. When I first met him, I was honestly star struck, so it has been a true honor to get to work with him. His expertise and guidance have helped me tremendously through writing this thesis. 
My father, Michael Biesiada, mother, Jeanine Herold, and sister, Holly Biesiada have also been a great source of support throughout my whole life and especially over the last couple years. I would not be the person I am today without their love and encouragement.

Finally, I would like to thank Dr. James Brophy from the geology department of Indiana University. When I began college, I did not think of myself as an 'exceptional student'. However, Dr. Brophy saw something in me and pushed me to do a senior thesis with him and then encouraged me to apply for graduate school. He has been a big influence on me as a student and as a geologist and I am forever grateful for him believing in me. 


\section{Contents}

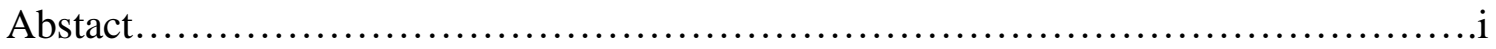

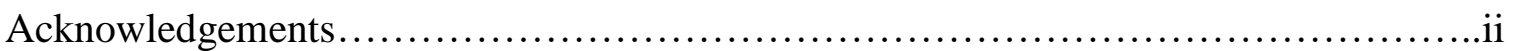

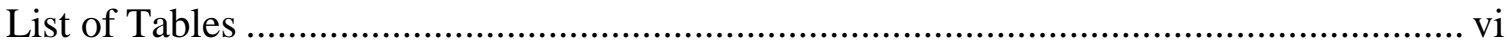

List of Figures ............................................................................................... vii

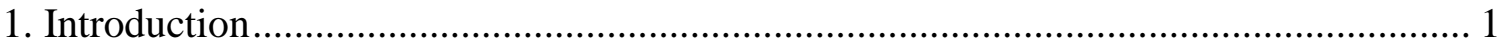

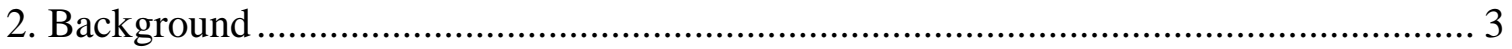

2.1 Geologic History of the Olympic Mountains ........................................................ 3

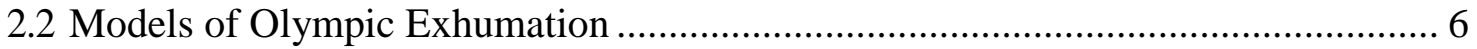

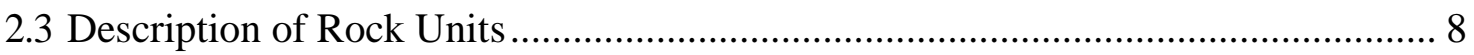

2.4 Structural Geology of the Olympic Mountains ........................................................ 9

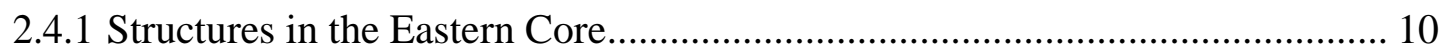

2.4.2 Structures in the Peripheral Rocks ............................................................... 14

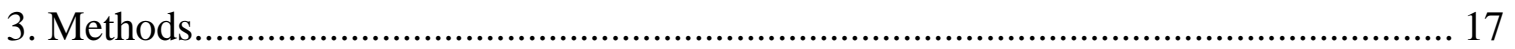

4. Meta-Sediments of the Hamma Hamma Transect ...................................................... 22

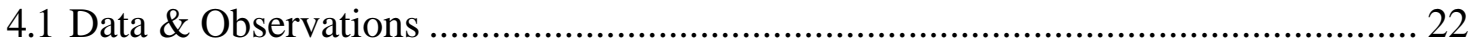

4.1.1 Field Observations ................................................................................ 22

4.1.2 Structural Orientation Data .......................................................................... 28

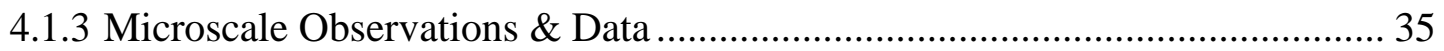

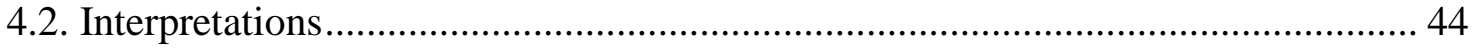

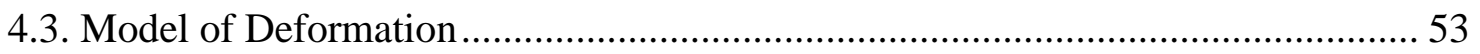

5. Pillow Basalts of the Hamma Hamma Transect …………………………………….... 57

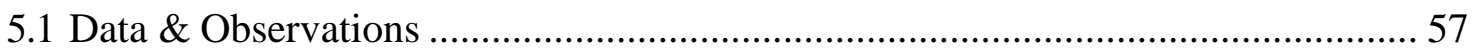

5.1.1 Field Observations ………………………………………………………..... 57

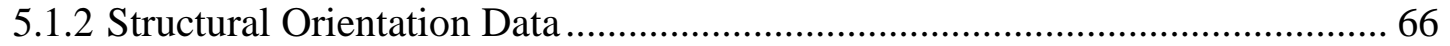

5.1.3 Microscale Data and Observations ……………………………………….... 73

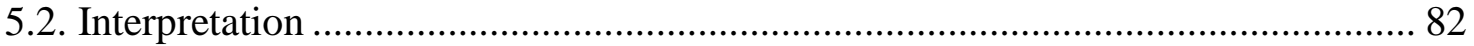

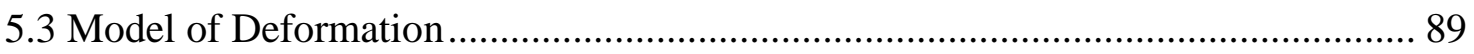

6. Comparison of Meta-Sediments and Pillow Basalts from the Hamma Hamma Transect 
7.1 Comparison of the Hamma Hamma Transect to Regional Structures ................. 100

7.1.1 Meta-Sediments of the Eastern Core .............................................................. 100

7.1.2. The Crescent Formation of the Peripheral Rocks ..................................... 102

7.2 Analysis of Regional Structures Relative to the Models for Exhumation ............ 105

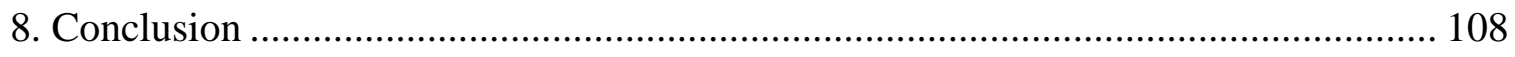

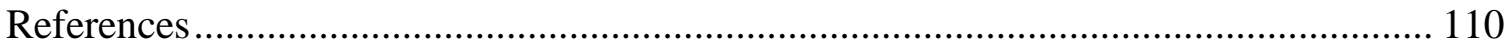

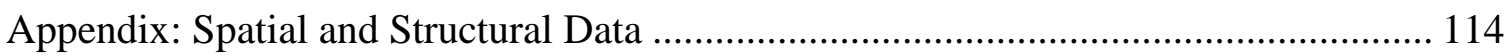




\section{List of Tables}

\begin{tabular}{|l|c|}
\hline \multicolumn{1}{|c|}{ Table Name and Title } & Page \\
\hline $\begin{array}{l}\text { Table 5.1. Description of confidence levels for identifying fault groups in the pillow basalt } \\
\text { outcrops. }\end{array}$ & 58 \\
\hline
\end{tabular}




\section{List of Figures}

\begin{tabular}{|c|c|}
\hline Figure Name and Title & Page \\
\hline Figure 2.1. Geologic map highlighting the major structures and units of the Olympic Peninsula. & 4 \\
\hline Figure 2.2. Cross sectional schematic of the Olympic Peninsula. & 5 \\
\hline $\begin{array}{l}\text { Figure 2.3. Schematic of the velocity field for the Pacific NW showing the clockwise rotation } \\
\text { of the Cascadian Forearc. }\end{array}$ & 7 \\
\hline Figure 2.4. Map of structures present in the Olympic Peninsula. & 12 \\
\hline $\begin{array}{l}\text { Figure 2.5. Structural domains for the eastern core identified by Tabor and Cady (1978) with } \\
\text { representative structural measurements (bedding, fold axes, and cleavage planes) in } \\
\text { stereographic projection. }\end{array}$ & 13 \\
\hline Figure 2.6. Plunge direction of pencil structures in the eastern core. & 14 \\
\hline $\begin{array}{l}\text { Figure 3.1. Geologic map with the sites chosen for this study. Sites } 1 \text { and } 2 \text { are in the Needles- } \\
\text { Gray Wolf Lithic Assemblage and Sites } 3 \text { and } 4 \text { are in Crescent Formation. }\end{array}$ & 18 \\
\hline $\begin{array}{l}\text { Figure 3.2. Diagram and corresponding stereonet of a representative compressional faulting } \\
\text { setting showing the geometry and principal stresses for Anderson's Theory of Faulting. }\end{array}$ & 21 \\
\hline $\begin{array}{l}\text { Figure 4.1. Diagram showing the length of each subsite of Sites } 1 \text { and } 2 \text { and the rock type } \\
\text { present at each. }\end{array}$ & 22 \\
\hline Figure 4.2. Photo of a fold hinge at Site 1c with an interpretive diagram. & 24 \\
\hline $\begin{array}{l}\text { Figure 4.3. Photo showing fractures crosscutting, but not offsetting, bedding and foliations at } \\
\text { site } 1 \mathrm{~b} \text {. }\end{array}$ & 24 \\
\hline $\begin{array}{l}\text { Figure 4.4. Photo of fractures cutting across meta-sandstone and slate layers with } \\
\text { corresponding interpretive diagrams. }\end{array}$ & 25 \\
\hline $\begin{array}{l}\text { Figure 4.5. Photos of a fractures with apparent offset at piercing points and corresponding } \\
\text { block diagrams. }\end{array}$ & 26 \\
\hline Figure 4.6. Photo of a fracture that has juxtaposed two beds of differing orientations. & 27 \\
\hline $\begin{array}{l}\text { Figure 4.7. Photo of veins cutting across bedding and foliations at Site } 1 c \text { with an interpretive } \\
\text { diagram. }\end{array}$ & 28 \\
\hline $\begin{array}{l}\text { Figure 4.8. Bedding planes and poles for the meta-sedimentary units of Sites 1a-f and } 2 \mathrm{a}-\mathrm{c} \text { and } \\
\text { axial trace measurements of identified fold hinges. }\end{array}$ & 30 \\
\hline
\end{tabular}




\begin{tabular}{|c|c|}
\hline Figure 4.9. Foliation planes and poles for the meta-sedimentary units of Sites 1a-f and $2 \mathrm{a}-\mathrm{c}$. & 31 \\
\hline $\begin{array}{l}\text { Figure 4.10. Fracture planes and poles and slickenline measurements for the meta-sedimentary } \\
\text { units of Sites } 1 \mathrm{a}-\mathrm{f} \text { and } 2 \mathrm{a}-\mathrm{c} \text {. }\end{array}$ & 32 \\
\hline Figure 4.11. Vein planes and poles for the meta-sedimentary units of Sites 1a-f and 2a-c. & 33 \\
\hline $\begin{array}{l}\text { Figure 4.12. All bedding, foliation, fracture, and vein data for the meta-sedimentary units } \\
\text { combined from Sites } 1 \mathrm{a}-\mathrm{f} \text { and } 2 \mathrm{a}-\mathrm{c} \text {. }\end{array}$ & 34 \\
\hline $\begin{array}{l}\text { Figure 4.13. Sample A (a) collected from Site } 1 \mathrm{~b} \text { and a corresponding interpretive diagram (b) } \\
\text { that outlines structures of interest and their orientations. }\end{array}$ & 37 \\
\hline $\begin{array}{l}\text { Figure 4.14. Sample B (a) collected from Site 1e and a corresponding interpretive diagram (b) } \\
\text { that outlines structures of interest and their orientations. }\end{array}$ & 38 \\
\hline $\begin{array}{l}\text { Figure 4.15. Image of a thin section created from Sample B and locations of the structures } \\
\text { shown in Figures } 4.16 \text { to } 4.20 \text {. }\end{array}$ & 39 \\
\hline $\begin{array}{l}\text { Figure 4.16. Photomicrograph and interpretive diagram of slate and meta-sandstone layers. } \\
\text { The mica-defined foliation is subparallel to bedding. Image } 1 \text { of Sample B (see Fig. 4.15) in } \\
\text { crossed-polarized light. }\end{array}$ & 40 \\
\hline $\begin{array}{l}\text { Figure 4.17. Photomicrograph and interpretive diagram of overprinting foliations in Image } 2 \text { of } \\
\text { Sample B. A second foliation (S2) crosscuts and overprints the bedding parallel foliation (S1). } \\
\text { Image shows cross-polarized light. }\end{array}$ & 41 \\
\hline $\begin{array}{l}\text { Figure 4.18. Photomicrograph and interpretive diagram of the relationship between a vein and } \\
\text { foliation in Image } 3 \text { of Sample B. The quartz vein crosscuts } S 1 \text { and is folded in an orientation } \\
\text { that correlates with S2. Image shows cross-polarized light. }\end{array}$ & 42 \\
\hline $\begin{array}{l}\text { Figure 4.19. Photomicrographs of quartz microstructures in Sample B. Microstructures are } \\
\text { consistent with bulging and subgrain rotation are both present. }\end{array}$ & 43 \\
\hline $\begin{array}{l}\text { Figure 4.20. Photomicrograph and interpretive diagram of offset on a fracture in Image } 6 \text { of } \\
\text { Sample B. The fracture is filled with very fine-grained quartz and crosscuts S1, offsetting } \\
\text { bedding layers. Image shows crossed-polarized light. }\end{array}$ & 44 \\
\hline $\begin{array}{l}\text { Figure 4.21. Outcrop map of Sites } 1 \mathrm{e} \text { and } 1 \mathrm{f} \text { showing the locations of strike and dip } \\
\text { measurements and an interpreted fold line. }\end{array}$ & 49 \\
\hline $\begin{array}{l}\text { Figure 4.22. Poles to all bedding planes with a cylindrical best fit plotted. The pole to the } \\
\text { cylindrical best fit is the calculated fold axis }(69 \rightarrow 342) \text {. The line through the fold axis and the } \\
\text { measured axial traces (outlined in Fig. } 4.4) \text { is the calculated axial plane }(337,88) \text {. The pole to } \\
\text { the axial plane is the principal stress }(\sigma 1) \text { which formed the folds }(02 \rightarrow 247) \text {. }\end{array}$ & 49 \\
\hline $\begin{array}{l}\text { Figure 4.23. Schematic geologic map of Site } 1 \text { along the Hamma Hamma Transect. The area is } \\
\text { one single fold with parasitic folds in its slaty limbs. }\end{array}$ & 50 \\
\hline
\end{tabular}


Figure 4.24. 3-dimensional block diagrams and stereographic projections for the current state

of the meta-sedimentary folds (b) and if the fold were backrotated to an upright orientation (a). If the folds started in an upright orientation, the geometry in (a) would be 'time 1' and the geometry in (b) would be 'time 2'. The strike of $\sigma 1$ required for this rotation is interpreted as NNW-SSE.

Figure 4.25. The meta-sedimentary foliation data compared to the calculated axial plane from the bedding data. The data shows that the foliation ranges around N-S striking and steeply dipping planes, which is not parallel to the axial plane as expected.

Figure 4.26. Poles to planes of the fracture and vein data from the meta-sedimentary Sites separately and then combined with $1 \%$ area contours applied. The blue boxes indicate the midpoint two data groups in the combined populations, and the blue lines show the plane to the representative midpoints.

Figure 4.27. The fracture groups from Figure 4.26 considered as conjugates and then rotated about the same axis as calculated by the fold rotation.

Figure 4.28. Stages in the deformational history of the meta-sedimentary rocks from the Hamma Hamma Transect Sites 1 and 2.

Figure 5.1. Diagram of Sites 3 and 4 showing the length of and rock type present at each subsite.

Figure 5.2. Photo of pillow basalt bedding defined by the most convex side of the pillows.

Figure 5.3. The location of each fault identified grouped by letter based on confidence and orientation. Fault Groups A, B, and C cut through the outcrops and strike non-parallel to the outcrop. Fault Group D is shown as a horizontal line because it strikes parallel to the outcrop.

Figure 5.4. Photo of a fault plane at Site $4 c$.

Figure 5.5. Photo of evidence for comminution on some faults.

Figure 5.6. Photo of slickenlines on fault planes at Site 4c

Figure 5.7. Photo of fractures cutting through the pillow basalts with an interpretive diagram at Site $4 b$.

Figure 5.8. Photo and interpretive diagram of veins cutting across an individual pillow.

Figure 5.9. Photo and interpretive diagram of a cluster of veins identified at Site $3 c$.

Figure 5.10. Photo and interpretive diagram of meta-sedimentary material between pillow basalt beds. Chunks of pillow basalt appear to be incorporated into this meta-sedimentary material. 


\begin{tabular}{|c|c|}
\hline Figure 5.11. Pillow basalt bedding planes and poles for Sites $3 a-c$ and $4 a-d$. & 68 \\
\hline $\begin{array}{l}\text { Figure 5.12. Grouping of fault plane measurements from the pillow basalt outcrops and } \\
\text { associated slickenline measurements from the faults. All slickenlines indicate a normal sense of } \\
\text { motion. }\end{array}$ & 69 \\
\hline $\begin{array}{l}\text { Figure 5.13. The orientation and location of fault planes and poles from the pillow basalt } \\
\text { outcrops, Sites } 3 a-c \text { and } 4 \mathrm{a}-\mathrm{d} \text {. Fault Groups A, B, and C cut through the outcrops whereas Fault } \\
\text { Group D strikes parallel to the outcrop. }\end{array}$ & 69 \\
\hline Figure 5.14. Fracture planes and poles from the pillow basalt outcrops, Sites $3 a-c$ and $4 a-d$ & 70 \\
\hline Figure 5.15. Poles to all fracture plane measurements from the pillow basalt outcrops. & 71 \\
\hline Figure 5.16. Vein planes and poles from the pillow basalt outcrops, Sites 3a-c and 4a-d. & 71 \\
\hline $\begin{array}{l}\text { Figure 5.17. Planes and poles of all structures from the pillow basalt outcrops, Sites } 3 a-c \text { and } \\
4 a-d .\end{array}$ & 72 \\
\hline $\begin{array}{l}\text { Figure 5.18. Slab scan images of pillow basalt Samples C and D. The pillow core, rim, and } \\
\text { meta-sedimentary matrix material are highlighted. Sample C is from Site } 3 a \text {; Sample D is from } \\
\text { Site } 4 c \text { and slabs are cut in map view. }\end{array}$ & 76 \\
\hline $\begin{array}{l}\text { Figure 5.19. Photomicrographs in polarized light of the pillow basalt ground mass at the center } \\
\text { of a pillow core and near the rim of a pillow. }\end{array}$ & 77 \\
\hline Figure 5.20. Photomicrographs in polarized light of pillow rims from Samples C and D. & 78 \\
\hline $\begin{array}{l}\text { Figure 5.21. Photomicrographs in polarized light of the sedimentary matrix from Samples C } \\
\text { and D. }\end{array}$ & 79 \\
\hline $\begin{array}{l}\text { Figure 5.22. Photomicrograph in polarized light of a calcite vein from Sample D. Calcite } \\
\text { crystals show twinning. }\end{array}$ & 79 \\
\hline $\begin{array}{l}\text { Figure 5.23. Photomicrograph in polarized light of two thin sections made from the rock slabs } \\
\text { with the apparent folds outlined as traced by the pillow rims. }\end{array}$ & 80 \\
\hline $\begin{array}{l}\text { Figure 5.24. Backscattered electron images of mineral fabric locally developed in the meta- } \\
\text { sedimentary matrix material. }\end{array}$ & 81 \\
\hline $\begin{array}{l}\text { Figure 5.25. Rose diagrams of the average alignment of oxide grains as measured from BSE } \\
\text { images. }\end{array}$ & 82 \\
\hline $\begin{array}{l}\text { Figure 5.26. Diagram showing the rotation of the pillow basalts from their orientation of } \\
\text { formation, horizontal, to their current position, vertical. }\end{array}$ & 86 \\
\hline
\end{tabular}




\begin{tabular}{|l|c|}
\hline Figure 5.27. Diagram showing how a fault forms from interconnection of a fracture network. & 86 \\
\hline $\begin{array}{l}\text { Figure 5.28. Representative orientations and an interpreted state of stress for Fault Groups A } \\
\text { and B. If conjugates, } \sigma 1 \text { is }(12 \rightarrow 265) \text { and } \sigma 3 \text { is }(52 \rightarrow 155) \text {. }\end{array}$ & 87 \\
\hline $\begin{array}{l}\text { Figure 5.29. Representative orientations and an interpreted state of stress for Fault Groups B } \\
\text { and C. If conjugates, } \sigma 1 \text { is }(87 \rightarrow 345) \text { and } \sigma 3 \text { is }(00 \rightarrow 119) \text {. }\end{array}$ & 87 \\
\hline $\begin{array}{l}\text { Figure 5.30. Estimated orientations for normal and reverse conjugates to Fault Group D. } \\
\text { Conjugates faults were estimated using measured slickenlines (black squares }\end{array}$ & 88 \\
\hline $\begin{array}{l}\text { Figure 5.31. A comparison of the state of stress for fracture planes and poles to vein planes for } \\
\text { the pillow basalts. }\end{array}$ & 88 \\
\hline $\begin{array}{l}\text { Figure 5.32. Stages in the deformational history of the pillow basalts from the Hamma Hamma } \\
\text { Transect Sites } 3 \text { and } 4 .\end{array}$ & $91-92$ \\
\hline Figure 6.1. Series of events in the model of deformation for the Hamma Hamma Transect. & $96-98$ \\
\hline $\begin{array}{l}\text { Figure 6.2. Diagrams showing the regional steps in deformationand the relative timing of the } \\
\text { events described in Figure } 6.1 \text {. }\end{array}$ & 99 \\
\hline $\begin{array}{l}\text { Figure 7.1. The Hamma Hamma Transect structural data for the meta-sedimentary Sites } 1 \text { and } \\
2 \text { compared to the data from Tabor \& Cady (1978). }\end{array}$ & 102 \\
\hline $\begin{array}{l}\text { Figure 7.2. The Hamma Hamma Transect structural data for the pillow basalt outcrops, Sites } 3 \\
\text { and 4, compared to regional structures of the Crescent Fm. }\end{array}$ & 104 \\
\hline $\begin{array}{l}\text { Figure 7.3. Hypothesis for the folding of the HRF by N-S shortening showing the proposed } \\
\text { initial and final positions of the fault. }\end{array}$ & 105 \\
\hline $\begin{array}{l}\text { Figure 7.4. A schematic of how the bedding and fault data for the Outer Edge Domains and the } \\
\text { Crescent Fm. would look if it were unfolded along with the HRF as depicted in Figure 7.3. }\end{array}$ & 107 \\
\hline
\end{tabular}




\section{Introduction}

The Olympic Mountains make up the Olympic Peninsula of northwestern Washington, USA, and mark the northern extent of the Coast Ranges, which run parallel to the coast of western Washington and Oregon. The Coast Ranges are underlain by a large basaltic terrane, Siletzia, which was accreted to North America along the Cascadia subduction zone in the Eocene, about $50 \mathrm{Ma}$. The oceanic basalt of the Crescent Formation (Fm.) in the Olympic Mountains is part of Siletzia (Wells et al., 2014), and it forms an arcuate backstop around the meta-sedimentary core of the Olympics. The core is composed of highly disrupted sediments that were accreted at the Cascadia subduction zone beneath Siletzia (Tabor \& Cady, 1978). The Hurricane Ridge Fault (HRF) is the major suture boundary between the Crescent Fm. and the meta-sedimentary core complex.

The peninsula has been mapped at the regional scale (Tabor \& Cady, 1978; Gerstel \& Lingley, 2000; Gerstel \& Lingley, 2003; Logan, 2003; Schasse, 2003a \& b), and Tabor and Cady (1979) interpreted the area to be a subduction accretionary complex exhumed by structural doming. Their model has several implications for the evolution of the major fault zones but a detailed analysis of the structures at the meso- and micro-scales has yet to be accomplished. A deeper understanding of the structures at a smaller scale will give insight into the deformational history of the rocks and better define the steps in their exhumation. The study area for this work is too small to directly make claims about the regional exhumational history, however, it is the beginning of a larger endeavor to map and understand meso- to micro- scale structures in the Olympics. 
This study analyzes structures in the rock units on both sides of the HRF and compares how strain was accommodated in the meta-sedimentary core and the Crescent Fm. For each side of the fault, a detailed description of each structure's morphological expression in outcrop is presented, followed by their orientation measurements and an analysis of micro-structures. These descriptions and data are then interpreted and compared with regional data and background literature to construct a deformational model for strain accommodation in the study area for the Crescent Fm. and the metasedimentary core. 


\section{Background}

The Olympic Peninsula is composed of core rocks and peripheral rocks that were accreted along the Cascadia subduction zone and subsequently tilted to near vertical orientations. The peripheral rocks refer to the turbidite composed Blue Mountain Unit, the basaltic Crescent Formation, and overlying sedimentary rocks. The core rocks are part of a meta-sedimentary accretionary complex, and can be divided into the eastern and western core (Fig. 2.1). The core rocks and peripheral rocks are separated by the Hurricane Ridge Fault (HRF). The core rocks are cut by major crustal faults that are subparallel to the HRF.

\subsection{Geologic History of the Olympic Mountains}

The Crescent Formation is part of Siletzia, a basaltic oceanic island chain that formed as a result of the Kula-Farallon Ridge moving over the Yellowstone Hotspot between 60 and 50 Ma (Duncan, 1982; Glassley, 1974; Wells et al., 2014). This large igneous province accreted onto North America approximately $50 \mathrm{Ma}$ and crops out in anticlinal uplifts along the Oregon and Washington Coast Range (Wells et al., 2014). The Crescent Fm. is the largest exposure of Siletzia and forms a large horseshoe shape on the peninsula that wraps around the meta-sedimentary core. 

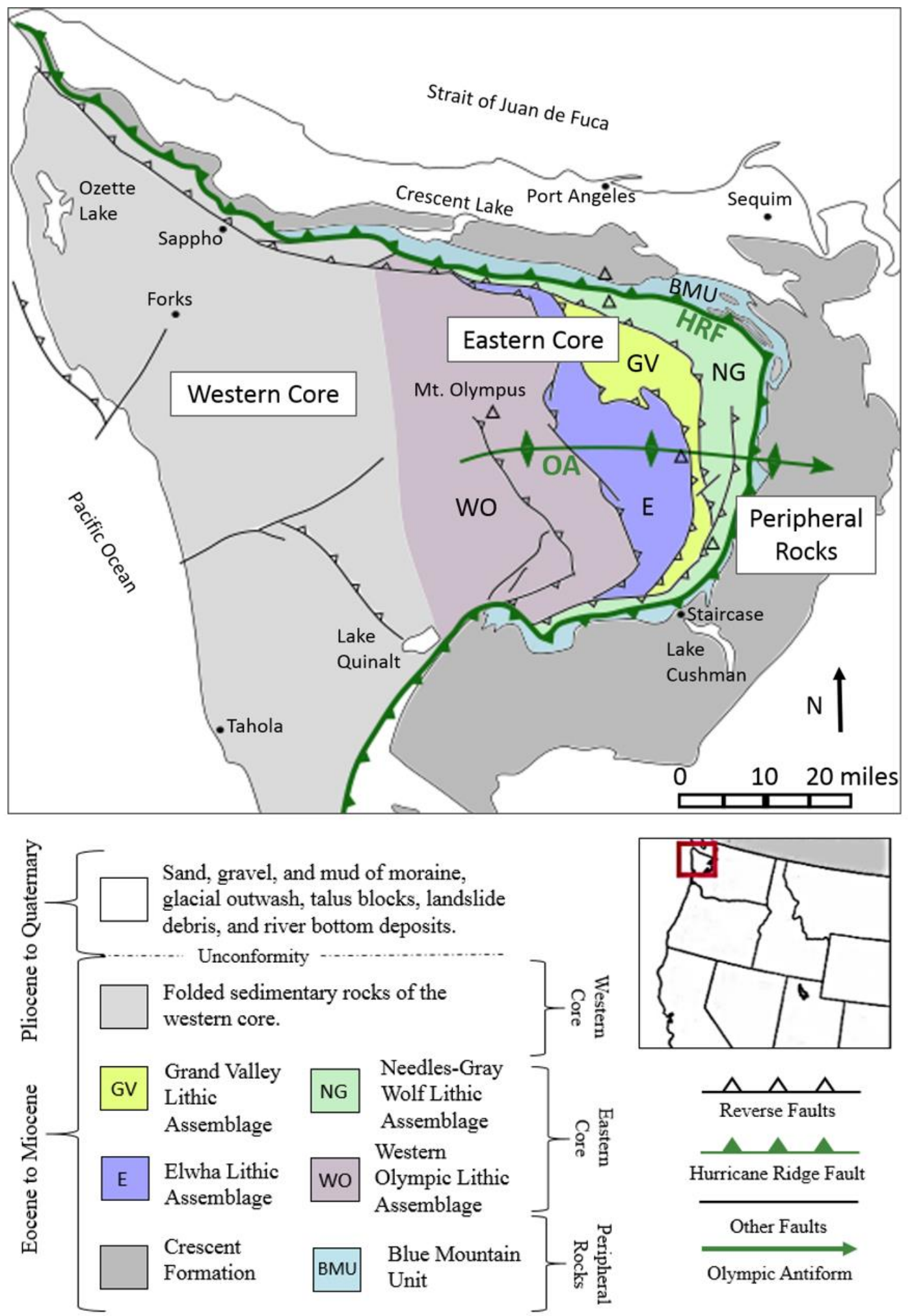

Figure 2.1. Geologic map highlighting the major structures and units of the Olympic Peninsula. Figure after Eddy, Clark, \& Polenz (2017) and Tabor \& Cady (1978). 


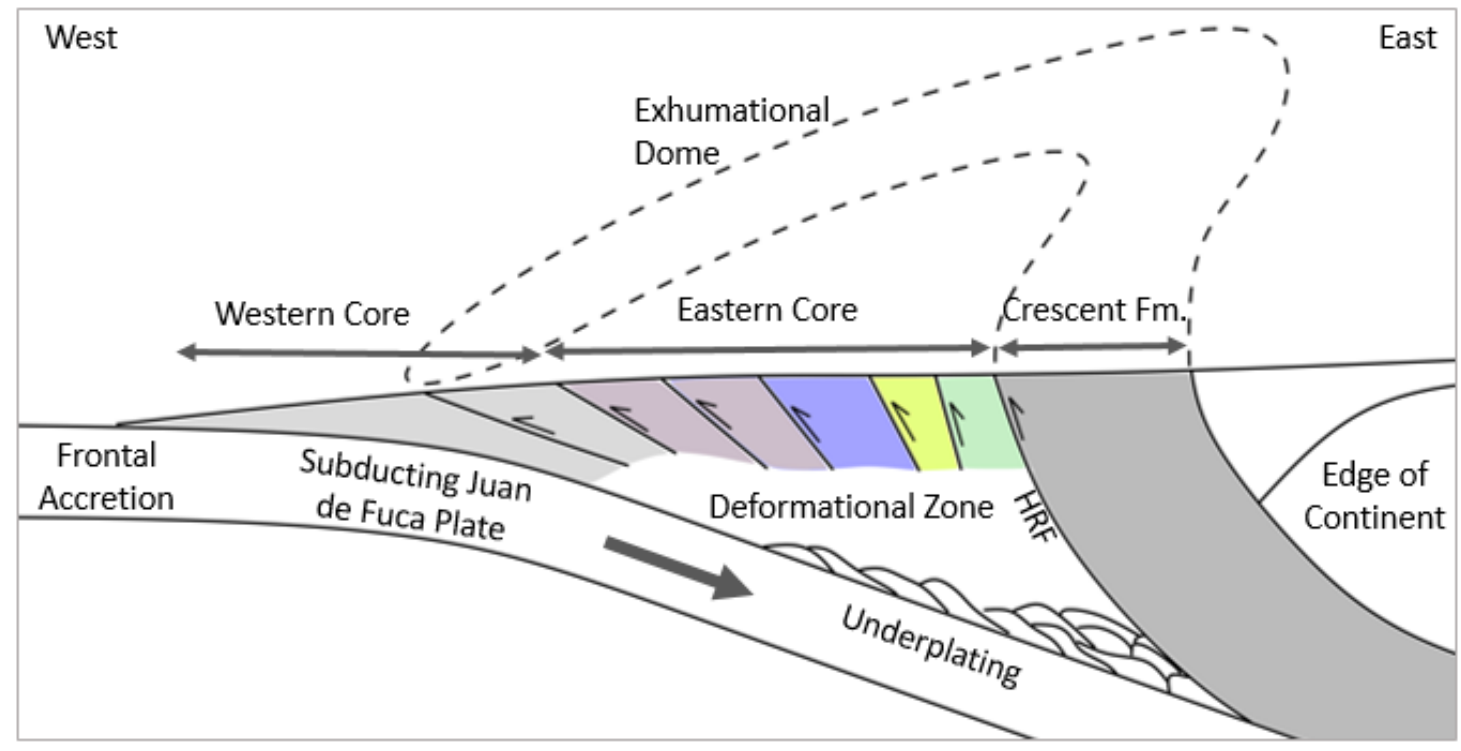

Figure 2.2. Cross sectional schematic of the Olympic Peninsula. Cross section runs west-east across the center of the peninsula. Figure interpreted and modified from Batt, Brandon, Farley, \& Roden-Tice (2001); Eddy, Clark, \& Polenz (2017); Tabor \& Cady (1978).

Following the accretion of Siletzia, sedimentary material was accreted to the margin forming the sedimentary core. The accretion of these sediments involved classic frontal accretion and underplating, a process by which material is added beneath the margin (Brandon \& Vance, 1992). The Crescent Fm. acted as a backstop to the metasediments, and continued E-W compression caused the sediments to deform by continued faulting and folding (Fig. 2.2; Tabor \& Cady, 1978). As this process proceeded, the HRF steepened to its current, near-vertical, position (Tabor \& Cady, 1978). Zircon and apatite fission track dating studies show that the Olympic Mountains began exhuming $18 \mathrm{Ma}$ and have been uplifting in a uniform manner for at least the last $14 \mathrm{Ma}$ (Batt et al., 2001; Brandon, Roden-Tice, \& Carver, 1998). 


\subsection{Models of Olympic Exhumation}

Two models exist for the driving mechanism of the exhumation of the Olympic Mountains. The first involves N-S oriented shortening from rotation of the micro-plates that make up the Pacific Northwest (McCaffrey et al., 2007; Wells, 1998; Wells \& McCaffrey, 2013), and the other involves internal deformation of the accretionary wedge and steady state doming (Batt et al., 2001; Brandon \& Vance, 1992; Pazzaglia \& Brandon, 2001).

Extensive mapping of the Pacific NW GPS velocity field shows clockwise rotation of the Cascadian forearc (McCaffrey et al., 2007). This causes E-W oriented extension in southeastern Oregon and N-S oriented shortening in northwestern Washington of Siletzia against the North American Buttress (Fig. 2.3; Wells et al., 1998; Wells \& McCaffrey, 2013). This rotation is caused in part by the oblique subduction of the Juan de Fuca plate beneath the North American plate (Wells et al., 2014; Wells \& McCaffrey, 2013). Field mapping, paleomagnetic, and magmatic studies track the rotation over the last 16 my (Wells \& McCaffrey, 2013).

$\mathrm{N}-\mathrm{S}$ oriented shortening from clockwise rotation of the Cascadia forearc is thought to drive faults in the Puget Lowland, including the Seattle Fault, the Tacoma Fault, the Olympic Fault, the Utsalady Point Fault, and the Southern Whidbey Island Fault (Wells et al., 1998; Blakely et al., 2009). In the Olympics, the Saddle Mountain, Canyon River, and Frigid Creek Faults, which are located in the Crescent Fm., have been interpreted as western extensions of the faults in the Puget Lowland, suggesting that the 
deformation from N-S shortening extends into the peninsula (Blakely et al., 2009; Lamb et al., 2012).

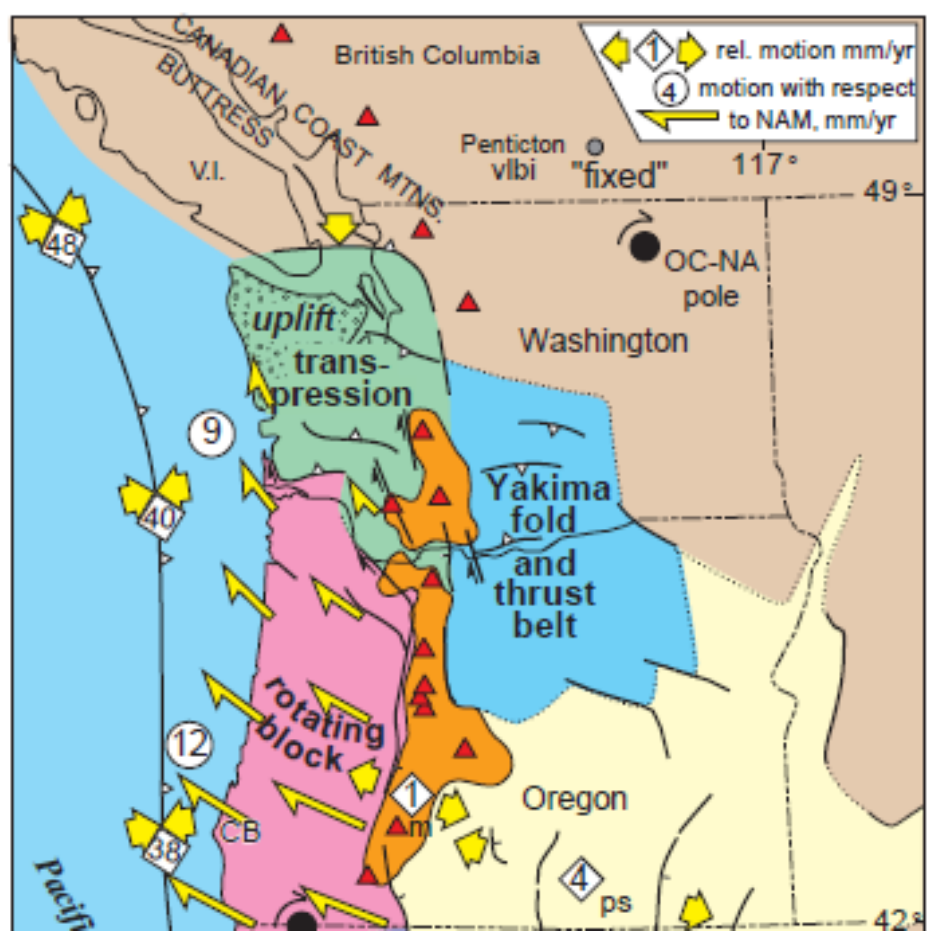

Figure 2.3. Schematic of the velocity field for the Pacific NW. The Oregon block (pink) and the Washington block (green) rotate clockwise about an Euler pole in NE Washington. This causes extension in southeastern Oregon and uplift and transpression in northwestern Washington. Modified from Wells et al. (2014).

The other model for Olympic exhumation posits that uplift resulted from internal deformation in the accretionary wedge (Tabor and Cady, 1979; Batt et al., 2001; Brandon \& Vance, 1992; Pazzaglia \& Brandon, 2001). Deformation within the meta-sedimentary core caused wedge thickening and exhumation of the Olympics as a mushroom-shaped dome over the last $18 \mathrm{Ma}$. Mass balance and zircon/apatite fission track studies indicate that the mountain range was in a steady-state flux, meaning that the amount of material being accreted was approximately equal to the erosional rate (Batt et al., 2001; Brandon \& Vance, 1992; Pazzaglia \& Brandon, 2001). This suggests that the only stresses that 
caused deformation in the mountain range were those associated with subduction zone convergence (Batt et al., 2001; Brandon \& Vance, 1992; Pazzaglia \& Brandon, 2001).

\subsection{Description of Rock Units}

The Crescent Fm. consists of Eocene basalts up to $16 \mathrm{~km}$ thick in the eastern portion of the peninsula. The formation consists of an upper member that outcrops in the east and a lower member that is exposed in the west. The Lower Crescent is tholeiitic in composition and is characterized by pillow basalts at the base that change upward stratigraphically to subaerial basalt (Eddy et al., 2017; Glassley, 1974). The basal portion of the Lower Crescent has a $53 \mathrm{Ma}$ age and has been metamorphosed to lower greenschist facies by burial (Eddy, Clarke, \& Polenz, 2017; Hirsch \& Babcock, 2009). The Upper Crescent has a 47 Ma age (Eddy, Clarke, \& Polenz, 2017) and is characterized by columnar and massive basalt and changes upward stratigraphically from tholeiitic to alkali basalts (Glassley, 1974).

The Blue Mountain Unit (BMU) beneath the Crescent Fm. is composed of marine turbidites (sandstone and mudstone), that formed from the erosion of the Crescent Fm. before it was accreted (Wells et al., 2014). The unit has an interfingering contact with the Crescent Fm. and overlies the HRF. The BMU has, until recently, been considered conformable with the Crescent Fm., however its age of 44 Ma suggests that it is thrust beneath the older Crescent Fm. (Eddy, Clarke, \& Polenz, 2017).

The meta-sedimentary core is Eocene-to-Miocene in age and is composed of metamorphosed sediments that were initially deposited offshore (Tabor and Cady, 1978). The core is separated into western and eastern sections based on metamorphic grade and 
degree of deformation. The rocks of the western core are younger and were metamorphosed to laumontite facies (Orange, Geddes, \& Moore, 1993). The eastern core comprises four lithic assemblages (ie., Needles-Gray Wolf, Grand Valley, Elwha, and Western Olympic; Fig. 2.1) separated by faults that run parallel to the HRF (Tabor and Cady, 1978). These assemblages contain varying amounts of slate, phyllite, schist, and feldspathic-to-basaltic lithic meta-sandstone that were metamorphosed to laumontite grade in the west and epidote-chlorite grade in the east (Hirsch \& Babcock, 2009; Tabor \& Cady, 1978). Folding is prevalent in the metasedimentary core, with a higher degree of deformation in the east than the west.

\subsection{Structural Geology of the Olympic Mountains}

The regional structure of the Olympic Peninsula is dominated by the Olympic Antiform (OA; Fig. 2.4) and the crustal faults of the meta-sedimentary core. The Olympic Antiform describes the horseshoe-shaped map pattern of the Crescent Fm., the axis of which runs E-W through the center of the peninsula. Tabor and Cady (1978) interpret this structure to be the result of mushroom-like doming of the Crescent Fm. during the exhumation of the meta-sedimentary core. The meta-sedimentary core is bound by the Hurricane Ridge Fault (HRF) and other faults that run roughly parallel to and join the HRF (Fig. 2.4). The HRF is interpreted as a high angle fault that juxtaposes the peripheral rocks (hanging wall) with the meta-sedimentary core (footwall) (Tabor \& Cady, 1978). Tabor and Cady (1978) infer the location of other crustal faults of the metasedimentary core by changes in lithology and presence of tectonic breccia. These faults separate the major lithic assemblages, which get younger to the west, and are interpreted 
as imbricate thrusts. In the northern and southern edges of the meta-sedimentary core (i.e., Southern and Calawah Fault Zones; SFZ and CAFZ, Fig. 2.5) NE-SW and NW-SE trending faults truncate the N-S trending faults that run across the core (Schasse, 2003).

\subsubsection{Structures in the Eastern Core}

Folds

Folding is prevalent in the meta-sedimentary core, and the area has been termed a 'chaotically' folded terrane (Tabor \& Cady, 1978). For the most part, the folds are outcrop scale and unmappable, however, there are some larger-scale folds in the western core (Fig. 2.4).

Folds are typically isoclinal, and fold axial planes are commonly subparallel to bedding. Following the structural domains of Tabor and Cady (1978) (Fig. 2.5), the beds and axial planes of the 'central domains' strike more N-S and dip to the west and those of the western domains strike NW to NNW and dip to the east. Fold axes were not measurable in all domains, but where they were measured, an observed pattern shows that the axes plunge away from the HRF in the east (domains 1, 2, 5, and 12) and towards it in the west (domains 16 and 17). Tabor and Cady (1978) consider these trends as evidence for the mushroom-like dome shape of the Olympic core that formed as it was exhumed.

The bedding planes and axial planes of the 'outer edge' domains follow the strike of the HRF and dip away from it (Fig 2.5). Tabor and Cady (1978) cite this trend as evidence that the horseshoe-shape of the Crescent Formation was established early. 


\section{Structural Fabrics}

There are two main structural fabrics of note in the Olympic core: cleavages and pencil structures.

Cleavages are defined by planar features that crosscut and, often, offset beds (Fig. 2.5). Where folds are isoclinal, cleavages are parallel to bedding measurements and show similar trends regionally. More than one generation of cleavage is documented throughout the meta-sedimentary core (i.e., domains 4, 12, and 16; Tabor \& Cady, 1978). Movement along cleavage planes commonly sheared off the hinges of folds, transposing beds into an orientation subparallel to the cleavage (Tabor \& Cady, 1978).

The pencil structures are thin slivers of rock that form at the intersection of either two cleavages or of a cleavage plane and a bedding plane (Tabor \& Cady, 1978). These pencils show a radial pattern in which they trend away from the HRF and plunge towards the core (Fig. 2.6). This is also cited as evidence by Tabor and Cady (1978) for the mushroom-like dome shape of the Olympic core. 


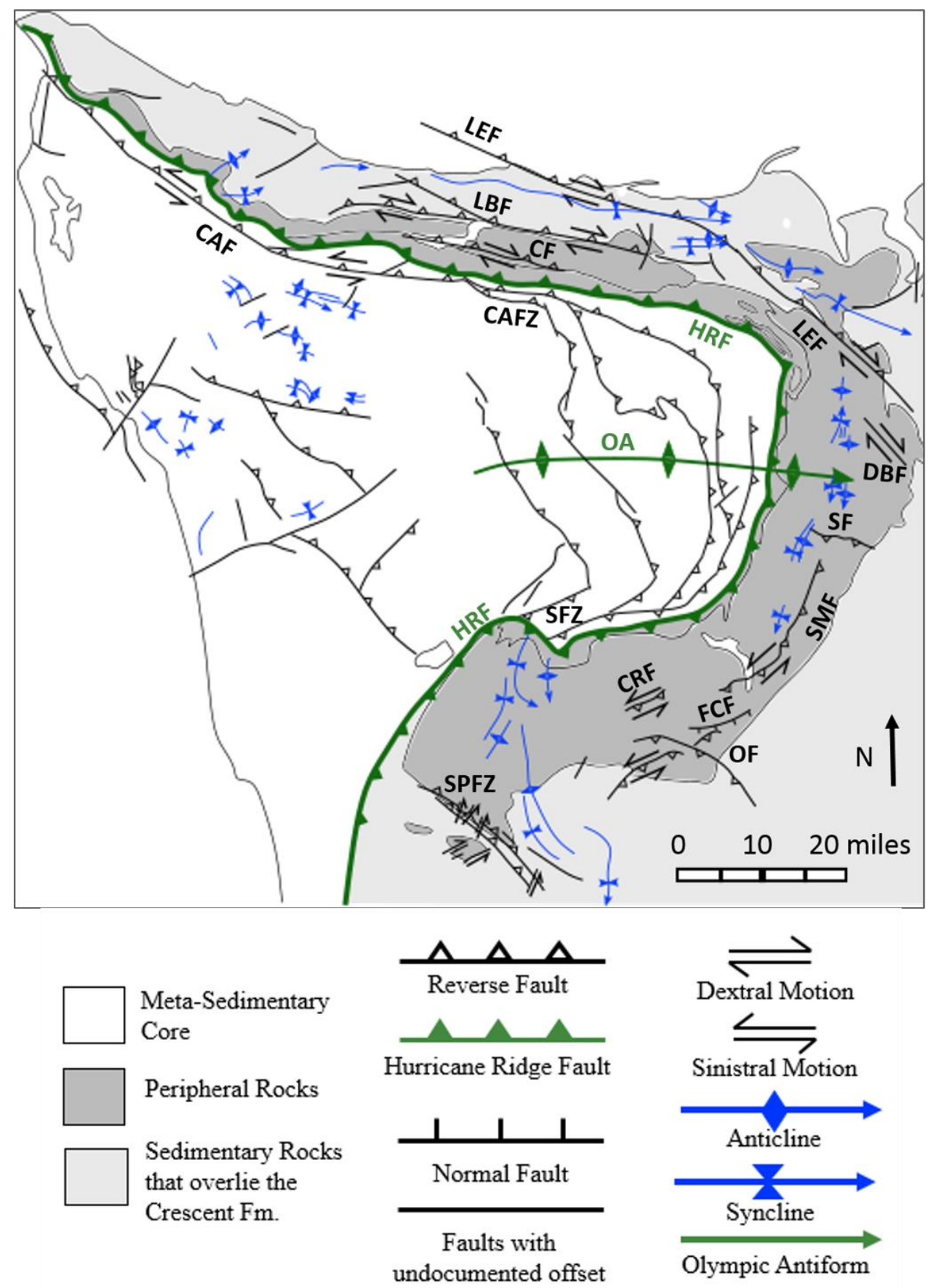

Figure 2.4. Map of structures present in the Olympic Peninsula. Information compiled and modified from: Blakely et al. (2009); Eddy et al. (2017); Gerstel \& Lingley (2000); Gerstel \& Lingley (2003); Joyner (2016); Logan (2003); Orange, Geddes, \& Moore (1993); Schasse (2003); Tabor \& Cady (1978). Abbreviations: $\mathbf{C A F}=$ Calawah Fault, $\mathbf{C A F Z}=$ Calawah Fault Zone $\mathbf{C F}=$ Crescent Fault, $\mathbf{C R F}=$ Canyon River Fault, $\mathbf{D B F}=$ Dabob Bay Fault, $\mathbf{F C F}=$ Frigid Creek Fault, $\mathbf{H R F}=$ Hurricane Ridge Fault, LBF=Lake-Creek-Boundary-Creek Fault, LEF=Lower Elwha Fault, $\mathbf{O A = O l y m p i c ~ A n t i f o r m , ~}$ $\mathbf{O F}=$ Olympic Fault, $\mathbf{S F}=$ possible extension of the Seattle Fault, $\mathbf{S M F}=$ Saddle Mountain Fault, SFZ=Southern Fault Zone. 


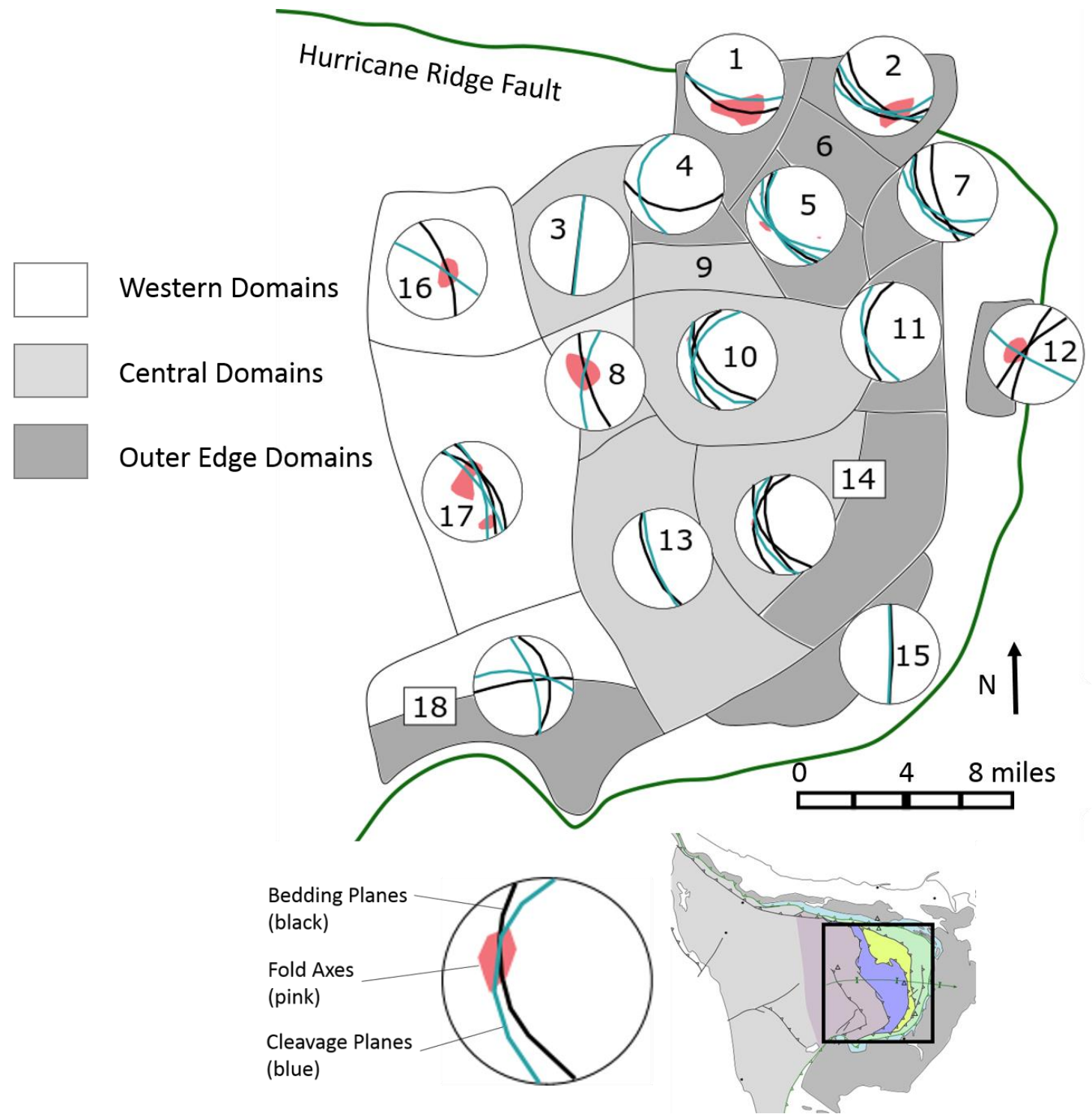

Figure 2.5. Structural domains for the eastern meta-sedimentary core with representative structural measurements. Domains are grouped into outer edge, central, and western areas based on trends in the data. Plots show lower hemisphere stereographic projections. Bedding and cleavage orientations show representative planes, and fold axes show the range of data points. Modified from Tabor and Cady (1978). 


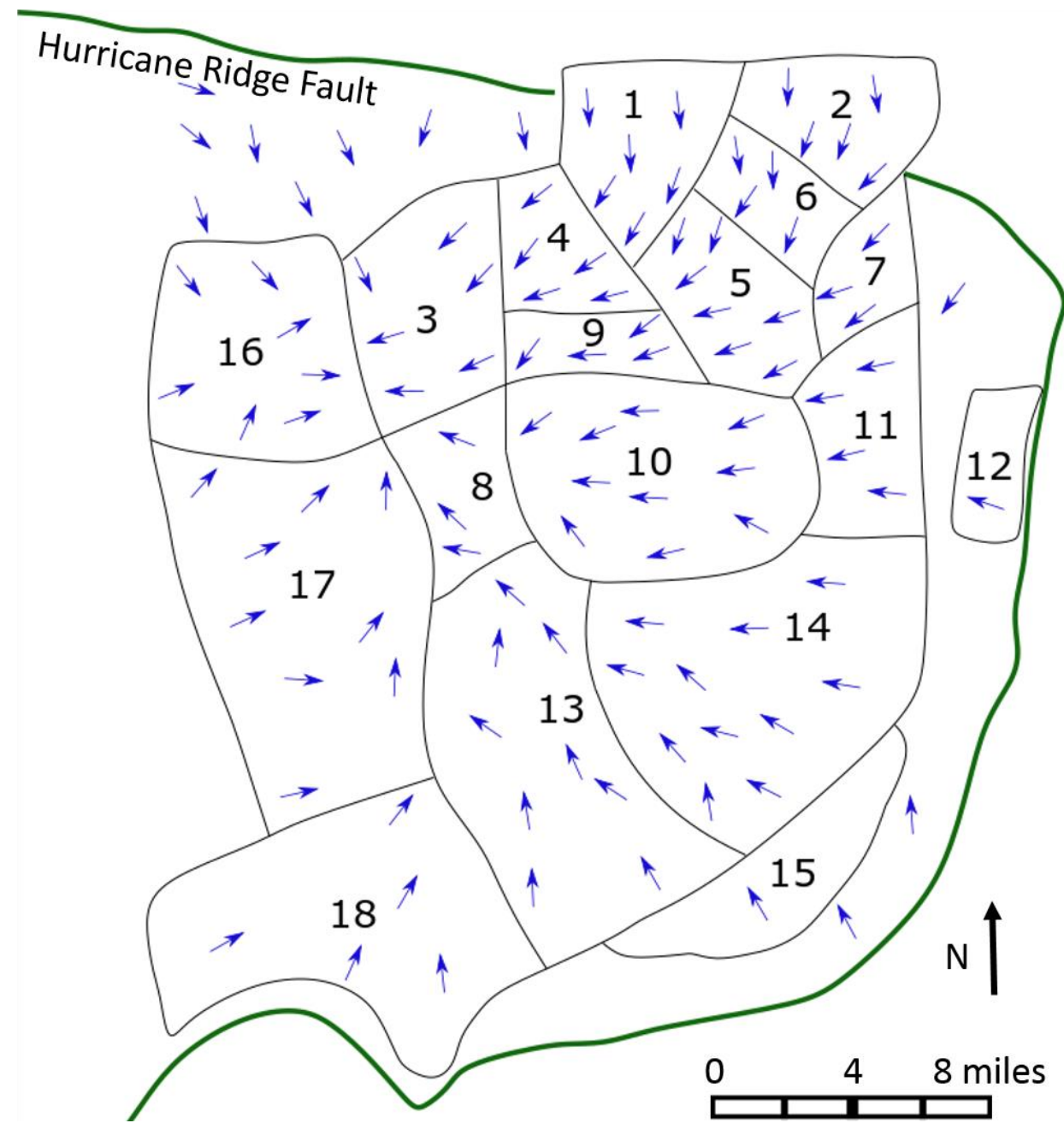

Figure 2.6. Plunge direction of pencil structures in the eastern core. Modified from Tabor and Cady (1978).

\subsubsection{Structures in the Peripheral Rocks}

\section{Faults}

Faults have been mapped throughout the peripheral rocks that strike parallel to the HRF and dip away from the core (Fig. 2.5). In the north, the Lake Creek-Boundary Creek, Lower Elwha, and Crescent faults are high angle, E-W oriented, reverse faults, with a component of dextral shear (Eddy et al., 2017; Joyner, 2016). These northern faults are interpreted as imbricates of one another and the HRF (Eddy et al., 2017). In the 
central east, the Dabob Bay fault strikes NW-SE, shows dextral motion, and is likely an en echelon portion of the Lower Elwha Fault (Blakely et al., 2009). The central east also shows a possible extension of the Seattle Fault, which has been inferred by magnetic anomalies (Blakely et al., 2009). In the southeast, NE-SW oriented faults including the Saddle Mountain, Canyon River, and other unnamed faults, show reverse, sinistral motions (Blakely et al., 2009; Logan, 2003, Walsh \& Logan, 2007). Also in the southeast are the normal Frigid Creek Fault and the reverse northernmost portion of the Olympic Fault (Blakely et al., 2009). An area at the southern edge of the peripheral rocks differs from the trend of the other faults in that these NE-SW oriented southernmost faults do not strike parallel to the HRF and are offset by mostly sinistral strike-slip faults (Logan, 2003).

Additional faults are inferred by geochronological inconsistencies. Recent dating of the Blue Mountain Unit shows that the Blue Mountain Unit and Lower Crescent Formation are not conformable, suggesting that there is a fault separating the two units (Eddy et al., 2017). This fault has not been officially mapped, but its presence would be a continuous fault that parallels the HRF.

Folds

Numerous folds are mapped in the peripheral rocks, though they are rarely discussed in literature (Gerstel \& Lingley, 2000; Gerstel \& Lingley, 2003; Logan, 2003; Schasse, 2003). The folds follow the same general pattern as the faults with axes that parallel the HRF, however, they are generally at the middle of the Crescent Fm., near the boundary between the Upper and Lower members. As with the faults in the southernmost 
part of the peripheral rocks, folds in this area do not follow the HRF but trend NNESSW. 


\section{Methods}

Four outcrops were chosen for this study (Fig. 3.1): two in the Needles-Gray Wolf Lithic Assemblage of the eastern core (referred to here as the meta-sediments), and two in the Crescent Fm. on the eastern side of the HRF (also referred to here as the pillow basalt). The transect is 5 kilometers long, and the outcrops are 50-150 meters long. Each site is further subdivided by letter (e.g., Figures 4.1 and 5.1). Site 1 begins at the Mildred Lakes Trailhead and is a semi-continuous meta-sedimentary outcrop; the Hamma Hamma River cuts through between Sites 1c and 1d. Outcrop exposures on the western side of the river are cliffs that lead down to the river. The eastern side exposures are steep to near vertical outcrops and run along the road. Site 2 is also in the meta-sediments, about $800 \mathrm{~m}$ northeast of Site 1, and is a steep to near vertical outcrop that runs along the road. Sites 3 and 4 are in the Crescent Fm. and are tall, steep outcrops of pillow basalt. Site 3 is approximately 1600 m east of Site 2 and about 320 m east of the Putvin Trailhead. Site 4 is $300 \mathrm{~m}$ east of Site 3 . 


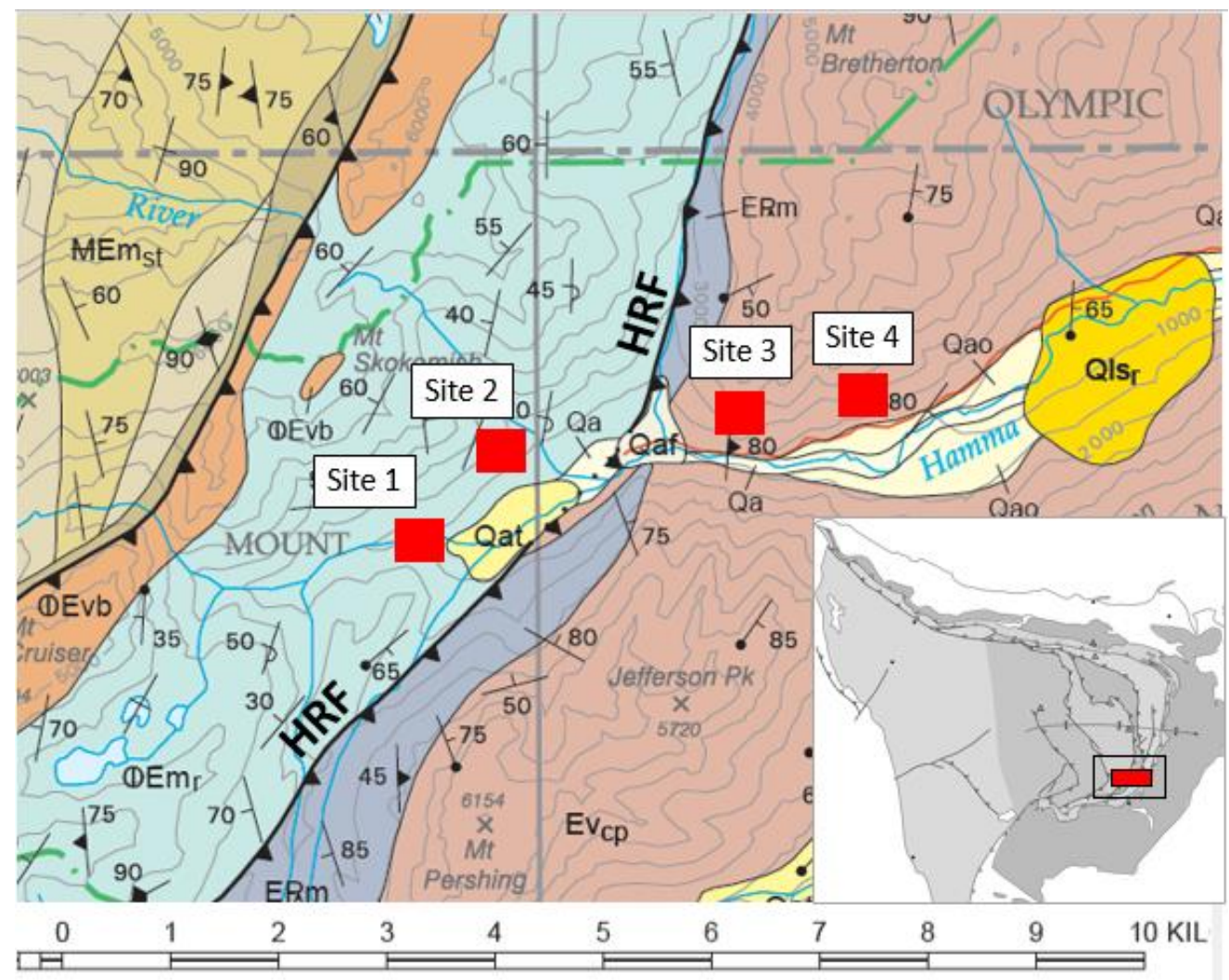

Figure 3.1. Geologic map with sites chosen for this study. Sites 1 and 2 are in the Needles-Gray Wolf Lithic Assemblage and Sites 3 and 4 are in Crescent Formation. Geologic map by Grestel and Lingley (2003).

At each site, I documented the type, orientation, and location of mesoscale structures (i.e., bedding, fractures, faults, veins, and fabrics) and crosscutting relationships between features. Outcrop maps were constructed in order to record the spatial relationship among the structures as well as the degree to which the structures are localized or homogenously distributed. Orientation measurements are representative of structure populations identified by qualitative observation. The exceptions to this are the faults identified in the pillow basalt outcrops, which were few in number and could be individually documented. 
Oriented samples were collected in the meta-sedimentary outcrops to investigate the relative timing of fabric formation with respect to other structures such as bedding, veins, and fractures. I collected samples in the meta-sediments of relatively undisturbed and highly disturbed regions and of different rock types within the unit to compare how the structures vary. Oriented samples were collected in the pillow basalts to track how the pillows accommodate deformation and to look for evidence of fabric formation from core to rim and in the sedimentary matrix between pillows.

Samples were reoriented and cut relative to regional and/or relevant structures observed in the field and prepared into thin sections. Samples from the meta-sediments were cut perpendicular to the dominant fabric, and samples from the basalt were cut in map view. A petrographic microscope and a scanning electron microscope were used to identify mineral fabrics, shear structures, crosscutting relationships, and the mineral assemblage in veins.

Structure orientation data were plotted and analyzed using a graphing program called Stereonet, version 9.8 (see Allmedinger, Cardozo, \& Fisher, 2013; Cardozo \& Allmendinger 2013). All stereographic projections are lower hemisphere, equal area projections. Strike and dip measurements of planar structures (i.e., bedding, foliations, fractures, and veins) are shown as lines, and trend and plunge measurements of linear structures (i.e., slickenlines) are shown as points. Groupings in measurements were made by plotting poles to planes and then adding smoothed, $1 \%$ contours to the poles, with an interval of 2 , significance level of 3 , and 20 grid nodes. When groupings could be made in the data or when a structure type showed a consistent orientation, a 'representative 
orientation' was identified by finding the midpoint of the data using the contours of the poles to planes. It is important to note that measurements should be considered qualitatively, as no statistical analysis has been conducted on the data.

Fold axes were determined by plotting poles to bedding planes and calculating the cylindrical best fit. Axial planes of folds were estimated by bisecting the plotted poles to bedding data, as guided by axial trace measurements taken in the field. Calculations of the principal stresses (i.e., $\sigma 1, \sigma 2$, and $\sigma 3$ ) were determined using Anderson's Theory of Faulting for fractures or faults interpreted as conjugates (Fig 3.2; Anderson (1905)). The point of intersection of the fractures or faults is $\sigma 2$, and the plane perpendicular to this intersection is the $\sigma 1-\sigma 3$ plane. The midpoint of the acute angle $\left(\sim 60^{\circ}\right)$ that the $\sigma 1-\sigma 3$ plane makes with the conjugate fractures or faults is $\sigma 1$, and the midpoint of the obtuse angle $\left(\sim 120^{\circ}\right)$ is $\sigma 3$. 

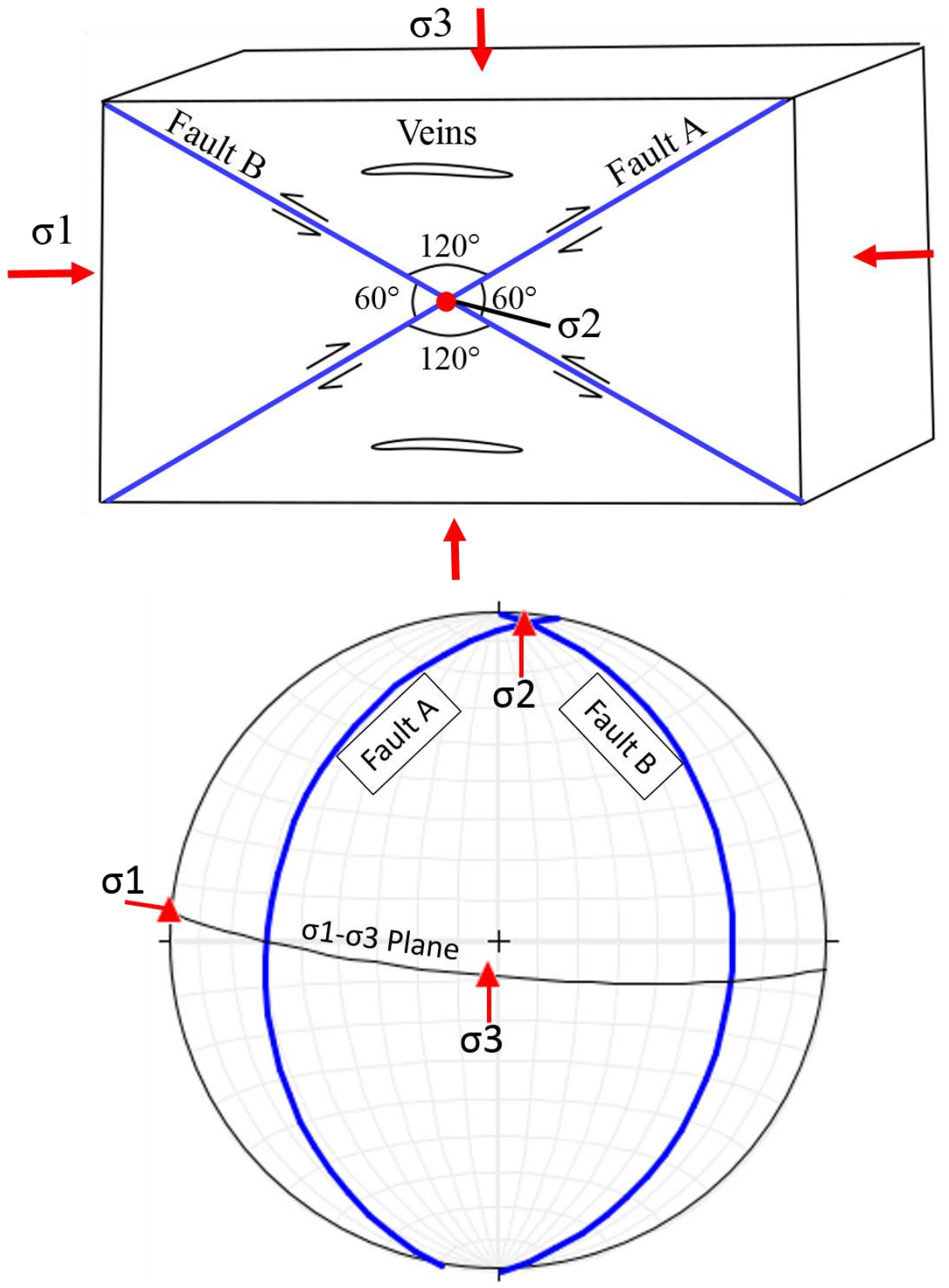

Figure 3.2. Diagram and corresponding stereonet of a representative compressional faulting setting showing the geometry and principal stresses for Anderson's Theory of Faulting. The example shown is that of two conjugate reverse faults, formed by E-W oriented maximum stresses $(\sigma 1)$, and vertical minimum stresses $(\sigma 3)$. 


\section{Meta-Sediments of the Hamma Hamma Transect}

\subsection{Data \& Observations}

\subsubsection{Field Observations}

At Sites 1 and 2, the structures of interest are bedding, foliations, fractures, and veins. Here, the bedding was defined by layers of slate and meta-sandstone. The layers range in thickness from $2 \mathrm{~mm}$ to about $2 \mathrm{~m}$. Sites 1a, 1e, and 1f are predominantly slate; Sites $1 \mathrm{~b}, 1 \mathrm{c}$ and $1 \mathrm{~d}$ are predominately meta-sandstone; and Site 2 has relatively equal amounts of both rock types (Fig. 4.1). Fold hinges were identified at sites 1c (Fig. 4.2) and $2 \mathrm{~b}$ indicating that the beds were folded.

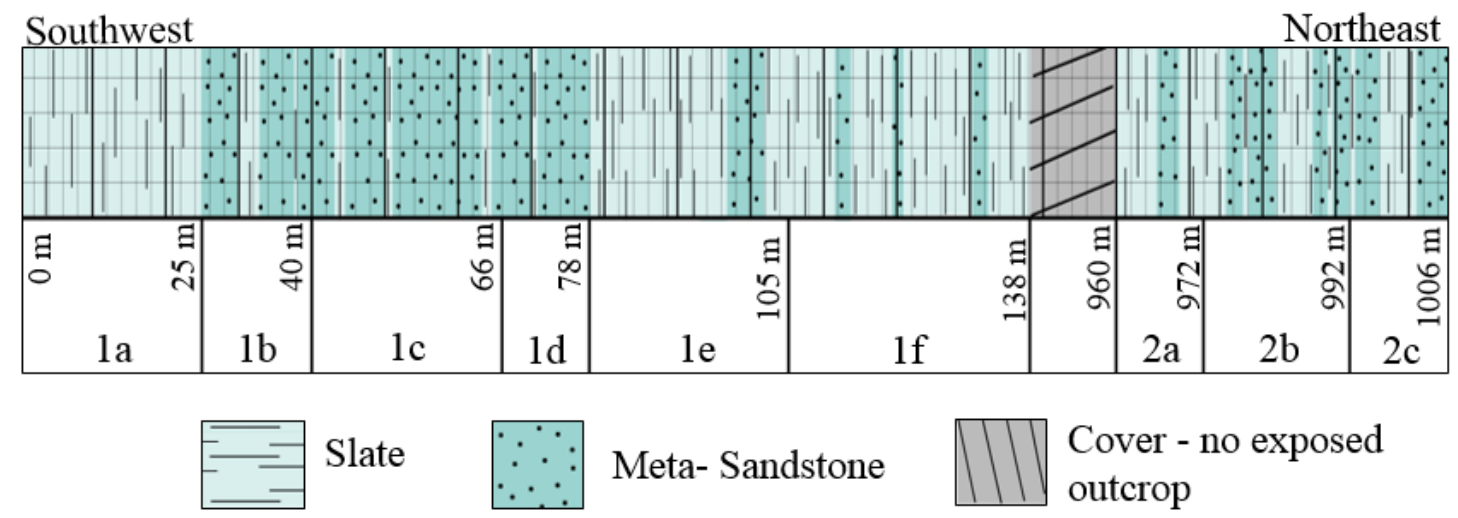

Figure 4.1. Diagram showing the length of each subsite of Sites 1 and 2 and the rock type present at each. The major lines of division on the column represent $10 \mathrm{~m}$. Site 1a begins at the Mildred Lakes Trailhead, which represents "zero", and the numbers indicate how far a subsite is from this point. The column is not continuous; there is approximately $820 \mathrm{~m}$ of cover between the two sites.

Foliations are defined by planar mineral fabrics that can be seen along bedding planes. They are not parallel to bedding planes. In the predominantly slate layers and in layers of thin $(0-10 \mathrm{~cm})$ interbedded slate and meta-sandstone, they cut across the bedding. In thicker (10-40) interbedded slate and meta-sandstone layers, they are 
confined to the slate layers (Fig. 4.3). Foliations are not well-defined in the thicker metasandstone layers.

The beds are discontinuous and disrupted by fractures that crosscut and, in some places, offset the beds and foliations. The relative degree of disruption appears to correlate with rock type (Fig. 4.4). In the meta-sandstone layers (Sites 1b, 1c, and 1d), the fractures show fewer instances of offset, and the offset is traceable and measureable. Where offset is identifiable, lateral and reverse apparent motions offset beds between 5 and $50 \mathrm{~cm}$ (Fig. 4.5). The slate (Sites 1a, 1e, and 1f) and interbedded (2a, 2b, and 2c) layers appear to be more highly disrupted by the fractures; the amount of offset is difficult to measure due to the similarity in beds, which makes it hard to correlate them across the fracture planes. In some places, the fractures juxtapose beds of differing orientations, which indicates that they have been offset (Fig. 4.6). Lineations on the fracture surfaces are interpreted as slickenlines and the slickensides are smooth up dip on the footwall side of the fracture, suggesting a reverse sense of motion.

Quartz veins were identified in the meta-sediment outcrops and crosscut bedding and foliations (Fig. 4.7). They are generally linear but bifurcate amongst each other where there are groups. Veins range from $1 \mathrm{~mm}$ to $2 \mathrm{~cm}$ in thickness. The thinner ones have smaller crystals, whereas the thicker ones are blockier and have larger crystals. Veins span up to a meter in length and their length appears to correlate with rock type; thicker meta-sandstone layers have longer, thicker, veins, whereas thinner slate layers have shorter, thinner, veins. They typically occur as clusters (e.g. Site 1c), but in some places, a single vein is observed locally. 

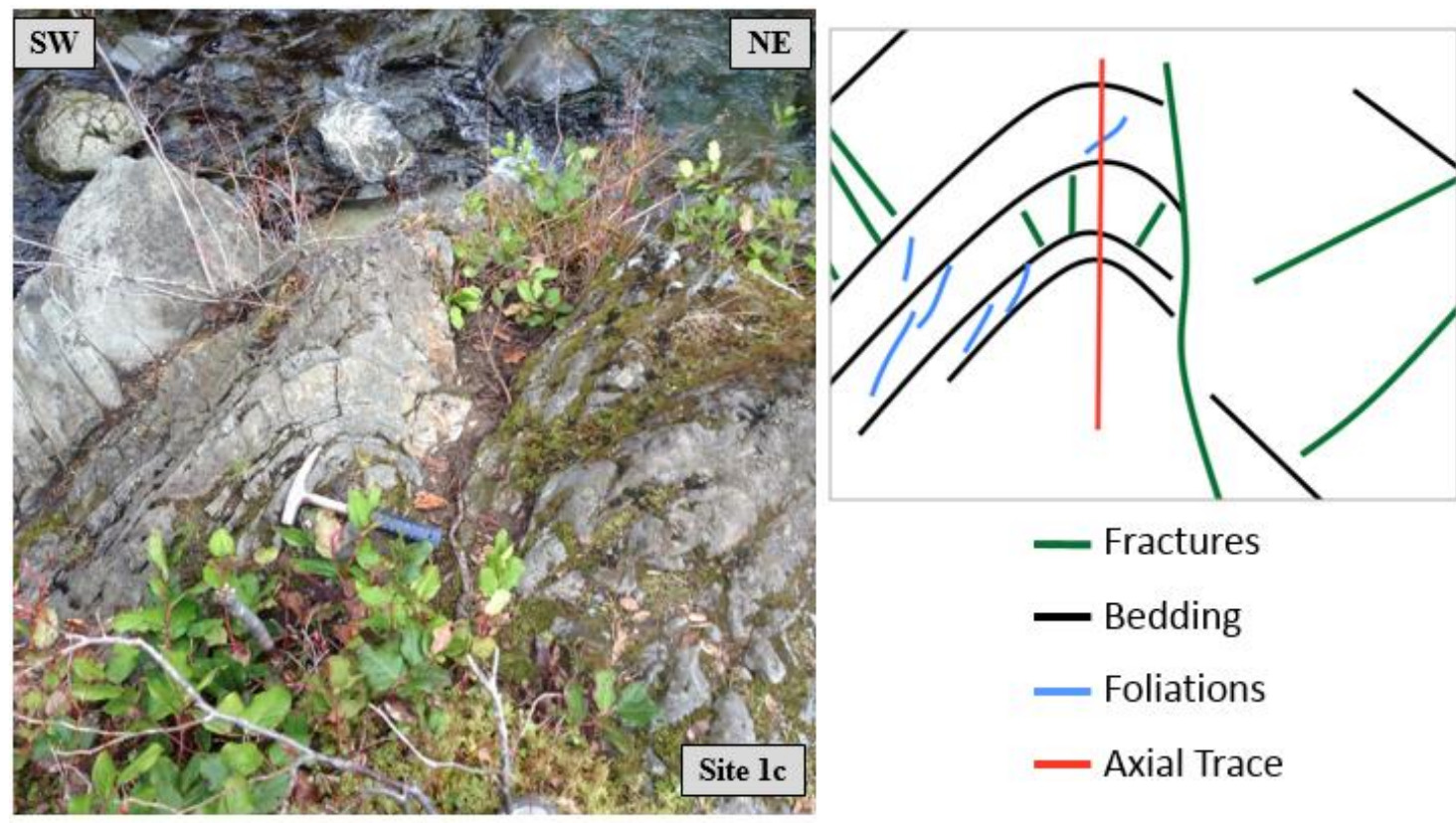

- Fractures

_ Bedding

- Foliations

_ Axial Trace

Figure 4.2. Photo of a fold hinge at Site 1c (left) with an interpretive diagram (right). The northeastern limb of the fold appears offset by a fracture. The photo was taken of a steeply inclined outcrop looking northwest. The rock hammer is $36 \mathrm{~cm}$ long.

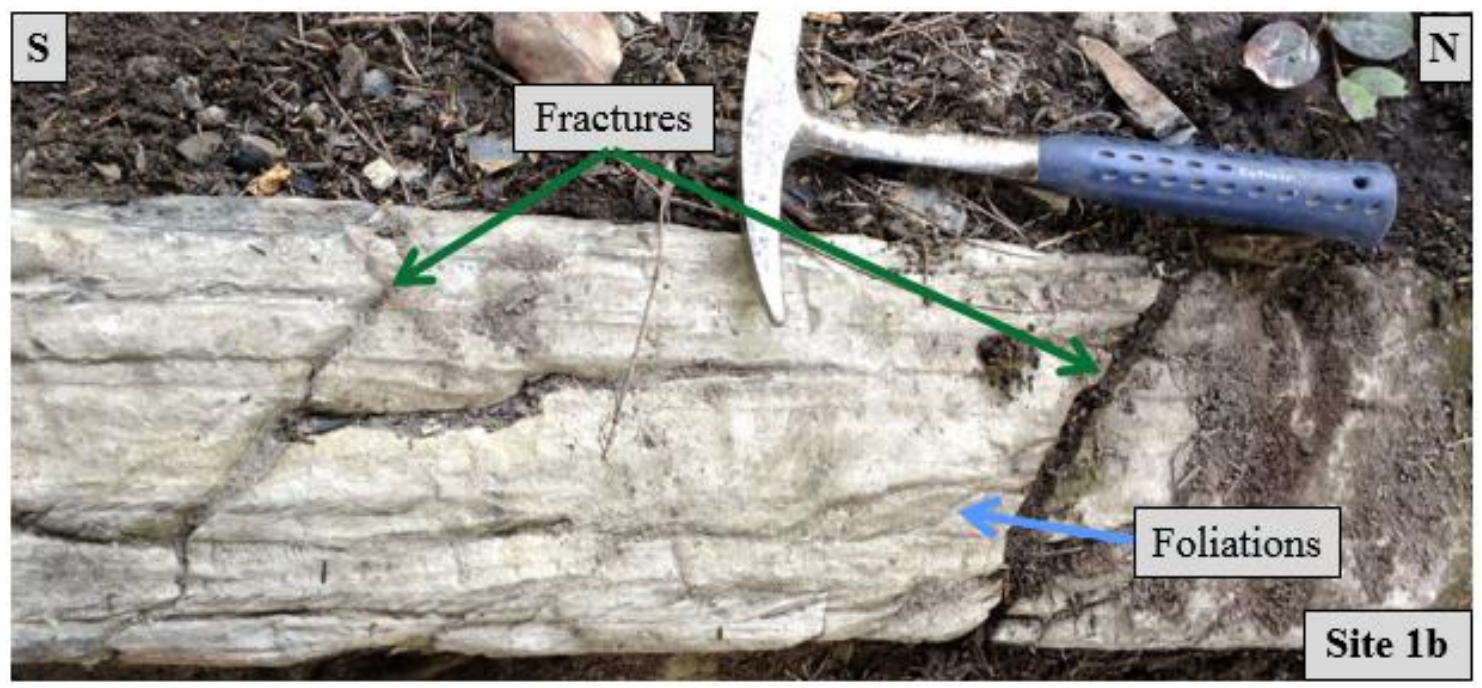

Figure 4.3. Photo showing fractures crosscutting, but not offsetting, bedding and foliations at Site $1 \mathrm{~b}$. Here, the bedding is thin layers of interbedded sand and slate. The photo is of a horizontal outcrop, with north to the right. The rock hammer is $36 \mathrm{~cm}$ long. 

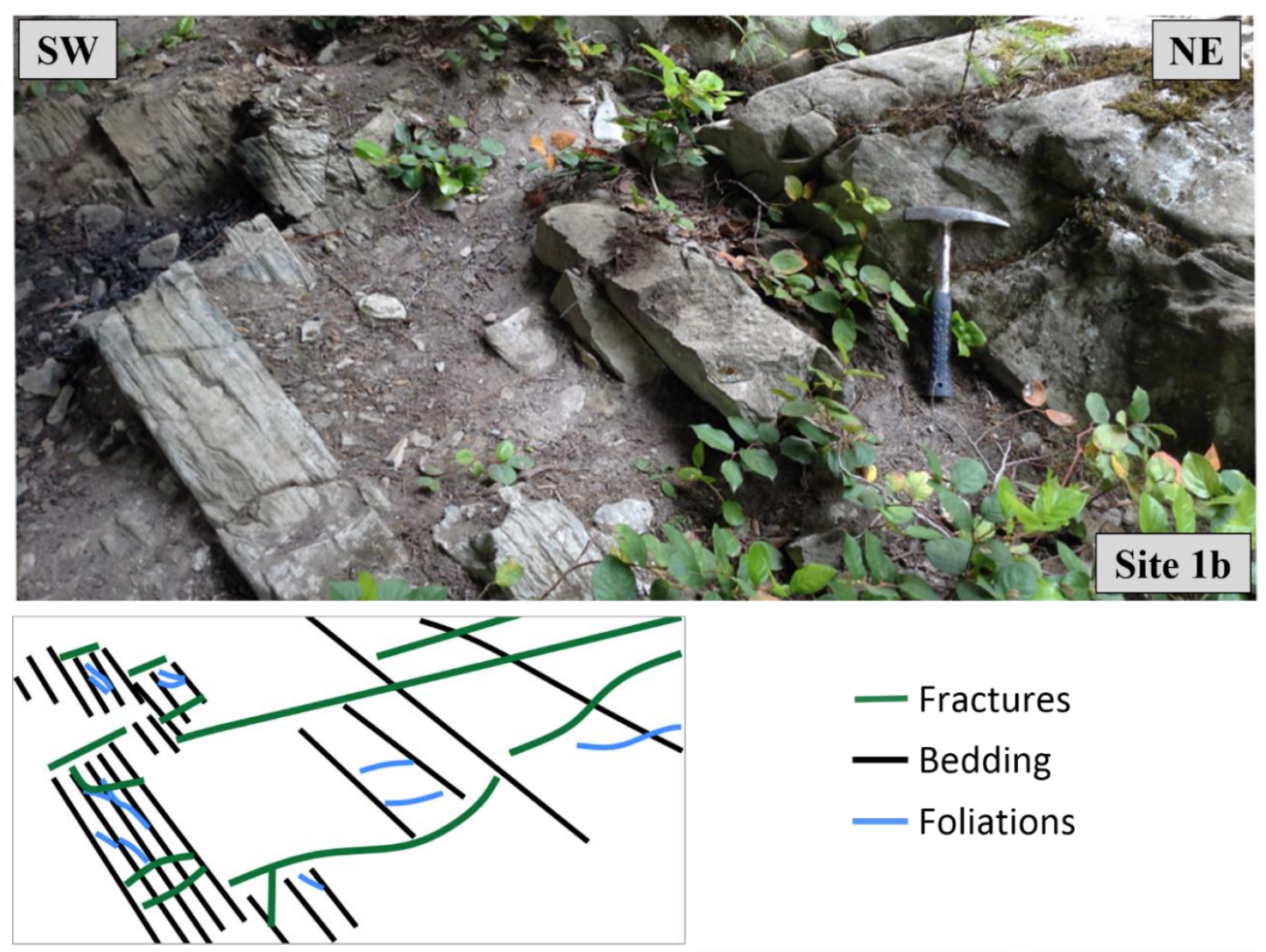

- Fractures

- Bedding

- Foliations
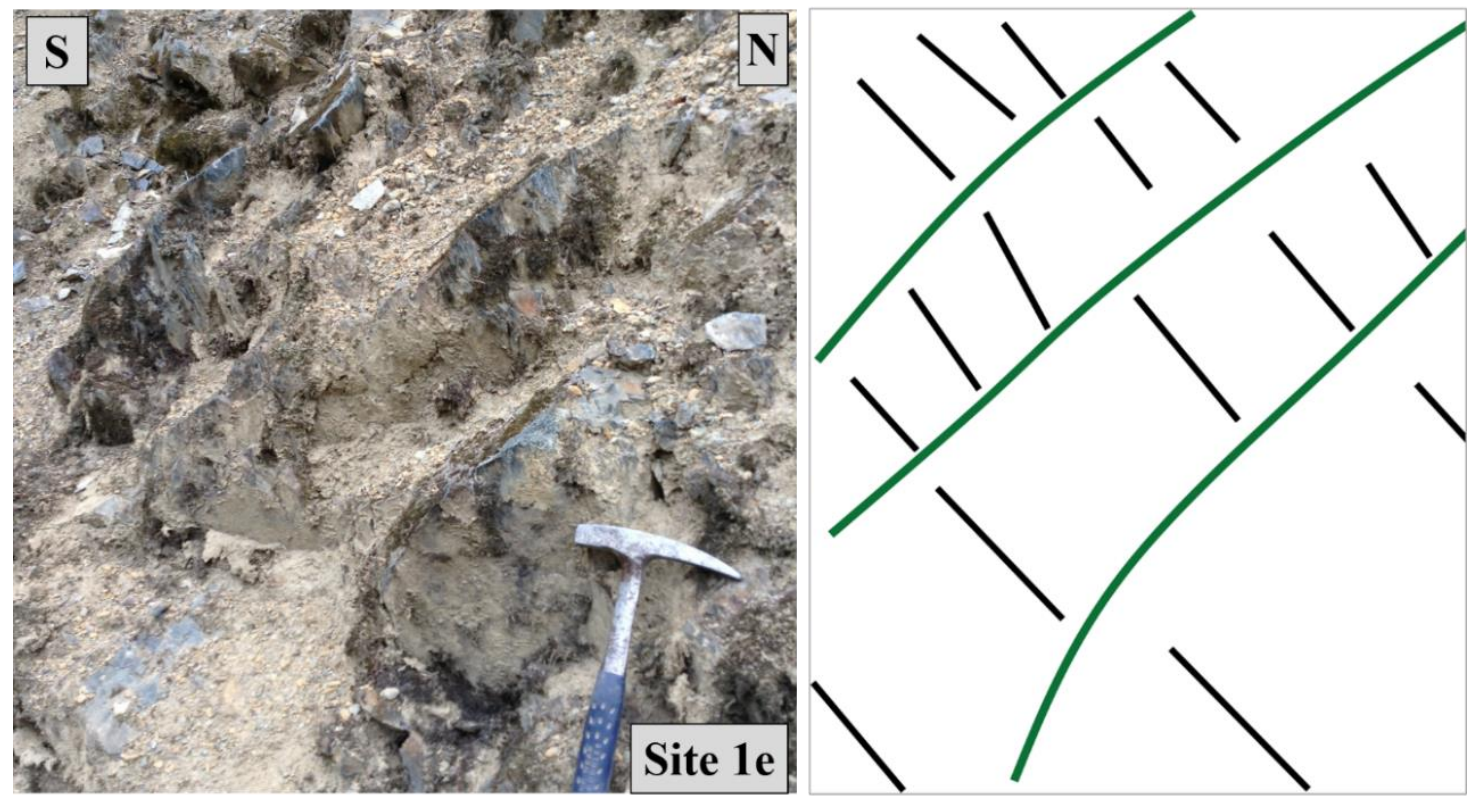

Figure 4.4. Photo of fractures cutting across meta-sandstone (above) and slate (below) layers with corresponding interpretive diagrams. The meta-sandstone layers show less disruption by fractures than the slate layers. In the meta-sandstone layers, bedding can be traced across fractures, and offset can be measured where present. Bedding and offset are more difficult to track across fractures in the slate layers. The meta-sandstone outcrop is horizontal and the slate outcrop is inclined. The rock hammer is $36 \mathrm{~cm}$ long. 

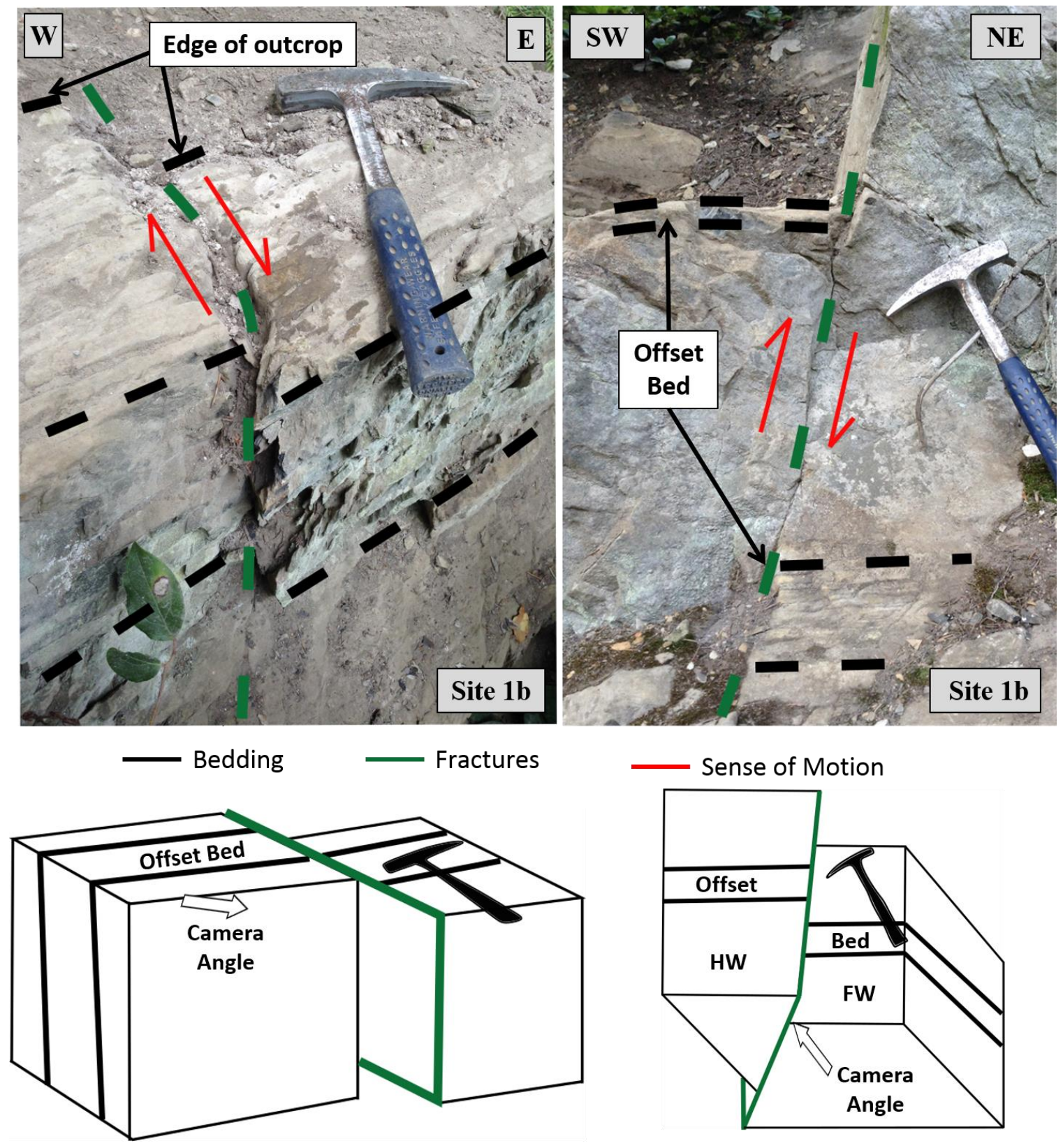

Figure 4.5. Photos of fractures with apparent offset at piercing points and corresponding block diagrams. The apparent right lateral offset of shale and meta-sandstone layers at left is approximately $10 \mathrm{~cm}$, as marked by the edge of the outcrop. The apparent reverse dip-slip offset at right is approximately $45 \mathrm{~cm}$, as marked by the offset bed. Block diagrams show the relationship among the offset beds, fractures, and camera angle. The rock hammer is $36 \mathrm{~cm}$ long. 


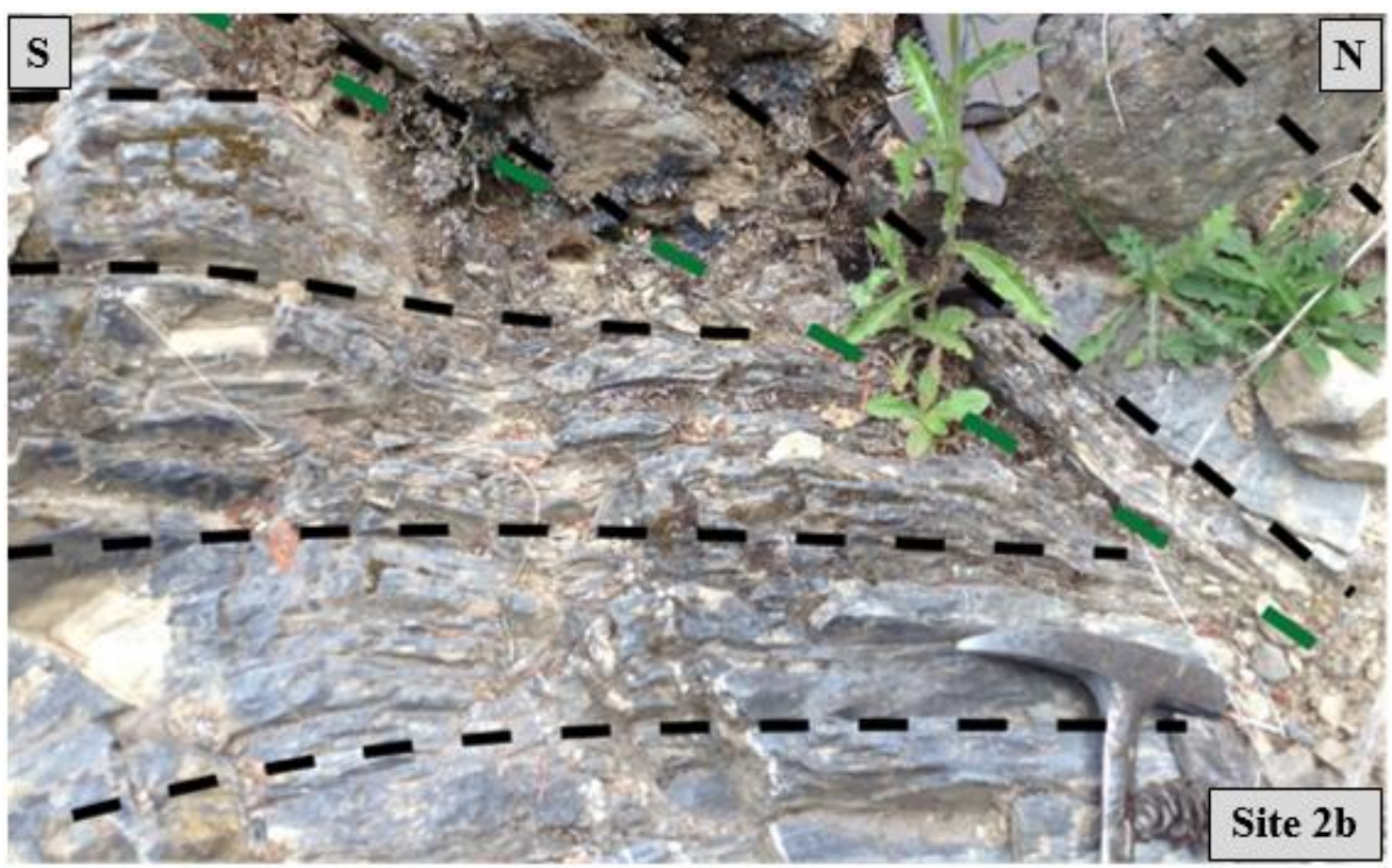

\section{Fractures - Bedding}

Figure 4.6. Photo of a fracture that has juxtaposed two beds of differing orientations. The beds, foliation, and veins in the bottom left [respectively, strike and dips of $(225,45),(189,60)$, and $(282,55)]$ have orientations that are different from the beds in the top right [strike and dip of $(028,58)]$. The fracture is oriented $(291,67)$. The photo was taken looking west and the head of the rock hammer is $15 \mathrm{~cm}$ long. 

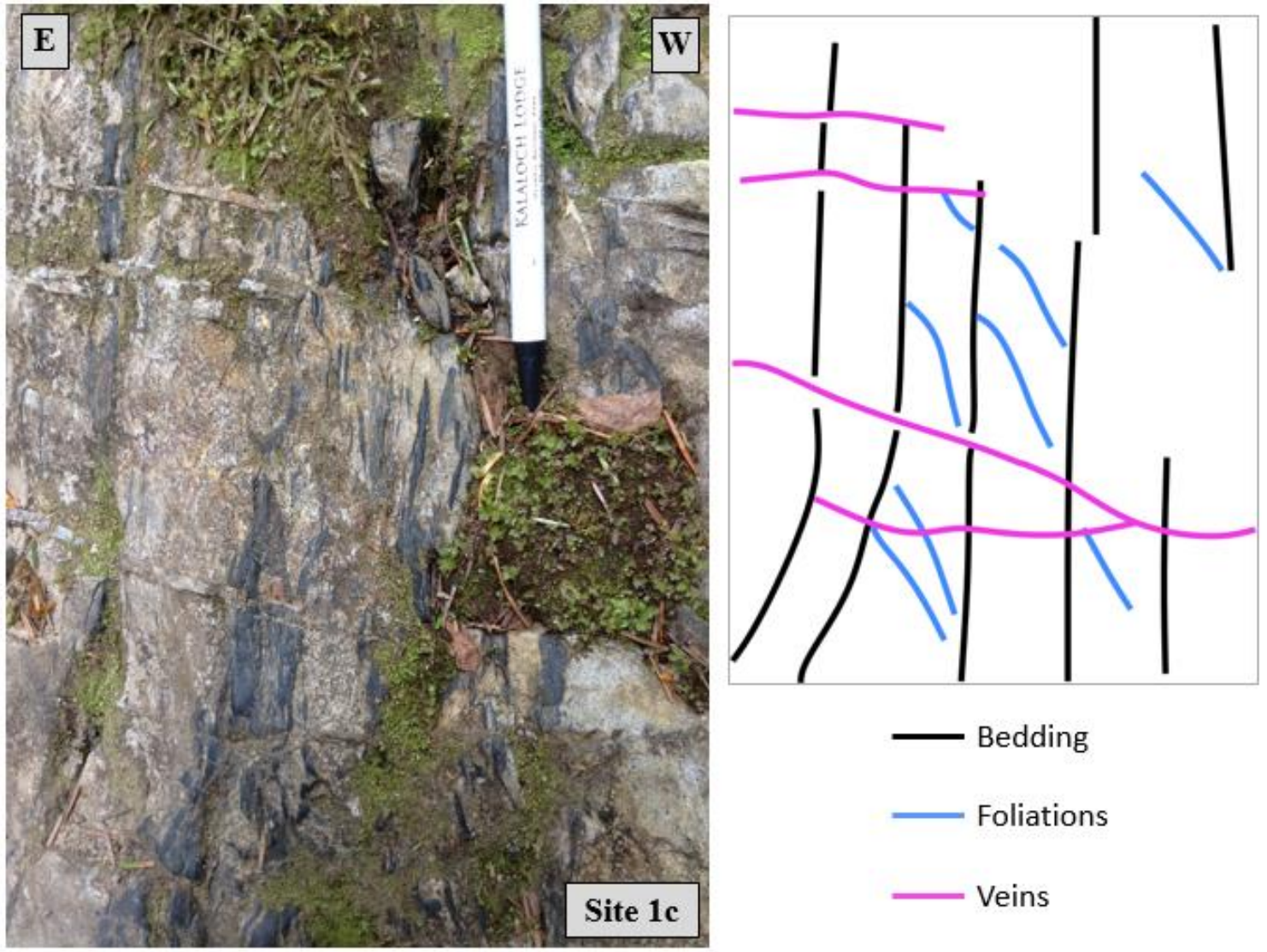

Figure 4.7. Photo of veins cutting across bedding and foliations at Site 1c (left) with an interpretive diagram (right). The photo of the near vertical outcrop was taken looking south. The pen is $15 \mathrm{~cm}$ long.

\subsubsection{Structural Orientation Data}

The bedding data show a wide range in orientations throughout the sites (Fig. 4.8). Sites 1a to $1 \mathrm{~d}$ show a gradual change from N-S oriented beds to NE-SW oriented beds. In general, these beds dip steeply to the west and northwest, however in Site 1c, some dip to the southeast. Sites 1e and 1f show a larger range in orientations. Site $2 \mathrm{a}$ shows NE-SW oriented, steeply dipping beds, similar to Site $1 \mathrm{~b}$. Sites $2 \mathrm{~b}$ and $2 \mathrm{c}$ also show a range in orientations that are similar to Sites 1e and 1f. The axial traces of the fold hinges on the outcrop surface were also measured and are plotted as points (red squares) along with the bedding data. 
The foliations show less of a range in orientation, and for the most part, strike N-S and dip to the east and west (Fig. 4.9). There are some deviations to this trend where foliations strike NNW-SSE and NW-SE and dip to the northeast and southwest (Sites 1a, 1e, 1f, and 2a). There are also a few instances where the foliations strike NNE-SSW and dip to the northeast (Sites 1e, 1f, and 2b).

In general, the fractures range in strike from E-W to NW-SE and dip to the south and southwest or to the north and northeast (Fig. 4.10). There is no apparent change in fracture orientation from site to site. Most sites show the range in orientations, with the exception of Site 1a which only shows E-W oriented fractures that dip to the south. The majority of the slickenline measurements are perpendicular to the strike of the planes, with some at a smaller angle to the horizon.

Vein orientations strike NW-SE and dip to both the northeast and southwest (Fig. 4.11). Many veins were identified at Site 1c and strike NW-SE; most dip to the southwest but a few dip to the northeast. A couple veins were identified at Site 1e and strike NNWSSE and dip to the WSW. Some veins were also identified at Site 1f, one strikes NW-SE and dips to the northeast, and one strikes NE-SW and dips to the northwest. Several veins were identified at Site $2 b$ and strike NW-SE and dip to both the northeast and southwest.

Figure 4.12 shows all of the bedding, fracture, foliation, and vein data combined. 

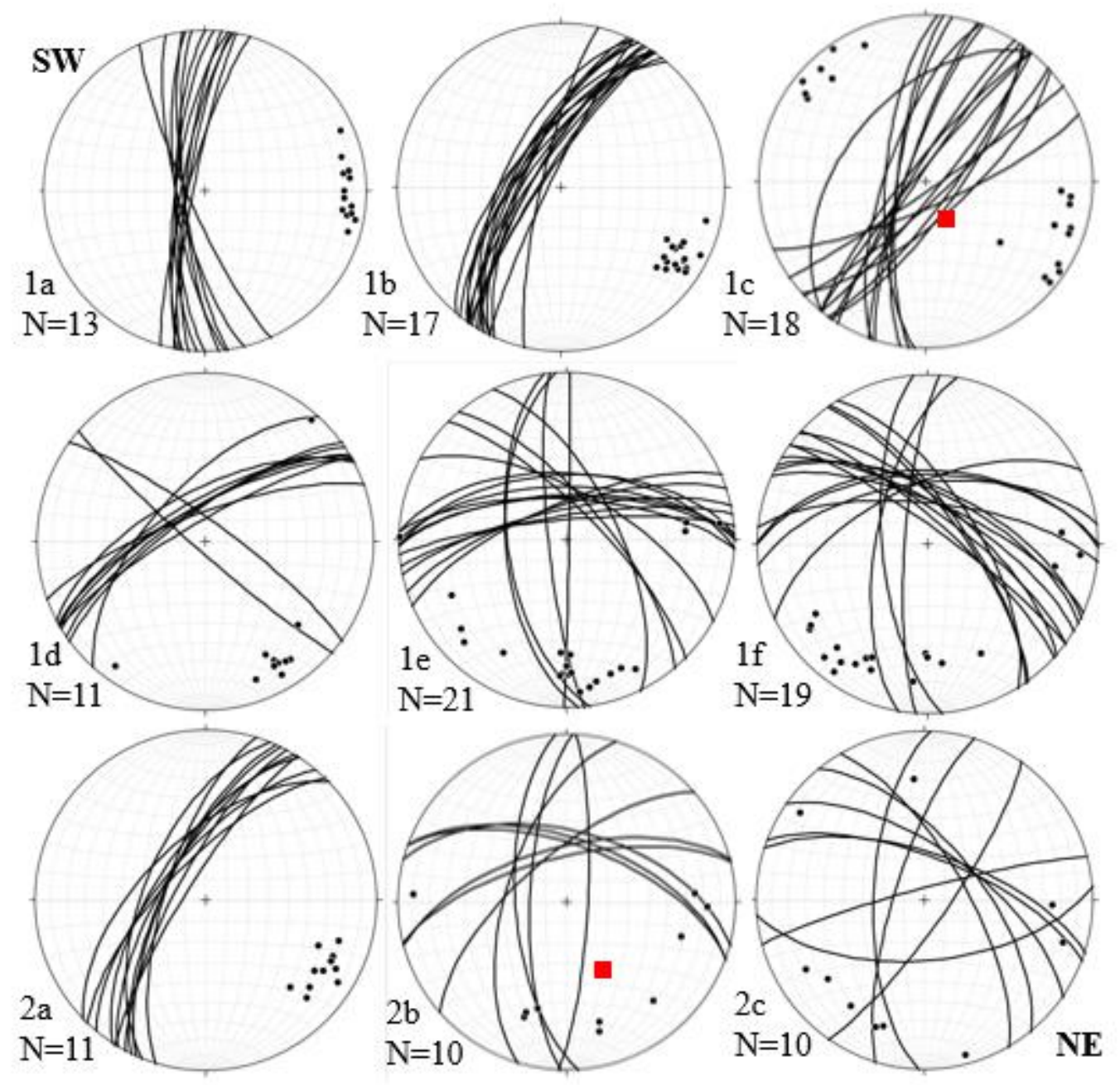

Figure 4.8. Bedding planes and poles for the meta-sedimentary units of Sites 1a-f and 2a-c and axial trace measurements of identified folds (red squares). Plots are lower hemisphere, equal area stereographic projections. $\mathrm{N}$ values refer to the number of measurements presented in each stereonet. 

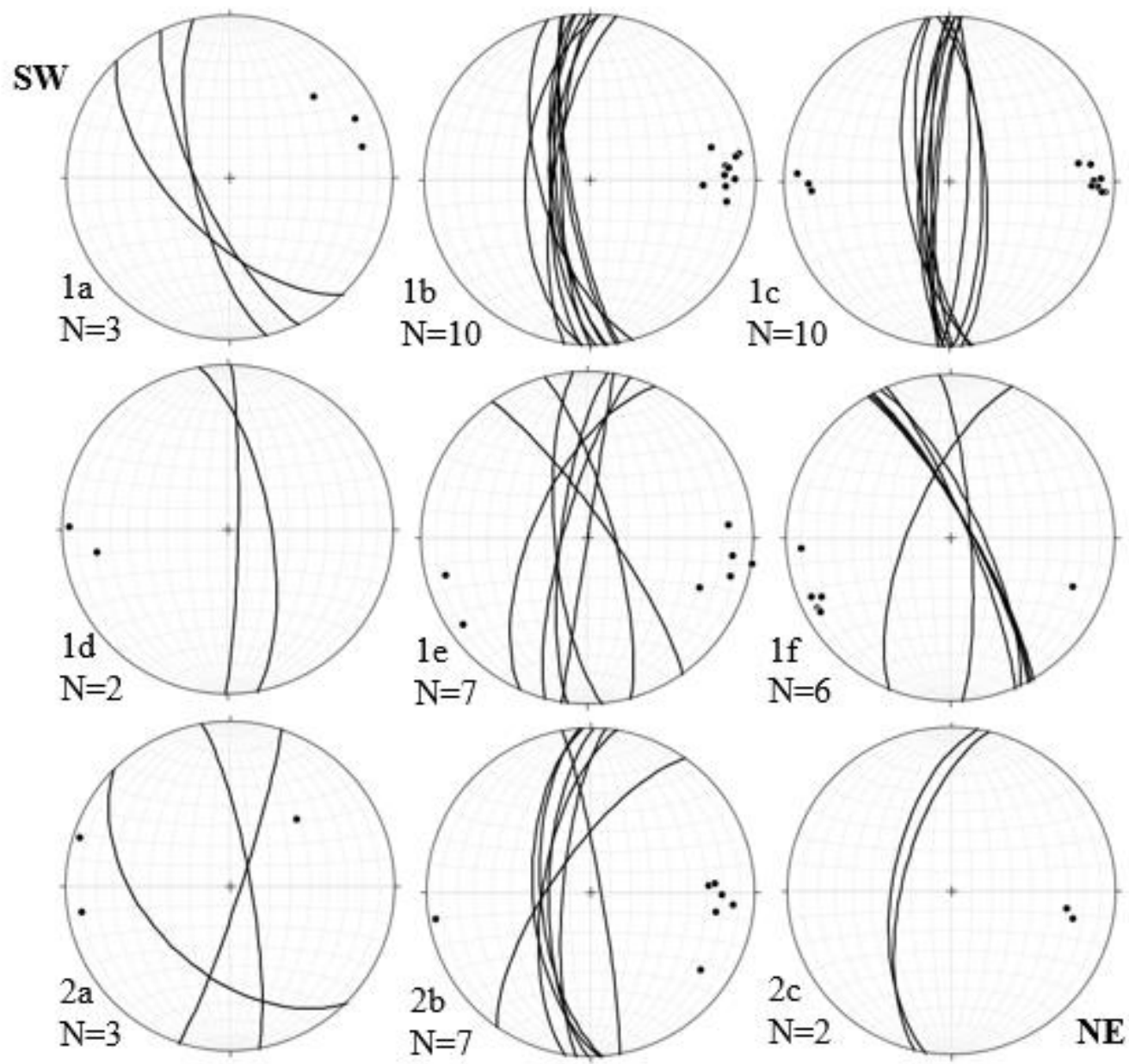

Figure 4.9. Foliation planes and poles for the meta-sedimentary units of Sites 1a-f and 2a-c. Plots are lower hemisphere, equal area stereographic projections. $\mathrm{N}$ values refer to the number of measurements presented in each stereonet. 

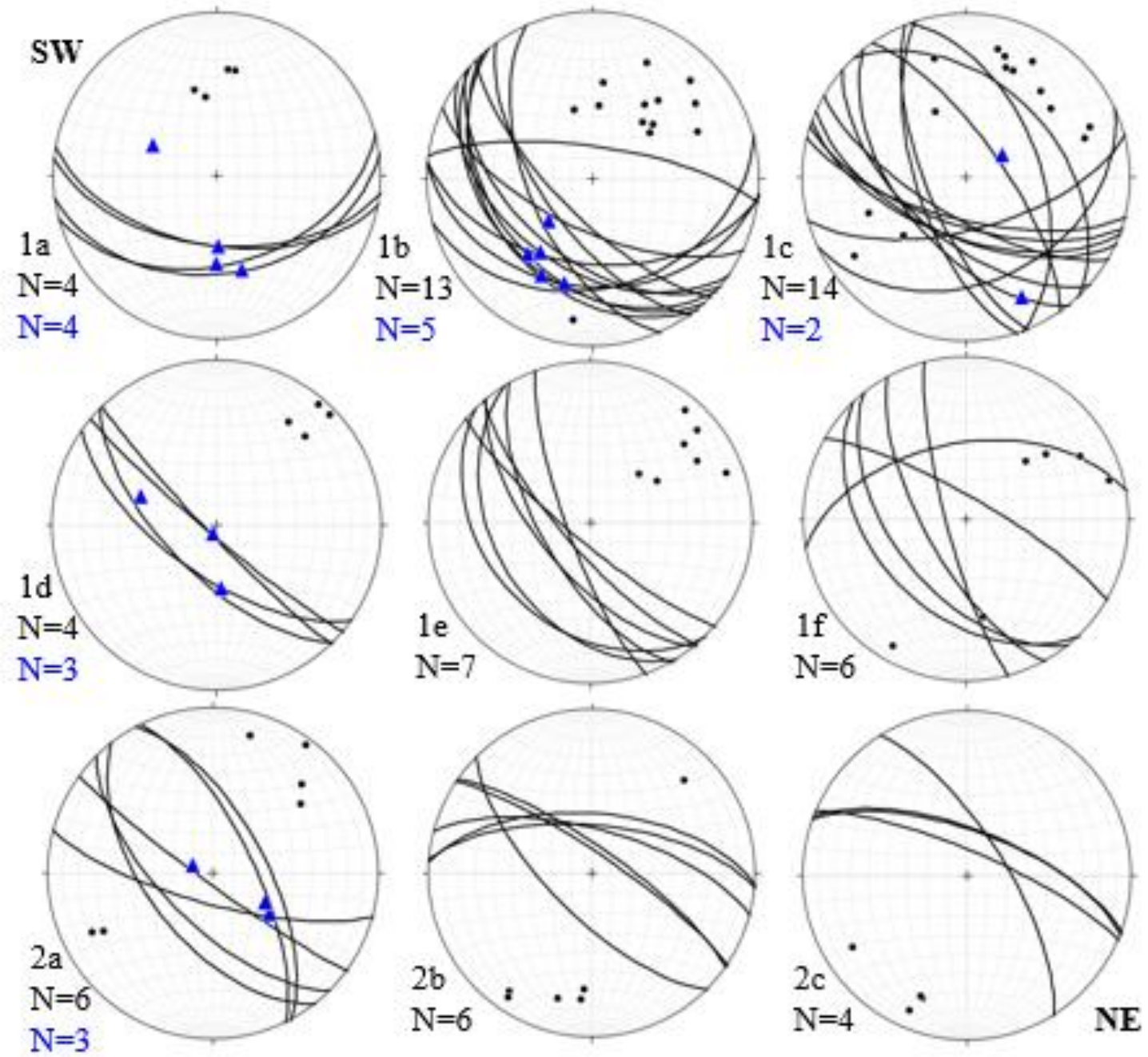

Figure 4.10. Fracture planes and poles (black lines and points) and slickenline measurements (blue triangles) for the meta-sedimentary units of Sites $1 \mathrm{a}-\mathrm{f}$ and $2 \mathrm{a}-\mathrm{c}$. Plots are lower hemisphere, equal area stereographic projections. $\mathrm{N}$ values are for fracture measurements (black) and slickenline measurements (blue) in each stereonet. 

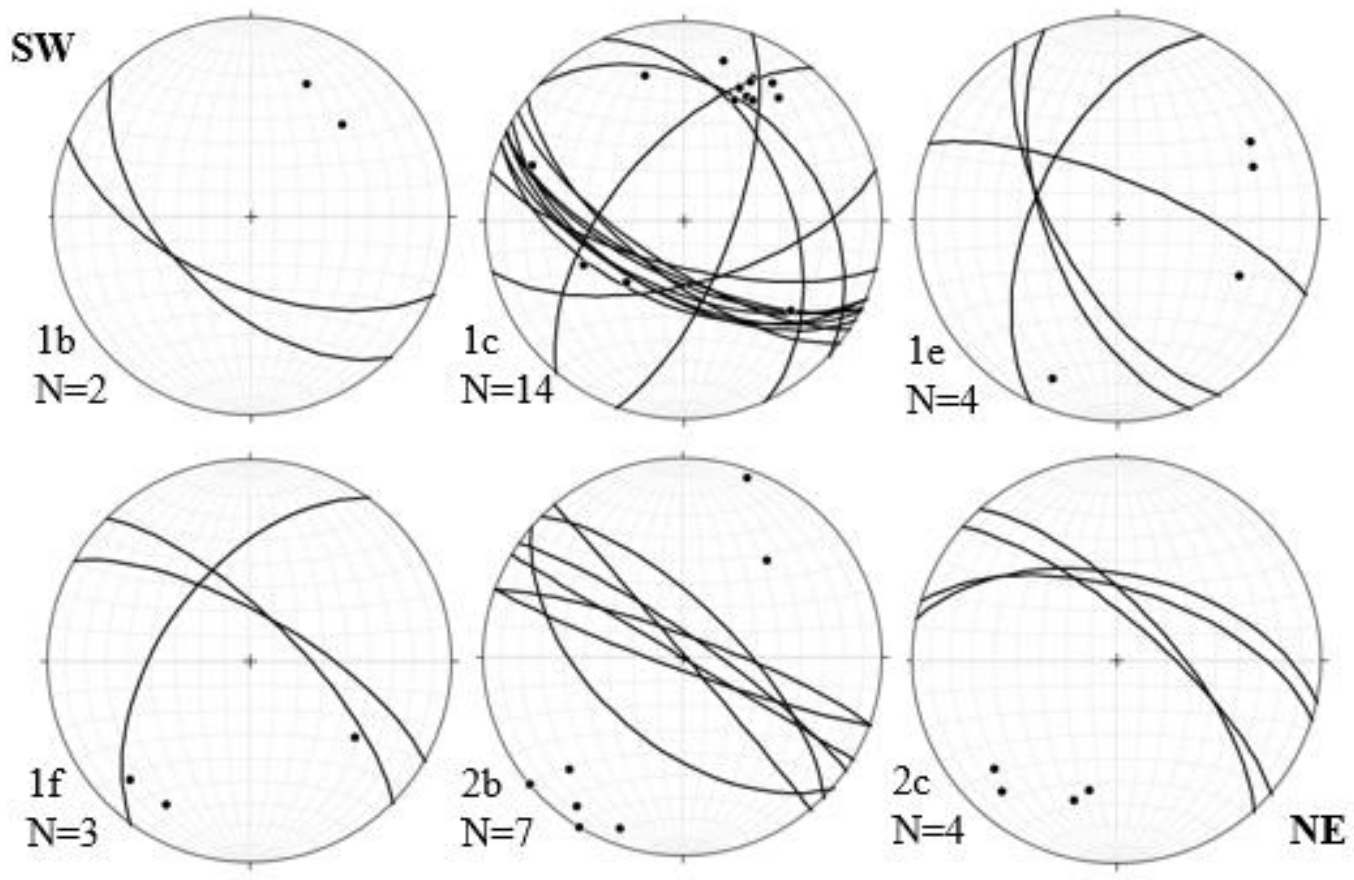

Figure 4.11. Vein planes and poles for the meta-sedimentary units of Sites 1a-f and 2a-c. Plots are lower hemisphere, equal area stereographic projections. $\mathrm{N}$ values refer to the number of measurements presented in each stereonet. 

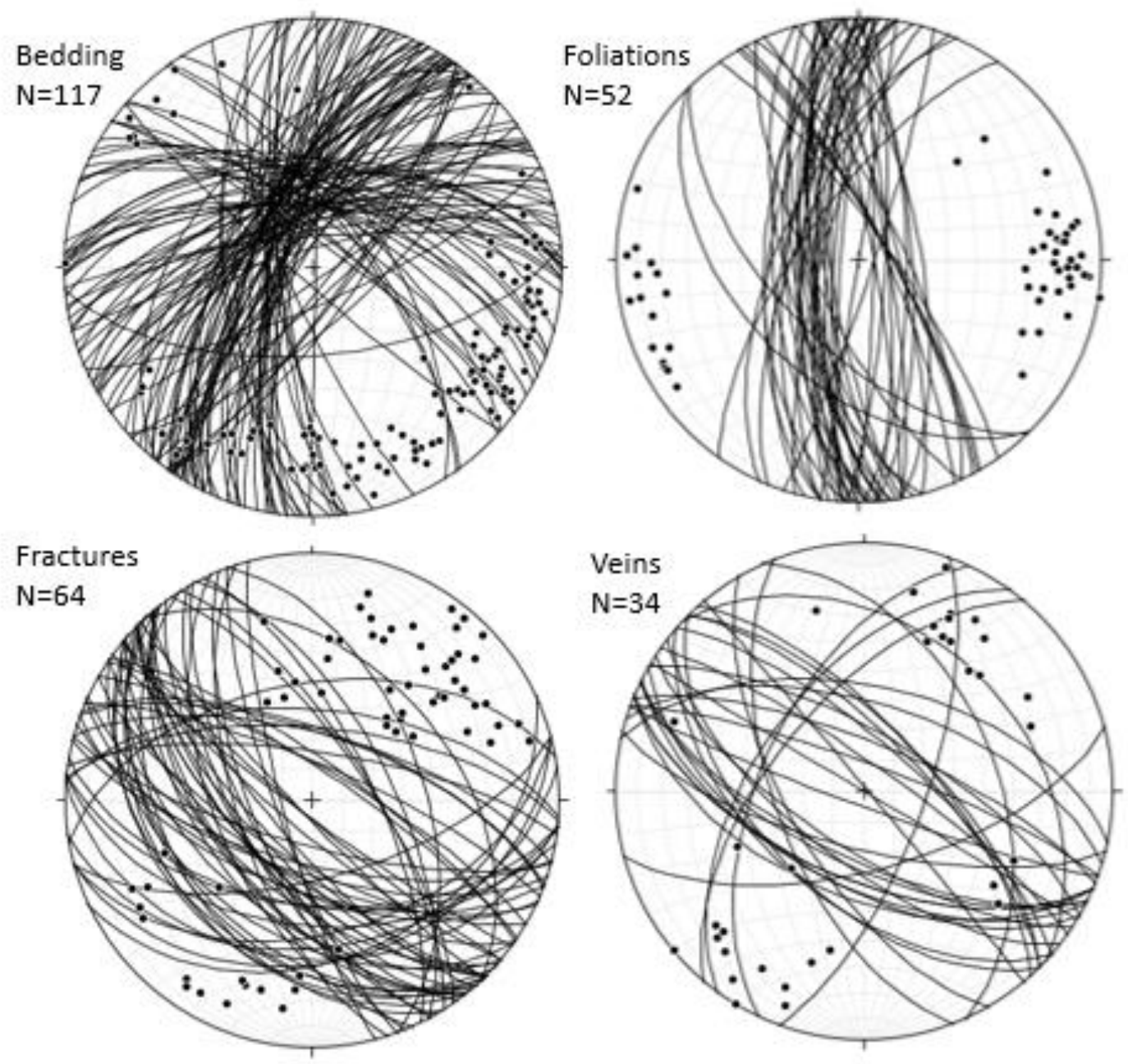

Figure 4.12. All bedding, foliation, fracture, and vein data for the meta-sedimentary units combined from Sites 1a-f and 2a-c. Plots are lower hemisphere, equal area stereographic projections. $\mathrm{N}$ values refer to the number of measurements presented in each stereonet. 


\subsubsection{Microscale Observations \& Data}

Two rock samples are used in this section to describe the range in disruption of the meta-sediments at the hand sample scale. As described in Section 4.1.1, the sites with more meta-sandstone appear to be less disturbed by fractures and foliations than those with more slate. Sample A (Fig. 4.13) is from the less-disturbed, meta-sandstone-rich sites, and Sample B (Fig. 4.14) is from the more disturbed slate-rich sites. A thin section from Sample B (Fig. 4.15) is also used to show how structures are expressed at the microscale.

At the hand sample scale, Sample A shows primary sedimentary features and secondary deformation features (Fig. 4.13). The sample has continuous, linear bedding of slate and meta-sandstone with primary features, such as cross beds, preserved in the meta-sandstone layers. Foliation is observed crosscutting the slate layers and is uniformly oriented throughout the sample.

Sample B shows a variety of deformational structures that disrupt primary structures at the hand sample scale (Fig. 4.14). The sample has discontinuous bedding of slate and meta-sandstone at a range of orientations, with some areas displaying folds. Bedding is crosscut and offset by foliations and fractures. Although they have a similar appearance at the hand sample scale, the foliation is a penetrative fabric, whereas the fractures are small, localized, and not expressed throughout the whole rock. Fractures are most confidently identified where they offset and crosscut bedding and where their orientation is similar to larger scale fractures measured at the sample site. Sample B also contains small veins that crosscut bedding and do not have a consistent orientation. These 
veins are not expressed at the sample site, but these may be smaller versions of those that are observed elsewhere at the outcrop scale.

At the micro-scale, the primary foliation of Sample B affects both the slate and meta-sandstone layers. The meta-sandstone layers are characterized by quartz and feldspar crystals that range from 5-75 $\mu \mathrm{m}$ in diameter, and the slate layers are characterized by white and brown mica that range in size from 1-5 $\mu \mathrm{m}$ in width and 5-100 $\mu \mathrm{m}$ in length (Fig. 4.16). The mica grains are in a preferred orientation and form a penetrative foliation that anastomoses around the quartz and feldspar grains. This foliation is especially apparent in the slate layers, but is also expressed in the metasandstone layers by sparse micas. The foliation is subparallel to bedding and is termed S1. This foliation is crenulated in some places.

A secondary foliation crosscuts and disrupts the bedding parallel foliation (S1) in Sample B (Fig. 4.17). This foliation (S2) is also defined by aligned mica grains. The crenulations in S1 are associated with S2 in orientation and spatial relationship; where S2 crosscuts $\mathrm{S} 1, \mathrm{~S} 1$ bends into $\mathrm{S} 2$.

Veins in Sample B crosscut many features in the rock and are deformed. They are composed of quartz crystals that are 50-200 $\mu \mathrm{m}$ in diameter (Fig. 4.18). The veins crosscut the bedding and, in places, cut S1. The veins are folded, commonly in an orientation consistent with $\mathrm{S} 2$. The quartz crystals also show microstructures consistent with bulging and subgrain rotation recrystallization, as described by Stipp, Stünitz, Heilbronner, \& Schmid (2002) (Fig. 4.19). The veins observed here are not necessarily the same veins that are observed at the outcrop scale. The veins at the outcrop scale are 
larger (on the order of a couple millimeters thick and up to a meter in length) and are composed of larger, blocky quartz grains.

Fractures are also observed at the micro-scale crosscutting and offsetting the bedding and foliation (Fig. 4.20). The fractures differ from the foliations in that they are not defined by the alignment of mica grains. They are filled with very fine grained quartz crystals, which may indicate that they are related to the veins.

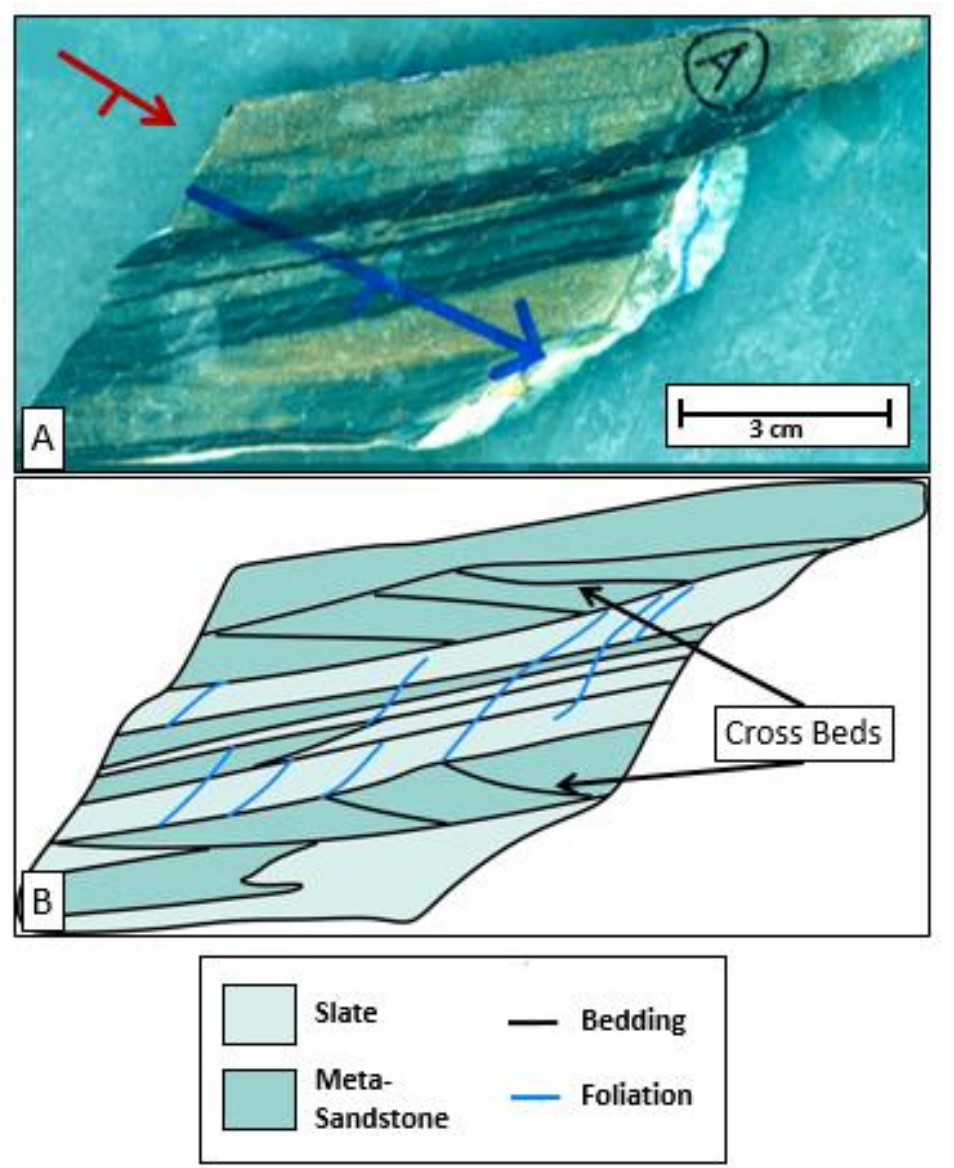

Figure 4.13. Sample A (a) and a corresponding interpretive diagram (b) that outlines structures of interest. The slab scan image shows a near cross sectional view on the plane $(053,22)$, as indicated by strike and dip markings. Sample A is collected from Site $1 \mathrm{~b}$. 


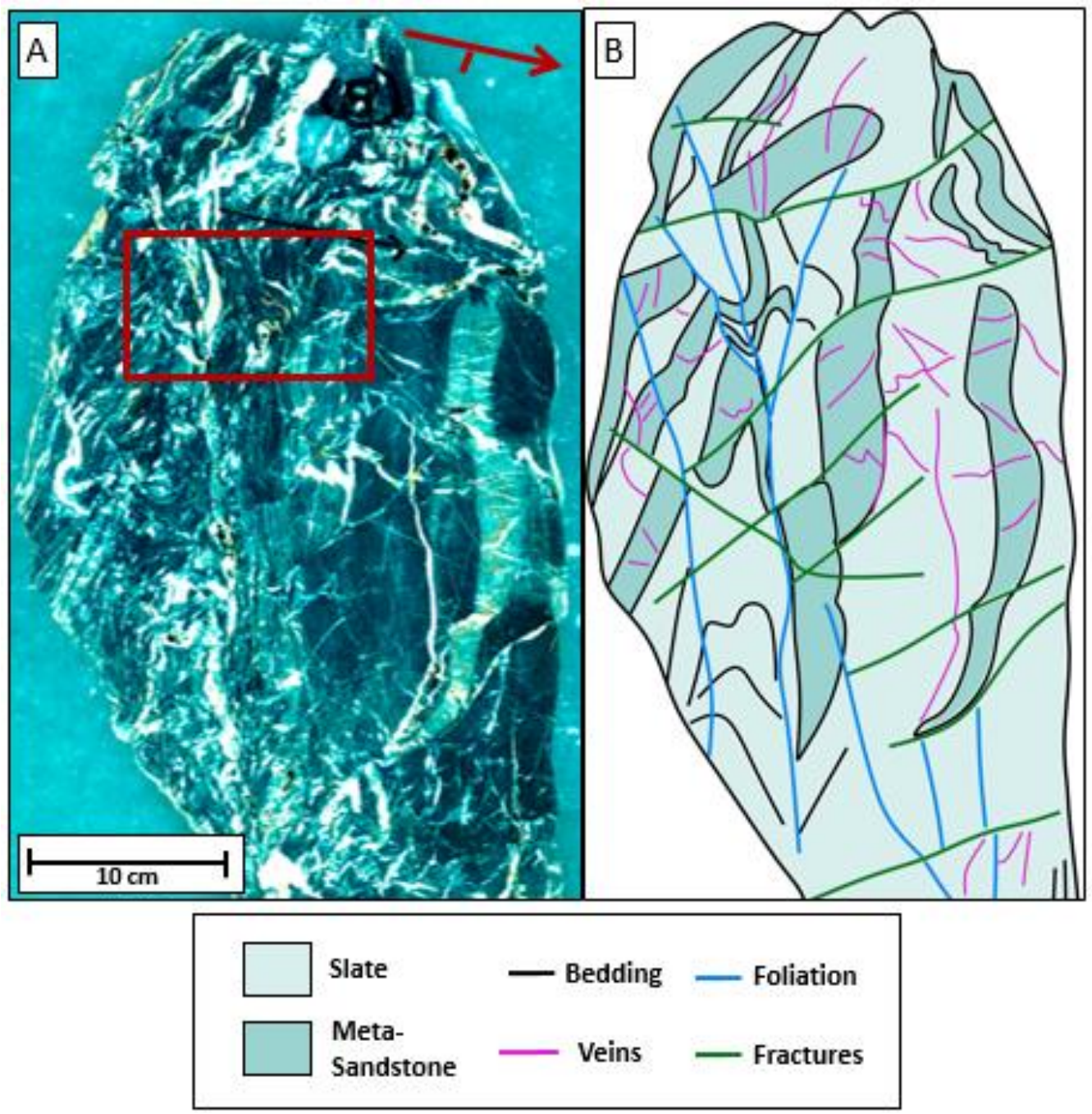

Figure 4.14. Sample B (a) and a corresponding interpretive diagram (b) that outlines structures of interest. The slab shows a near cross sectional view on the plane $(071,84)$, as indicated by the strike and dip markings. The red box outlines the area of the thin section shown in Figure 4.15. Sample B was collected from Site 1e. 


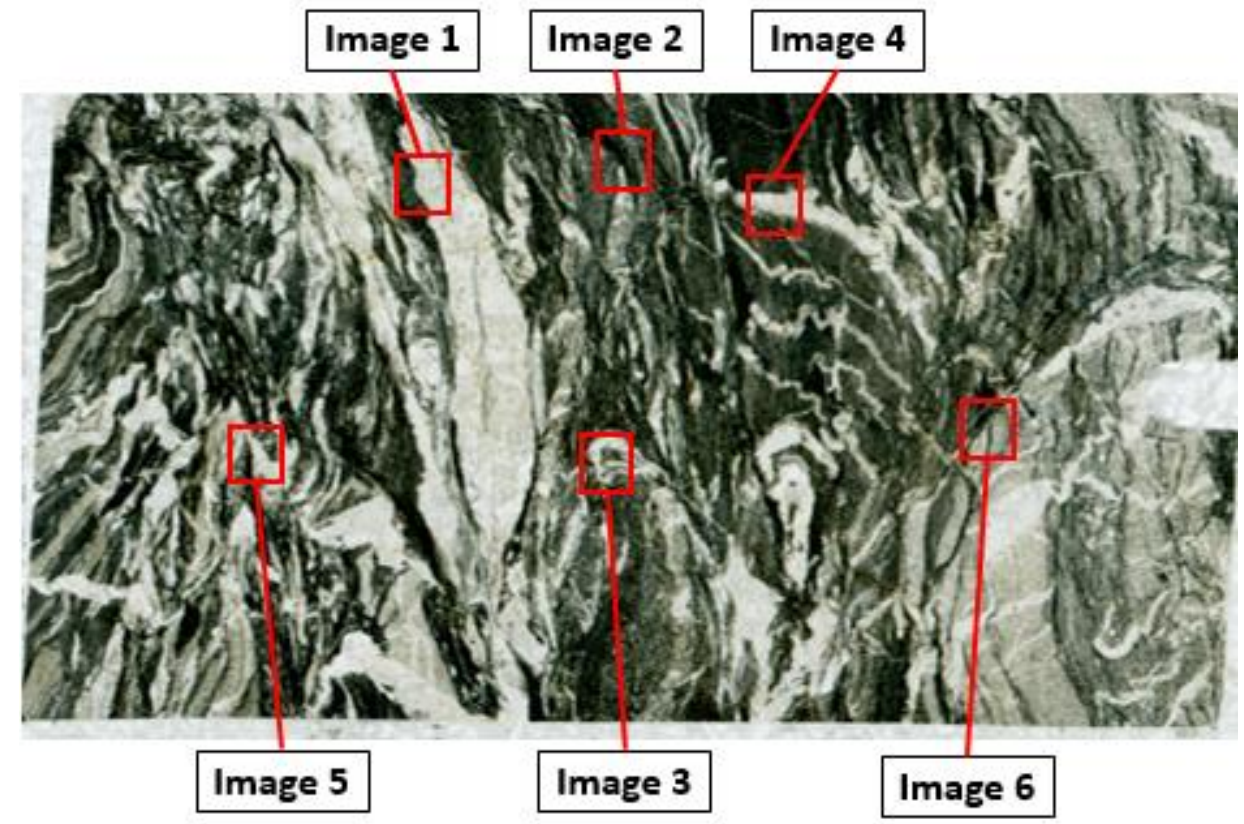

Figure 4.15. A thin section created from Sample B (red box in Fig. 4.14) and locations of the structures shown in Figures 4.16 to 4.20 . 

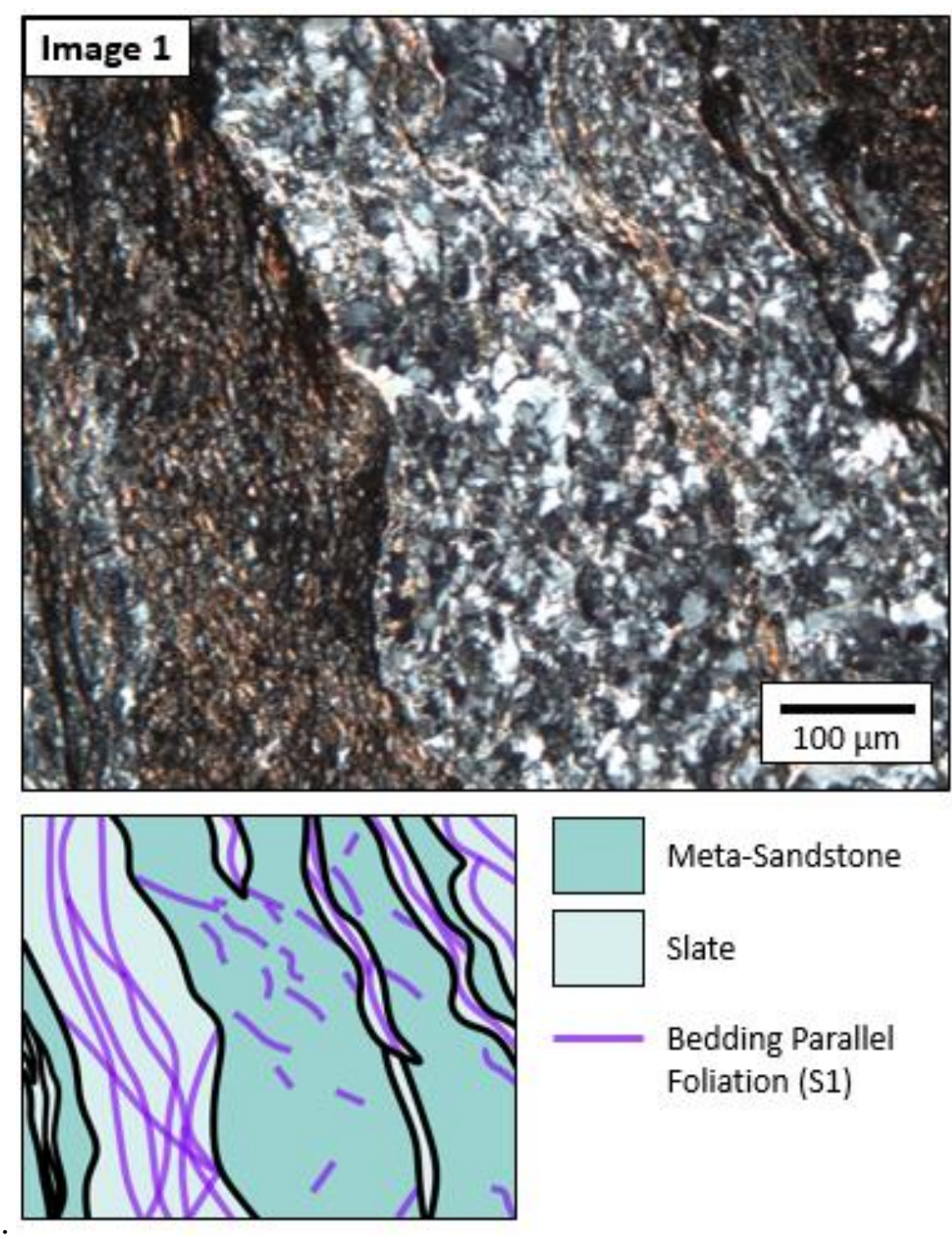

\section{Bedding Parallel}

Foliation (S1)

Figure 4.16. Photomicrograph and interpretive diagram of slate and meta-sandstone layers. The micadefined foliation is subparallel to bedding. Image 1 of Sample B (see Fig. 4.15) in crossed-polarized light. 


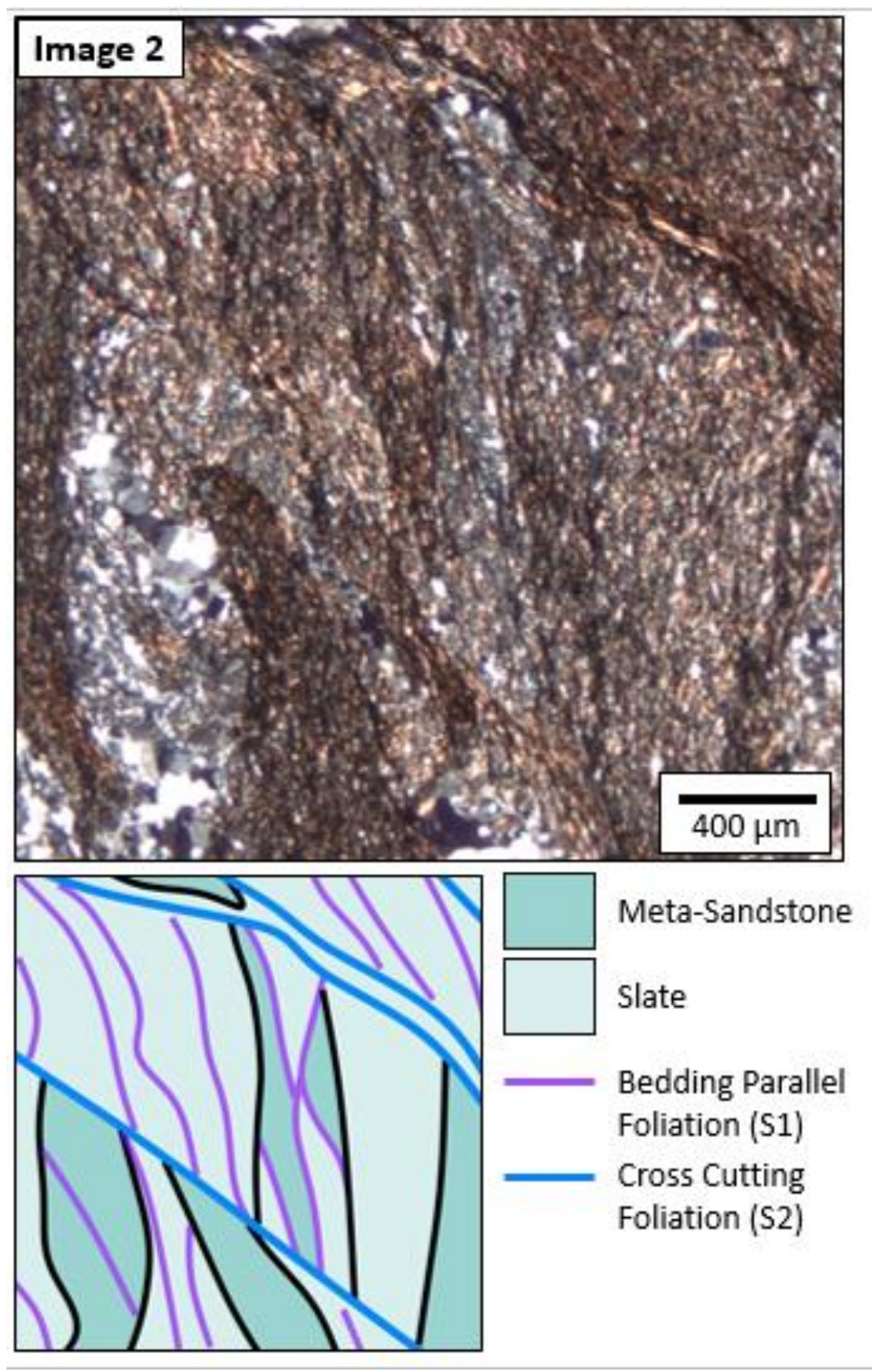

Figure 4.17. Photomicrograph and interpretive diagram of overprinting foliations in Image 2 of Sample B (see Fig. 4.15). A second foliation (S2) crosscuts and overprints the bedding parallel foliation (S1). Image shows cross-polarized light. 

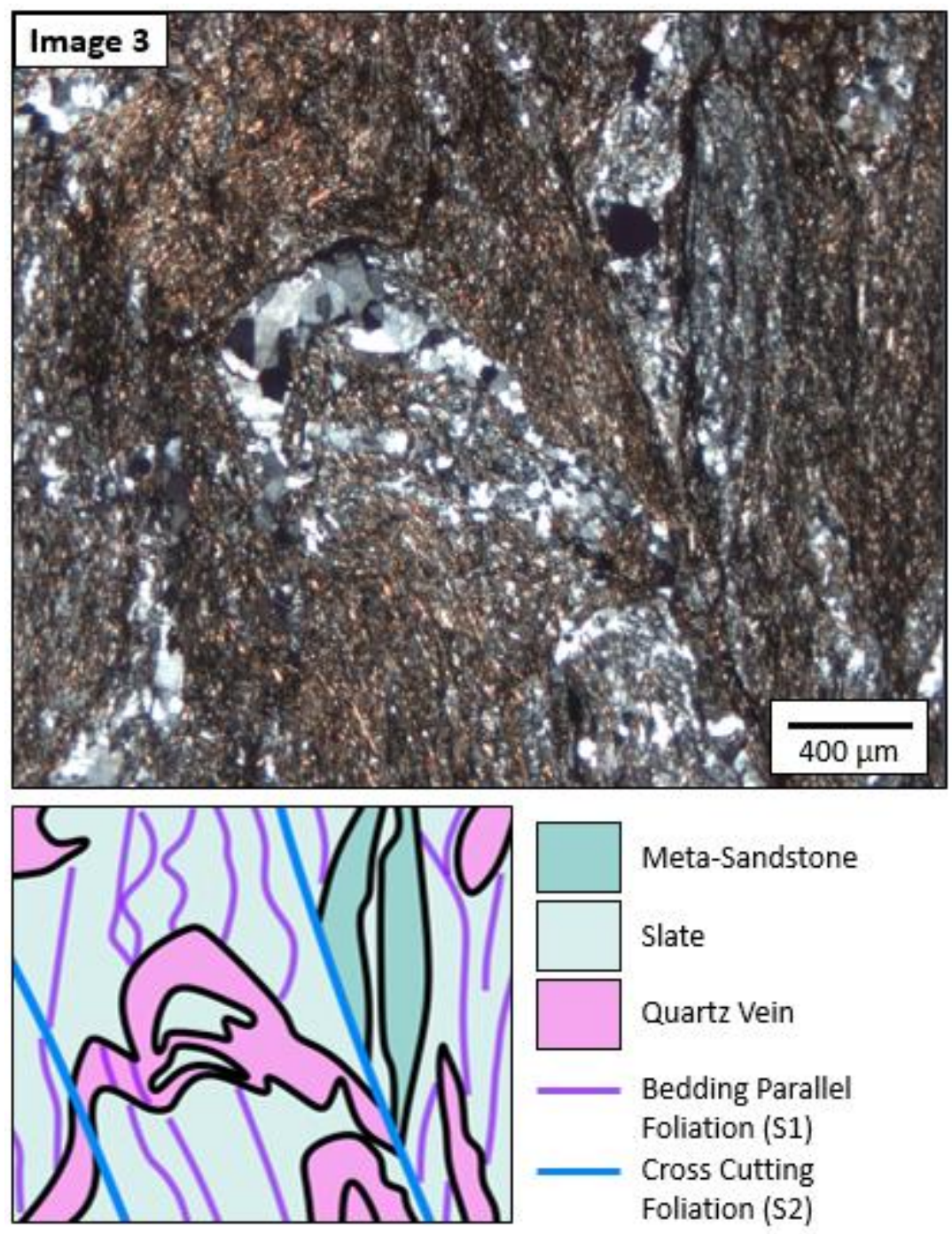

Figure 4.18. Photomicrograph and interpretive diagram of the relationship between a vein and foliation in Image 3 of Sample B (see Fig. 4.15). The quartz vein crosscuts S1 and is folded in an orientation that correlates with S2. Image shows cross-polarized light. 

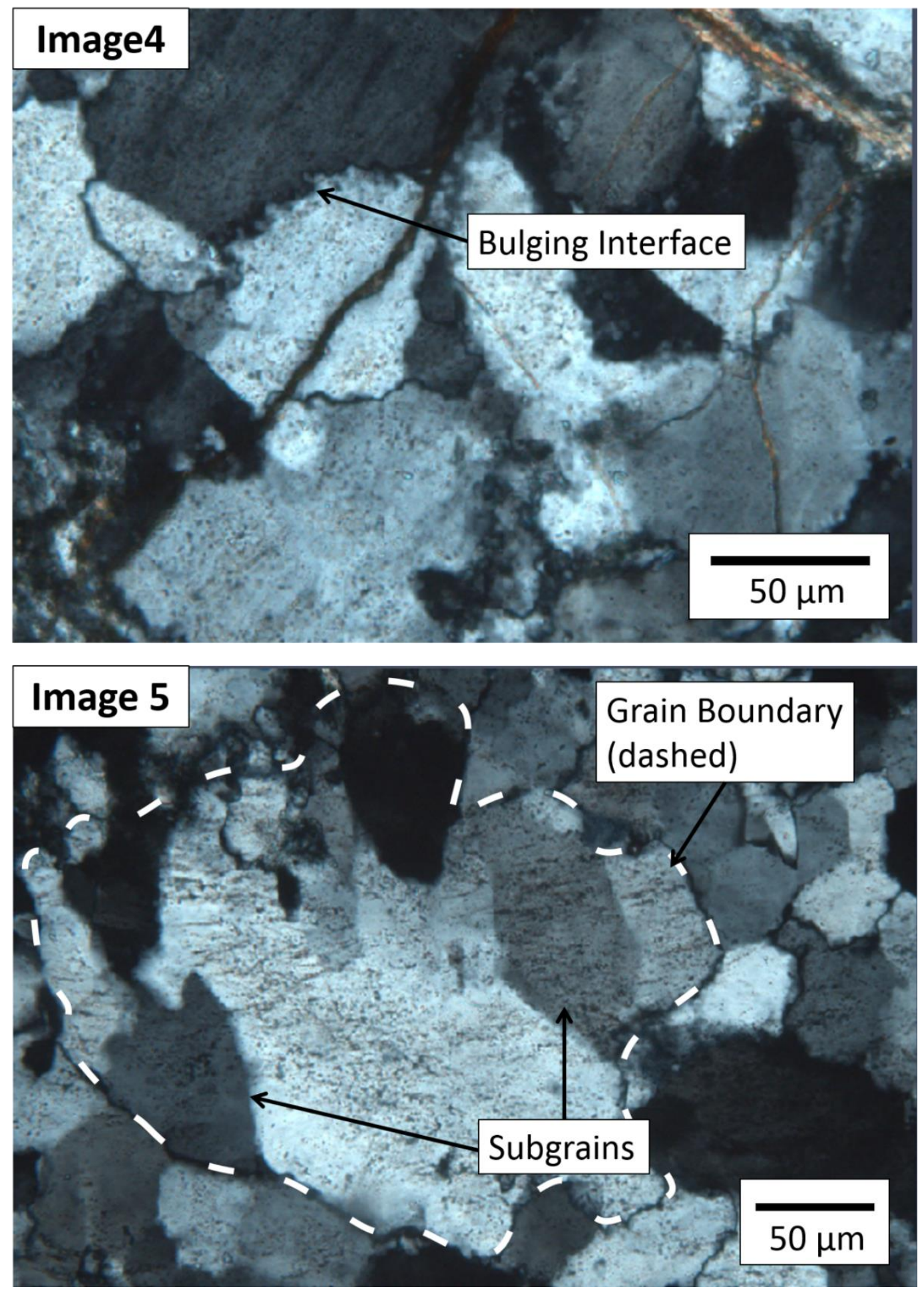

Figure 4.19. Photomicrographs of quartz microstructures in Images 4 and 5 of Sample B (see Fig. 4.15). Microstructures are consistent with bulging (Image 4) and subgrain rotation (Image 5) are both present. Images show cross-polarized light. 

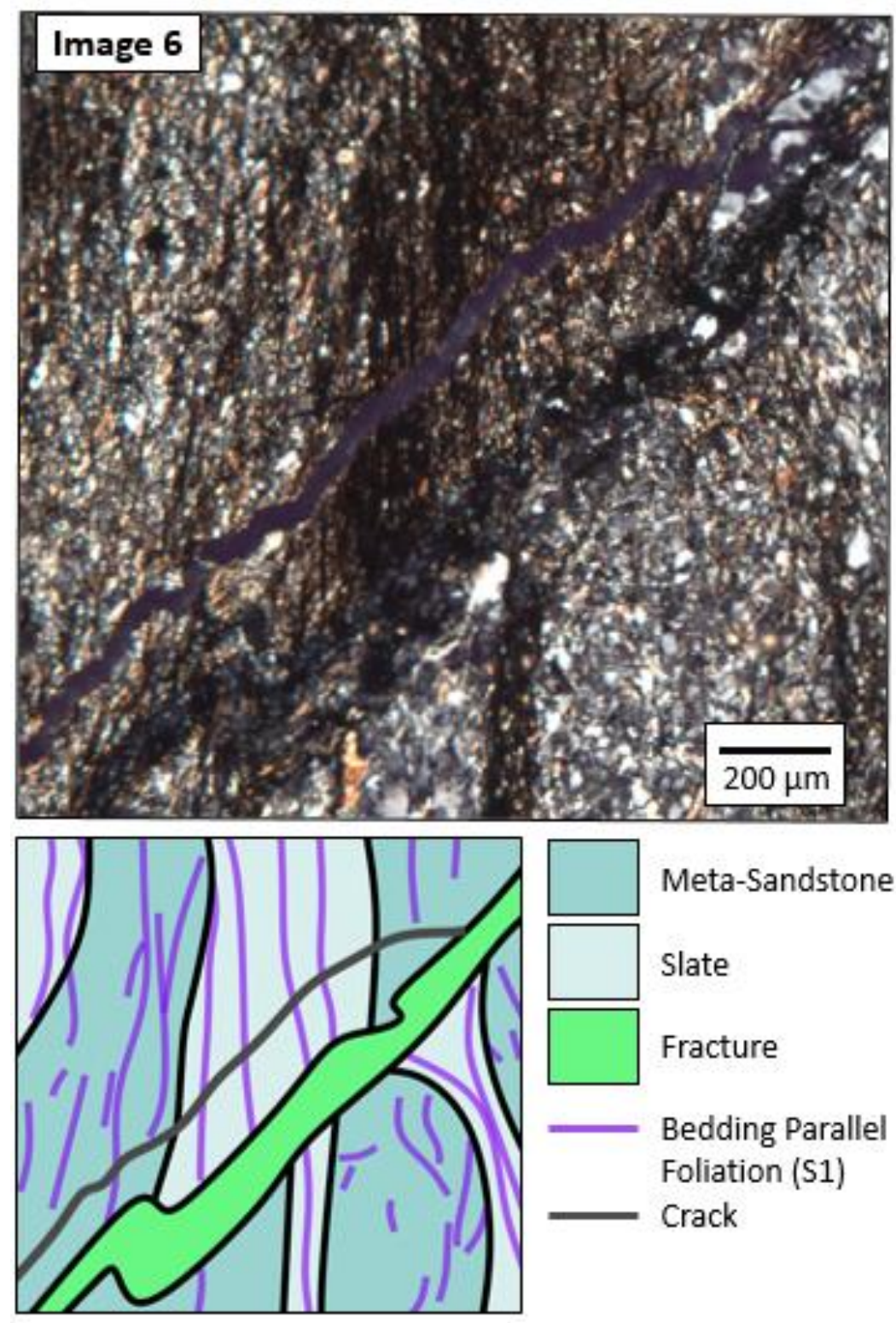

Figure 4.20. Photomicrograph and interpretive diagram of a fracture in Image 6 of Sample B (see Fig. 4.15). The fracture is filled with very fine-grained quartz and crosscuts $S 1$, offsetting bedding layers. Image shows crossed-polarized light.

\subsection{Interpretations}

This section presents interpretations made of field observations, structural data, and micro-scale observations from the meta-sedimentary outcrops, Sites 1 and 2, of the Hamma Hamma Transect. 
Sites $1 \mathrm{a}, 1 \mathrm{~b}, 1 \mathrm{c}$, and $1 \mathrm{~d}$ represent a single fold, the fold hinge of which was identified at Site 1c (Fig. 4.2). This is supported by the progressive change in bedding orientation along these sites (Fig. 4.8). The pattern of bedding measurements relative to location suggest several smaller scale folds at Sites 1e and 1f. Figure 4.21 shows where bedding measurements were taken along these sites and the interpreted fold outline. Fold hinges were not identified at these sites due to cover. Site 2 shows a similar fold pattern as Sites 1e and 1f. The bedding data from Sites 1a-1d span a similar range as the data for Sites 1e and 1f (Fig. 4.8), indicating that the folds are related and oriented similarly. When the poles to bedding planes from all sites are considered with the axial trace measurements, a fold axis of $(69 \rightarrow 342)$ and an axial plane of $(337,88)$ was calculated (Fig. 4.22). The principal stress $(\sigma 1)$ necessary to form these folds is oriented $(02 \rightarrow 247)$, ENE-WSW.

Considering the calculated axial plane, location of fold hinge, and rock type present at each site, the schematic map in Figure 4.23 was created for Site 1. The area shows a steeply plunging, single anticline, with the hinge at Site 1c. The rocks at Site 1a are interpreted as the same layer as those at Sites 1e and 1f. The smaller scale folds at Sites $1 \mathrm{e}$ and $1 \mathrm{f}$ are interpreted as parasitic folds, which is consistent with folding in less competent slate layers.

Sedimentary layers are expected to be initially deposited horizontally, and an initial folding is expected to be upright with some shallowly dipping beds and a horizontal fold axis. This is not what was observed in the study area, suggesting that folds were rotated into their current position. The axis of rotation necessary for this process is 
$(00 \rightarrow 073)$ with a magnitude of $69^{\circ}$ counterclockwise, and the $\sigma 1$ necessary for this rotation is oriented NNW-SSE. Figure 4.24 shows the poles to bedding data and an interpretation of how the data would look if it was rotated to put the folds in an upright orientation.

Two foliations were identified at the microscale, S1 and S2. S1 is bedding parallel, and I interpret it to have formed from compression due to the burial of the sediments. S2 overprints S1 at the microscale (Fig. 4.17), however, at the hand sample scale, the two foliations are undistinguishable from one another (Fig. 4.14). It is unclear whether both foliations are expressed at the hand sample and outcrop scale or if only S2 is apparent and measureable. Since $\mathrm{S} 1$ appears bedding-parallel, if it was formed from burial rather than folding, it would have been folded with the bedding and would show a range in orientations, similar to the bedding data. The foliation measured at the outcrop scale strikes pretty consistently N-S and is not similar to the beds, so therefore, I interpret the foliation measured at the outcrops as the S2 observed in thin section. A more detailed microscale analysis with a wider range of samples from around the map-scale folds would be required to determine the timing and relationship among the microscale S1 and S2, the outcrop-scale foliation, and the outcrop-scale fold data.

The fold and foliation data do not support the interpretation that the outcrop-scale foliation measurements formed axial planar to the folds. If the folds and foliation formed under the same state of stress, then the axial plane should be parallel to the foliation. This is not the case for the foliation measured in outcrop (S2) and the calculated axial plane from bedding data (Fig. 4.25). The foliation has a range of orientations that center around 
a N-S strike, whereas the axial plane strikes NNW-SSE. There are several possible explanations for this discrepancy. There may have been a component of shear in which the $\sigma 1$ is oriented at an angle to the foliation and the folds are drag folds associated with strain partitioning on shear planes. This would indicate that the folds and foliation may have formed under the same state of stress. Alternatively, it may be that the foliation formed later than and overprints the folds, and therefore the two are not related.

Orientation data and microscale observations support the interpretation that the fractures and veins are genetically related. The fractures and veins have similar orientations throughout the outcrops (Fig. 4.26), and at the micro-scale, the fractures appear as very fine-grained quartz, indicating mineralization (Fig. 4.20). Because of this, I interpret the veins to represent mineralized Mode II fractures rather than Mode I fractures. When the data for the fractures and veins are combined, two groups stand out with representative orientations: Group A $(115,61)$ and Group B $(303,76)$ (Fig. 4.27a).

The orientation of combined fracture and vein groups are consistent with the interpretation that they are conjugate fractures. The maximum principal stress $(\sigma 1)$ for these conjugates would be $(76 \rightarrow 254)$, which is nearly vertical (Fig. 4.27a). If the assumption of conjugates is correct and if they formed in their current orientation, this suggests a normal motion. The slickensides, however, indicate that the last motion on the fracture planes was reverse (i.e., smooth up dip on the footwall side). One interpretation for this relationship is that the state of stress changed to account for the change in slip direction. This interpretation is not preferred because it is not consistent with a 
convergent plate setting. Another interpretation is that the fractures actually formed with a reverse geometry and were then rotated into their current position.

If both the fractures and folds have been rotated and the rotation occurred after both structures formed, then it is possible that the same degree of rotation from the fold data could be applied to the fracture data. When the fracture groups are rotated about the same rotation axis calculated for the folds $\left([00 \rightarrow 073]\right.$ with a magnitude of $69^{\circ}$, counterclockwise) an initial $\sigma 1$ of $(21 \rightarrow 178)(\mathrm{N}-\mathrm{S})$ is calculated (Fig 4.27b). This state of stress is sub-perpendicular to the strike of the interpreted axis of rotation and therefore could be the driving force for the rotation.

I propose two stages of deformation throughout the rocks' history, with two different states of stress. The first stage had a $\sigma 1$ oriented ENE-WSW or E-W which formed the folds and foliation (S2). It is unclear if the folds and foliation formed during the same event or if the foliation overprints the folds, however, it is possible that they formed under a similar state of stress. The second stage had a $\sigma 1$ oriented N-S or NNWSSE, which formed the fractures and caused the rotation of the folds and fractures into their current orientation. 


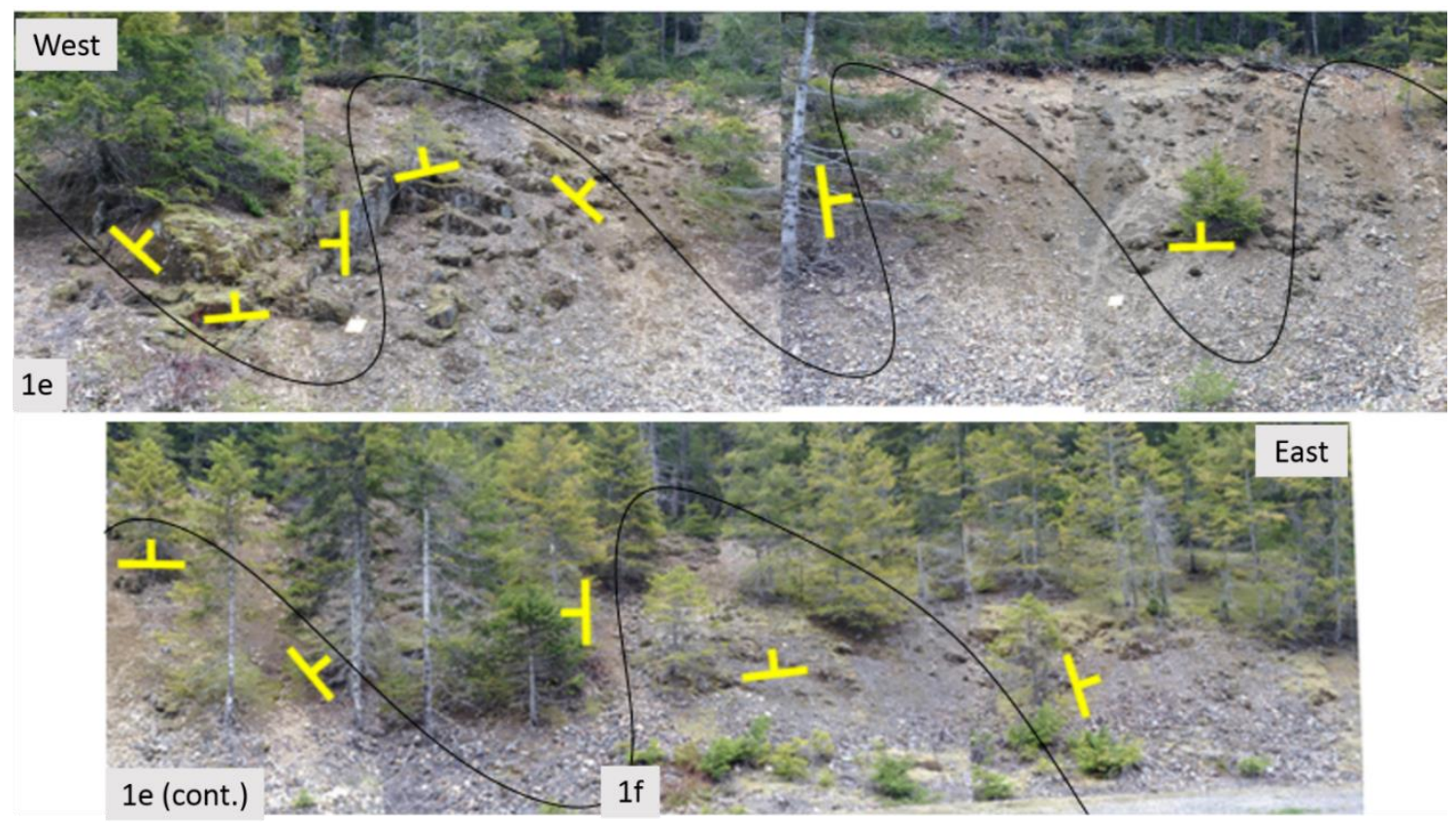

Figure 4.21. Outcrop map of Sites 1e and 1f showing the locations of strike and dip measurements and an interpreted fold line.

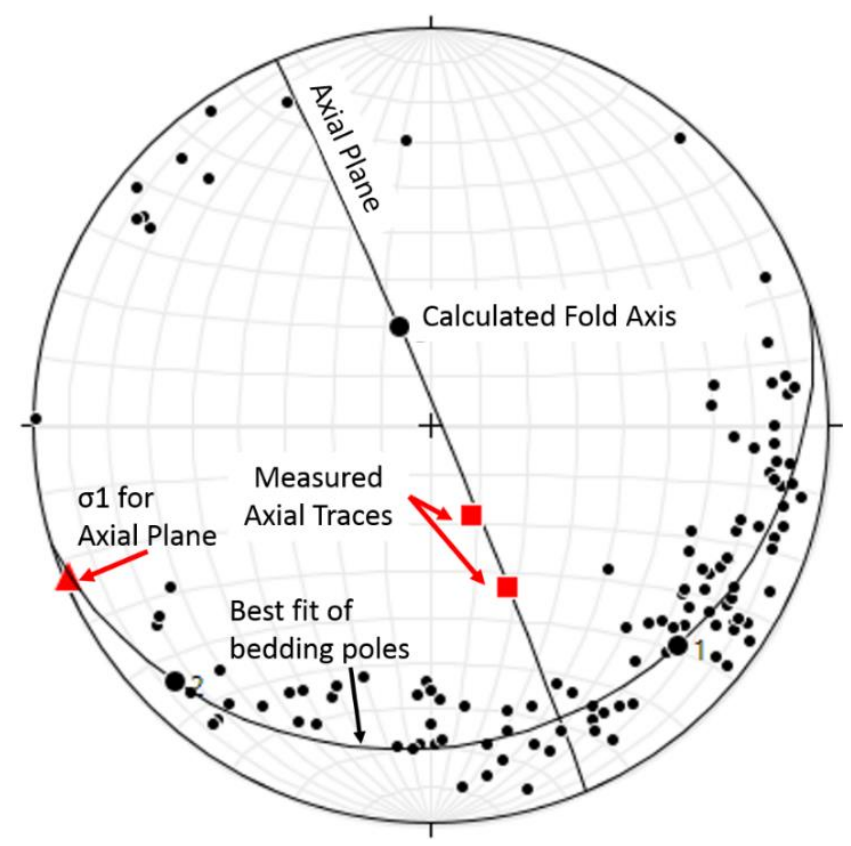

Figure 4.22. Poles to all bedding planes with a cylindrical best fit plotted. The pole to the cylindrical best fit is the calculated fold axis $(69 \rightarrow 342)$. The line through the fold axis and the measured axial traces (outlined in Fig. 4.4) is the calculated axial plane $(337,88)$. The pole to the axial plane is the principal stress $(\sigma 1)$ that formed the folds $(02 \rightarrow 247)$. 


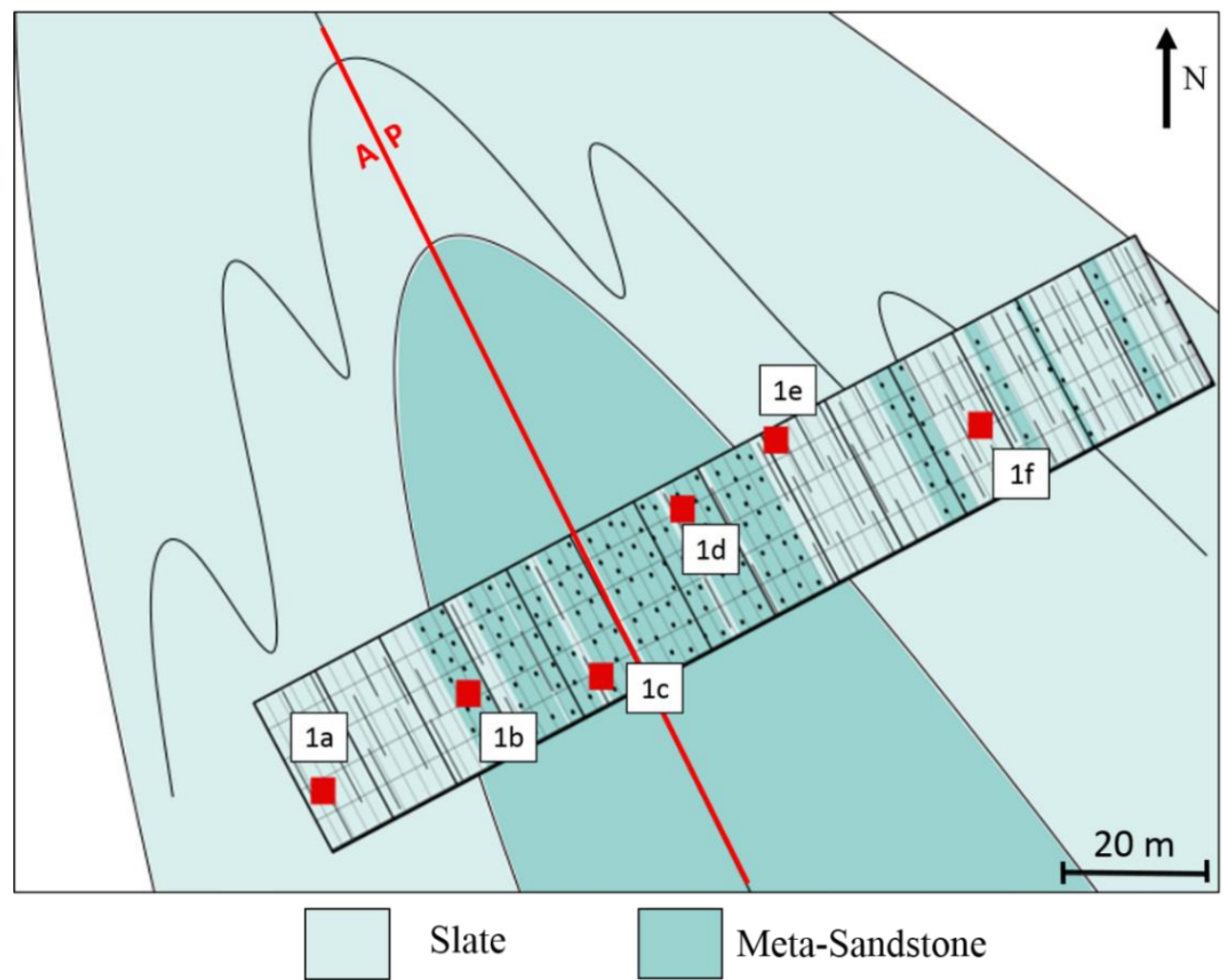

Figure 4.23. Schematic geologic map of Site 1 along the Hamma Hamma Transect. The area is interpreted as one single fold with parasitic folds in the slaty layers of the fold limbs. 


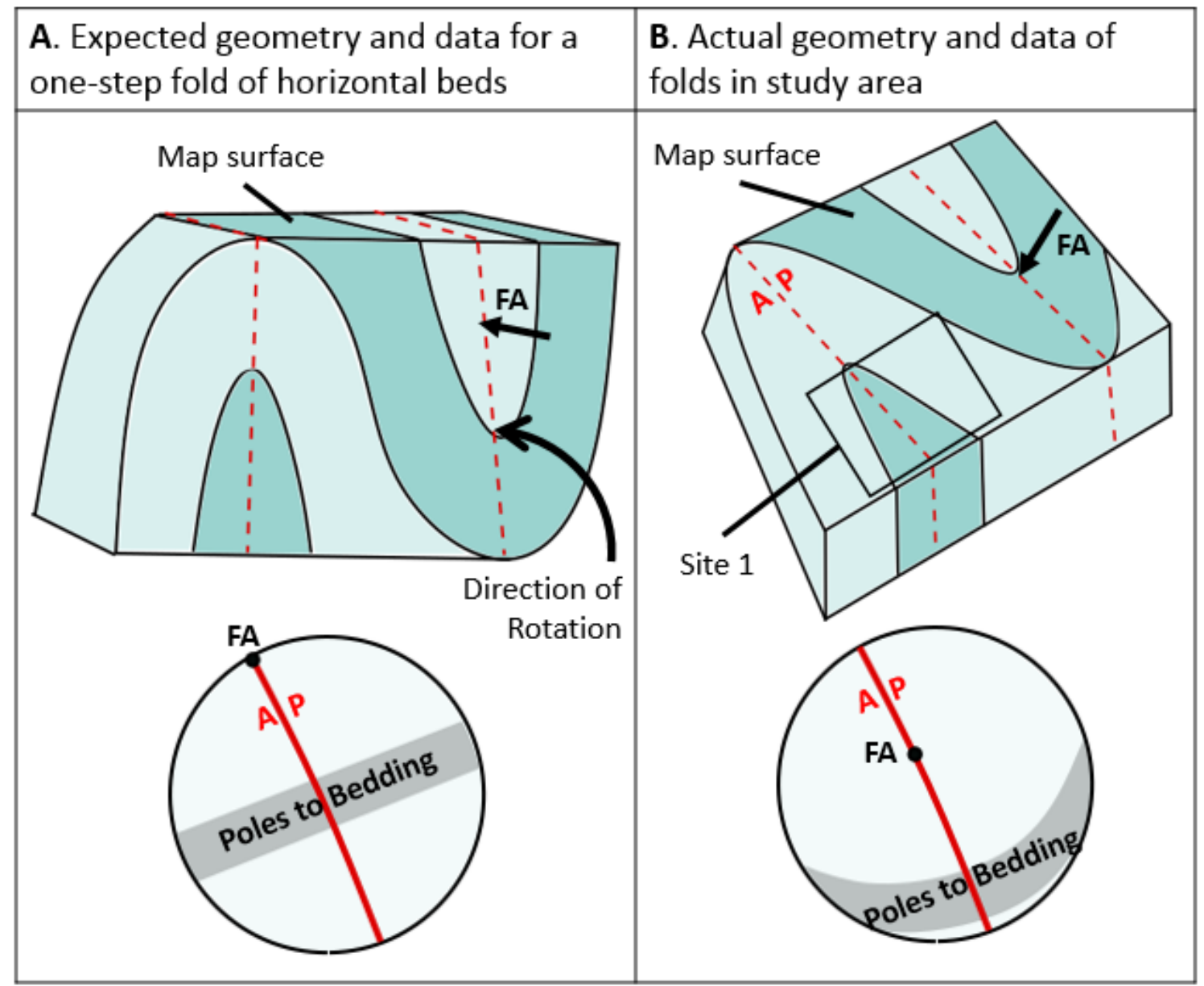

Figure 4.24. 3-dimensional block diagrams and stereographic projections for the current state of the metasedimentary folds (b) and if the fold were backrotated to an upright orientation (a). If the folds started in an upright orientation, the geometry in (a) would be 'time 1' and the geometry in (b) would be 'time 2'. The strike of $\sigma 1$ required for this rotation is interpreted as striking NNW-SSE. 


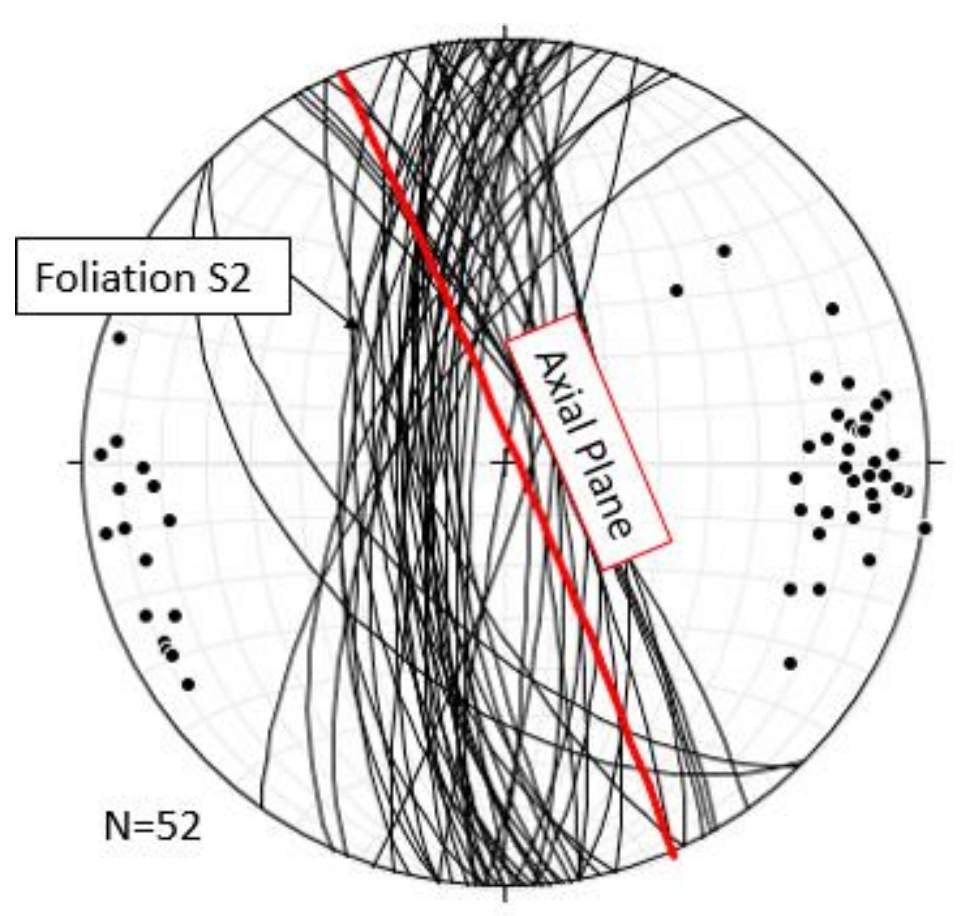

Figure 4.25. The meta-sedimentary foliation data compared to the calculated axial plane from the bedding data. The data shows that the foliation ranges around N-S striking and steeply dipping planes, which is not parallel to the axial plane as expected.
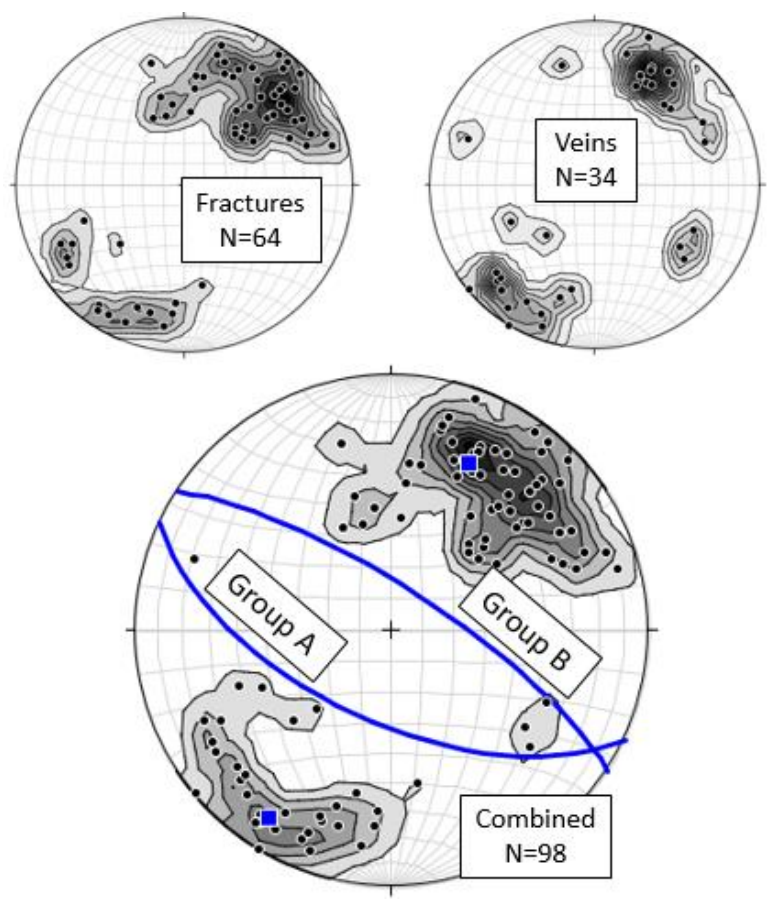

Figure 4.26. Poles to planes of the fracture and vein data from the meta-sedimentary sites. Fracture and vein data are show separately (above) and combined (below). Stereographic projections are lower hemisphere with $1 \%$ area contours. The blue boxes indicate the midpoint two data groups in the combined populations, and the blue lines show the plane to the representative midpoints. 

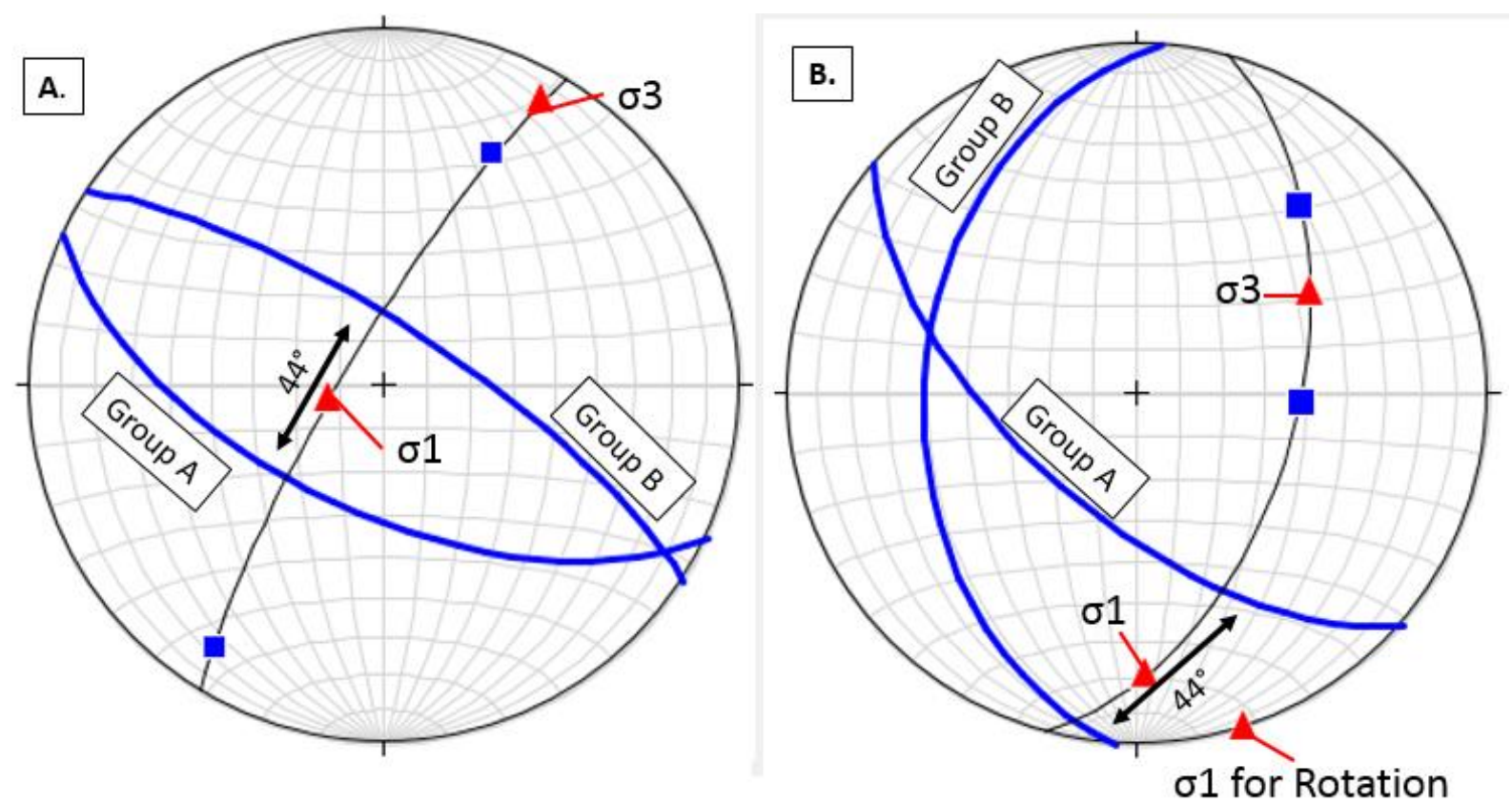

Figure 4.27. The representative orientations and state of stress for the current orientation (a) of fracture groups A and B and for the rotated state (b). (a) shows the interpreted state of stress if the groups are conjugate fractures $(\sigma 1: 76 \rightarrow 256 ; \sigma 3: 10 \rightarrow 029)$. The fractures are rotated (b) about the same axis as the folds $\left[(00 \rightarrow 073) 69^{\circ}\right.$, counterclockwise] for a historical state of stress $(\sigma 1: 21 \rightarrow 178 ; \sigma 3: 42 \rightarrow 060)$. The approximate $\sigma 1$ for the rotation is also plotted.

\subsection{Model of Deformation}

Based on the interpretation of the field observations, structural data, and microscale analysis of the meta-sedimentary sites along the Hamma Hamma Transect, the following is one proposed model for the deformational history of the rocks. The stages in the deformational history are denoted by T1-6 and refer to Figure 4.28.

The rock units were first deposited on the ocean floor as horizontal layers of sediments and then buried and compacted by subsequent deposition (T1). The overburden of burial and being at depth initiated metamorphism of the sediments; the muddier layers 
became slate and the sandier layers became meta-sandstone (T2). This is when foliation $\mathrm{S} 1$ formed in the slate layers, subparallel to bedding.

These rock packages were then accreted to the North American continent at the Cascadia subduction zone. The regional state of state of stress was compressive, with a $\sigma 1$ oriented E-W and $\sigma 3$ oriented vertically. The rocks were at a depth where ductile processes dominate and responded to the stress by folding (T3). The $\sigma 1$ calculated for the folds, $(02 \rightarrow 247)$, is not perfectly E-W, which could be due to the subsequent rotation, or the continent not being completely straight (e.g. if rocks are accreted into an embayment). Nonetheless, the folds are considered to have formed at depth by the E-W compression of the subduction zone. Foliation S2 also formed at a depth where ductile processes dominate as a penetrative fabric in response to the $\mathrm{E}-\mathrm{W}$ compression. It is not clear if the foliation and folding are related.

After the folding, there was a change in the state of stress, and $\sigma 1$ became more NNW-SSE or N-S oriented. The rocks must have been exhuming during this time (or perhaps the exhumation was caused by the change) because the fracture network formed under this state of stress and under conditions where fracturing dominated over folding (T4). The NNW-SSE or N-S stresses also caused the rotation of the rocks about the calculated axis of rotation into their current orientation (T5 \& T6). While it is not clear when the fractures formed relative to the rotation, I interpret that the fractures formed before the rotation and that the same state of stress caused the rotation. 


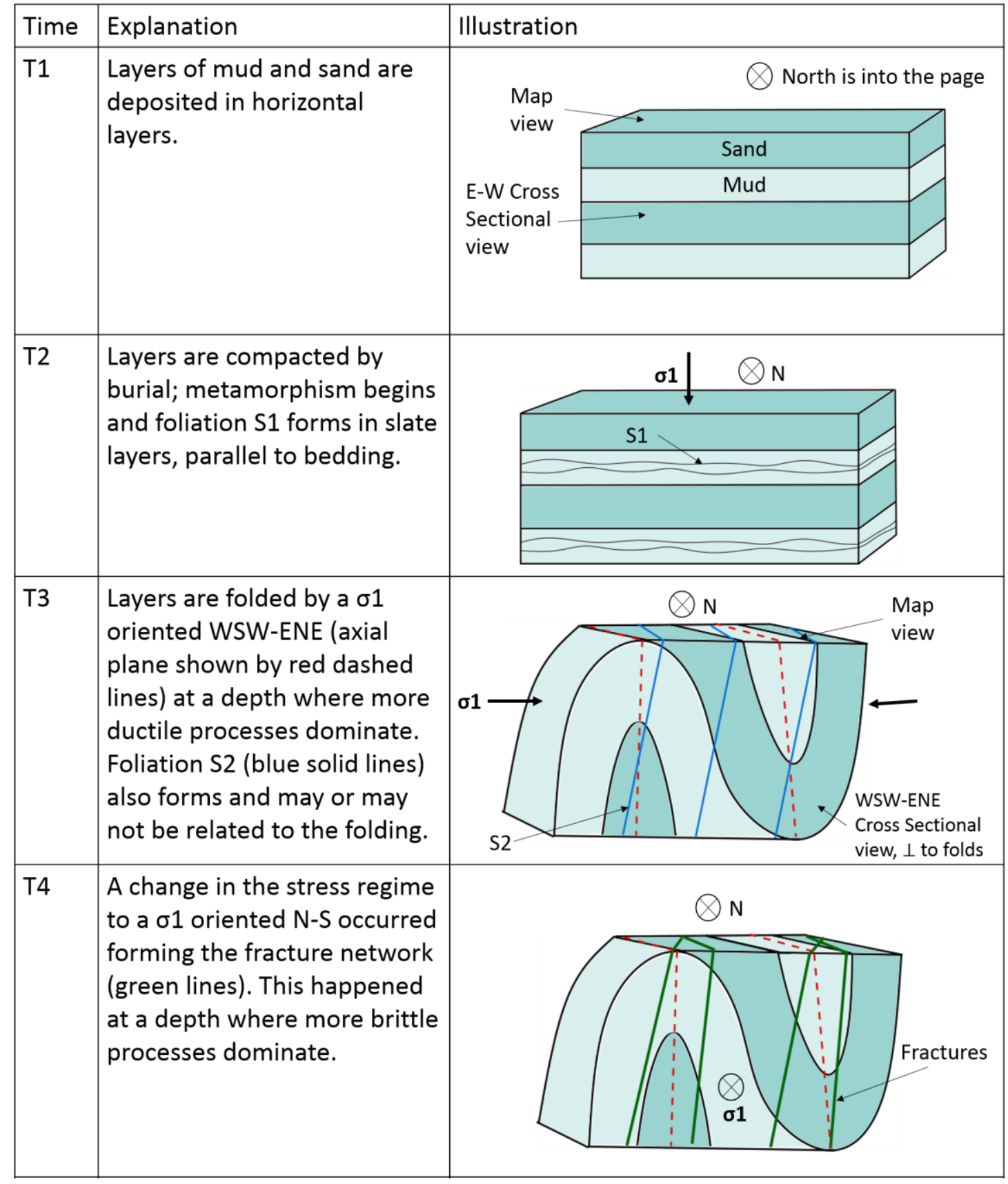

(continued on next page) 


\begin{tabular}{|l|l|l|l|}
\hline T5 & $\begin{array}{l}\text { A o1 oriented more NNW-SSE } \\
\text { causes the rocks to rotate 69 } \\
\text { counterclockwise about an } \\
\text { axis of rotation oriented } \\
(00 \rightarrow 073) \text { into their current } \\
\text { position. }\end{array}$ \\
\hline T6 & $\begin{array}{l}\text { Exhumation brings the rocks } \\
\text { to the surface, during or after } \\
\text { their rotation. Structures } \\
\text { have present orientation. }\end{array}$
\end{tabular}

Figure 4.28. Stages in the deformational history of the meta-sedimentary rocks from the Hamma Hamma Transect Sites 1 and 2. Diagrams are not to scale. 


\section{Pillow Basalts of the Hamma Hamma Transect}

\subsection{Data \& Observations}

\subsubsection{Field Observations}

Sites 3 and 4 are in the Crescent Formation, east of the HRF, and are characterized by tall outcrops of subvertical pillow basalt. The structures of interest are bedding, faults, fractures, veins, and interbedded meta-sedimentary layers.

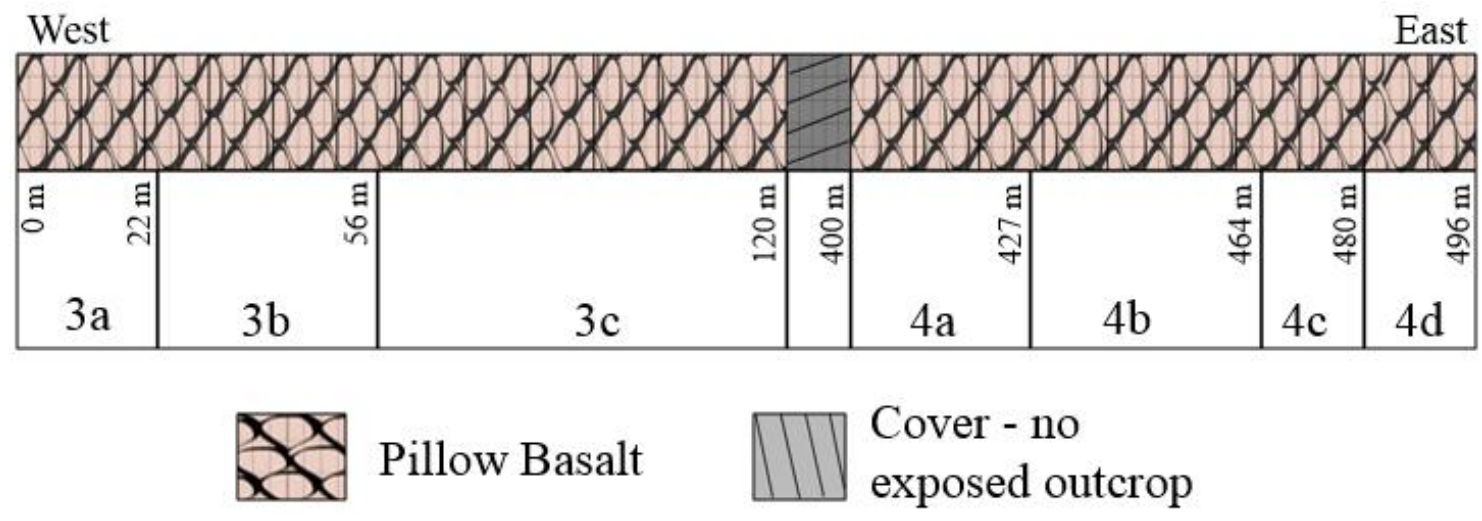

Figure 5.1. Diagram of Sites 3 and 4 showing the length of and rock type present at each subsite. The major lines of division on the column represent $10 \mathrm{~m}$. Site $3 \mathrm{a}$ begins at the far west side of outcrop Site 3 , which represents "zero", and the numbers indicate how far a subsite is from this point. The column is not continuous; there is approximately $280 \mathrm{~m}$ of cover between the two sites.

Pillow basalts are elongate tubes that form by underwater volcanism. The outcrops in this study expose a surface approximately perpendicular to the long axis of these tubes, exposing them as a cross section. The most convex side of the pillow basalts indicates the up direction at the time of deposition and defines bedding. At the study sites, the convex sides are steeply-dipping to vertical and face east (Fig. 5.2).

Nine faults were identified in the field with varying levels of confidence, as outlined in Table 5.1. These faults are grouped based on the level of confidence as well 
as their orientation (see Section 5.1.2). Four faults were identified at Site 3a, two faults at Site $3 b$, and one fault was found at each of the remaining sites (i.e., Sites $4 a, 4 b$, and 4c). No faults were identified at Sites 3c or 4c. The location of each fault is shown in Figure 5.3. Faults are expressed as continuous planes that cut across the outcrops (Fig. 5.4), show offset, and have measureable slickenlines. Some faults show evidence for comminution in the form of fault gouge and cataclasite (Fig. 5.5). Offset is inferred because individual pillows cannot be traced across the faults. The amount and sense of offset is difficult to determine because there are no clear piercing points. The slickensides (Fig. 5.6) are smooth down dip on the footwall side of the fault plane, indicating that the footwall moved up relative to the hanging wall (i.e., normal motion).

Table 5.1. Description of confidence levels for identifying fault groups in the pillow basalt outcrops.

\begin{tabular}{|l|l|c|}
\hline Confidence Level & Description & Group(s) \\
\hline High $-5 / 5$ & $\begin{array}{l}\text { Faults clearly cut through the outcrop, } \\
\text { offset pillows, have measureable } \\
\text { slickensides, and show evidence for } \\
\text { comminution }\end{array}$ & A \\
\hline Moderately High $-4 / 5$ & $\begin{array}{l}\text { Faults clearly cut through the outcrop, } \\
\text { offset pillows, have measureable } \\
\text { slickensides, but show no evidence for } \\
\text { comminution }\end{array}$ & B \& C \\
\hline Moderate $-3 / 5$ & $\begin{array}{l}\text { Faults cut through the outcrop, but strike } \\
\text { subparallel to the outcrop and are difficult } \\
\text { to discern; offset is not observed but } \\
\text { inferred by slickensides on the fault } \\
\text { surface; no evidence for comminution }\end{array}$ & D \\
\hline
\end{tabular}


The pillow basalt outcrops also have many fractures, semi-continuous cracks that do not show offset or slickensides (Fig. 5.7). The fractures cut across the pillows but do not span the whole outcrop like the faults; they cut across smaller pillows and terminate against larger pillows. Two distinct fracture orientations are identifiable in outcrop, referred to here as Group A and Group B. Group A appears to dip to the east, and Group B appears to dip to the west. The fracture groups have a mutually cross-cutting relationship in which they terminate into one another (Fig. 5.7). The fractures are relatively evenly distributed across the outcrops and between sites.

Veins are present in the pillow basalts that are contained within the pillows and that cross-cut the pillows. Veins that are contained within the pillows are small, thin, irregular, and splay radially. Larger veins cut across the pillows and are composed of calcite and quartz (Fig. 5.8). These veins are generally linear allowing for orientation measurements, but sometimes they are more irregular. They are not distributed evenly throughout the outcrops, some are solitary veins that cut the outcrop (spaced on the order of $10 \mathrm{~s}$ of meters) and others occur as localized clusters. At Site $3 \mathrm{c}$, there is a $3 \mathrm{~m}$ zone that is relatively rich in veins (Fig. 5.9). The cluster of veins at Site $3 c$ is cross-cut by fractures.

Meta-sedimentary material originating from fine-grained, calcareous mud are interlayered with the basalt (Fig. 5.10), as first described by Garrison (1972 \& 1973). The layers are not planar; they follow the bedding planes of the pillows. Where present, this material fills the spaces around pillows, and in some places, fragments of pillow 
basalt are incorporated into this material. In general, it is green at Site 3 and pink at Site 4. This meta-sedimentary material is crosscut by the veins and the fractures.

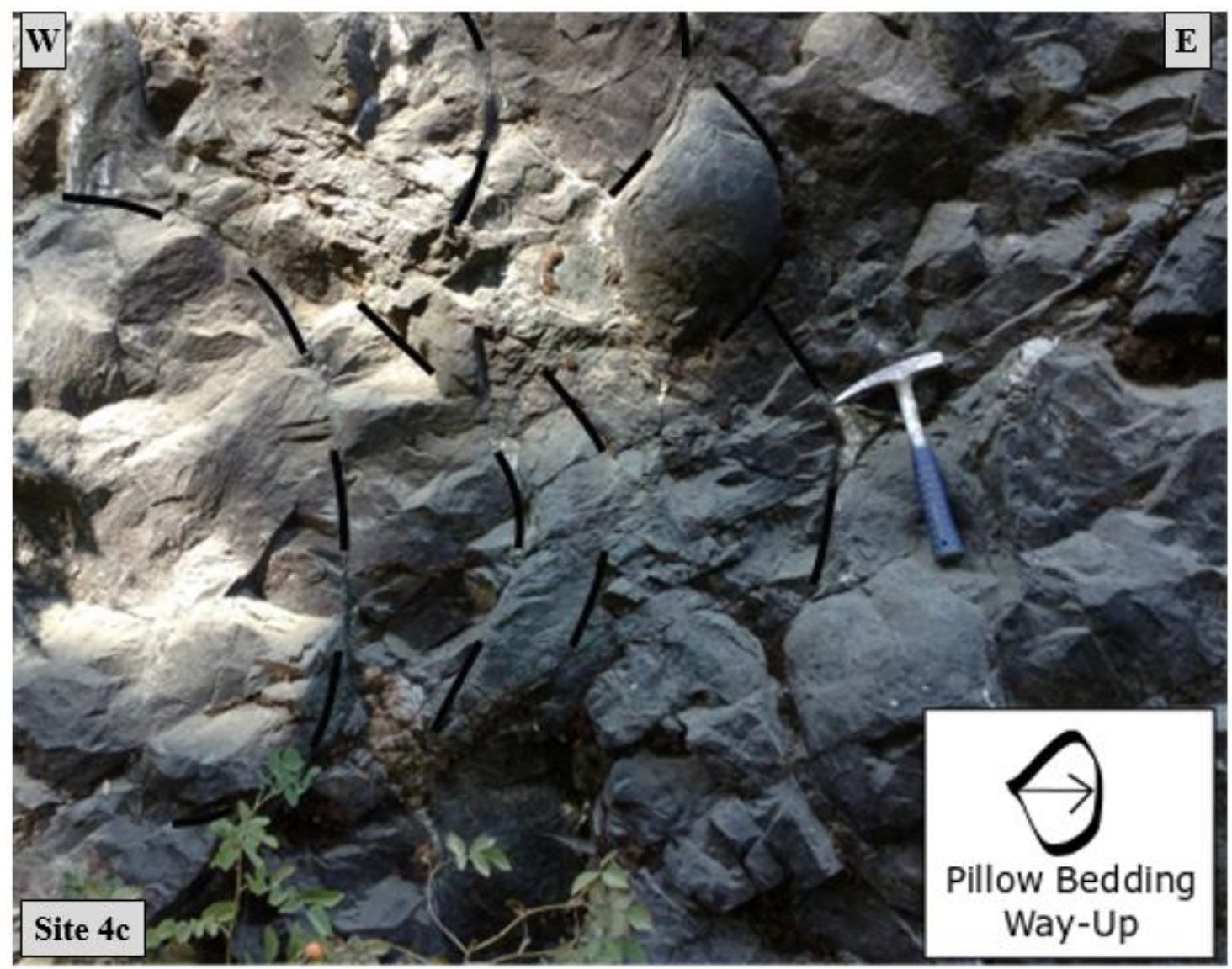

Figure 5.2. Photo of pillow basalt bedding. The most convex side of the pillows (outlined in black dashed lines) defines bedding. Rock hammer is $36 \mathrm{~cm}$ long. Photo was taken at Site $4 \mathrm{~d}$ of a subvertical outcrop facing north. 


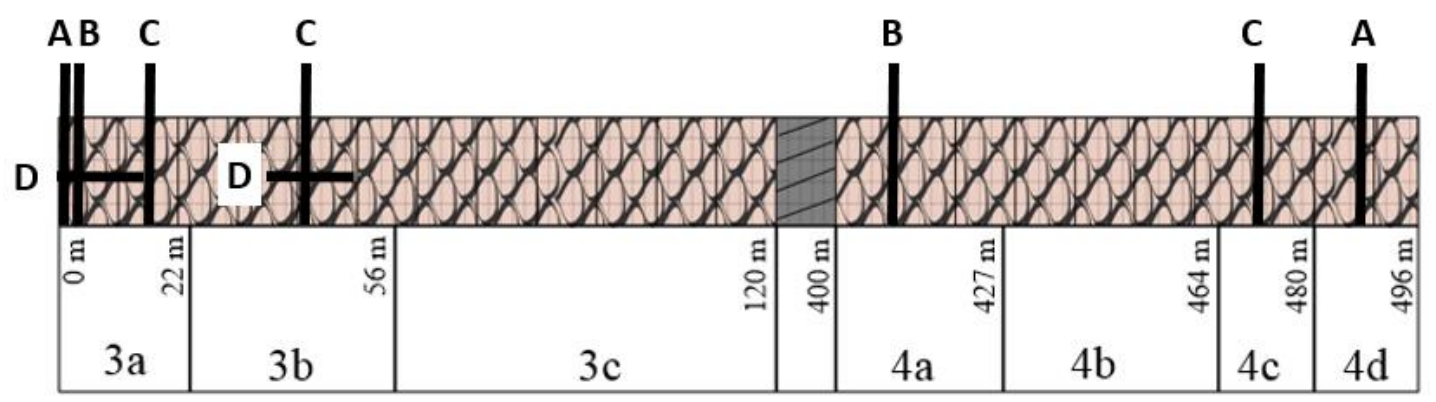

Figure 5.3. The location of each fault observed in outcrop along the west to east transect. Fault Groups A, $\mathrm{B}$, and $\mathrm{C}$ are shown as vertical lines because their strikes are at an angle to the face of the outcrop. Fault Group D is shown as a horizontal line because it strikes parallel to the outcrop.

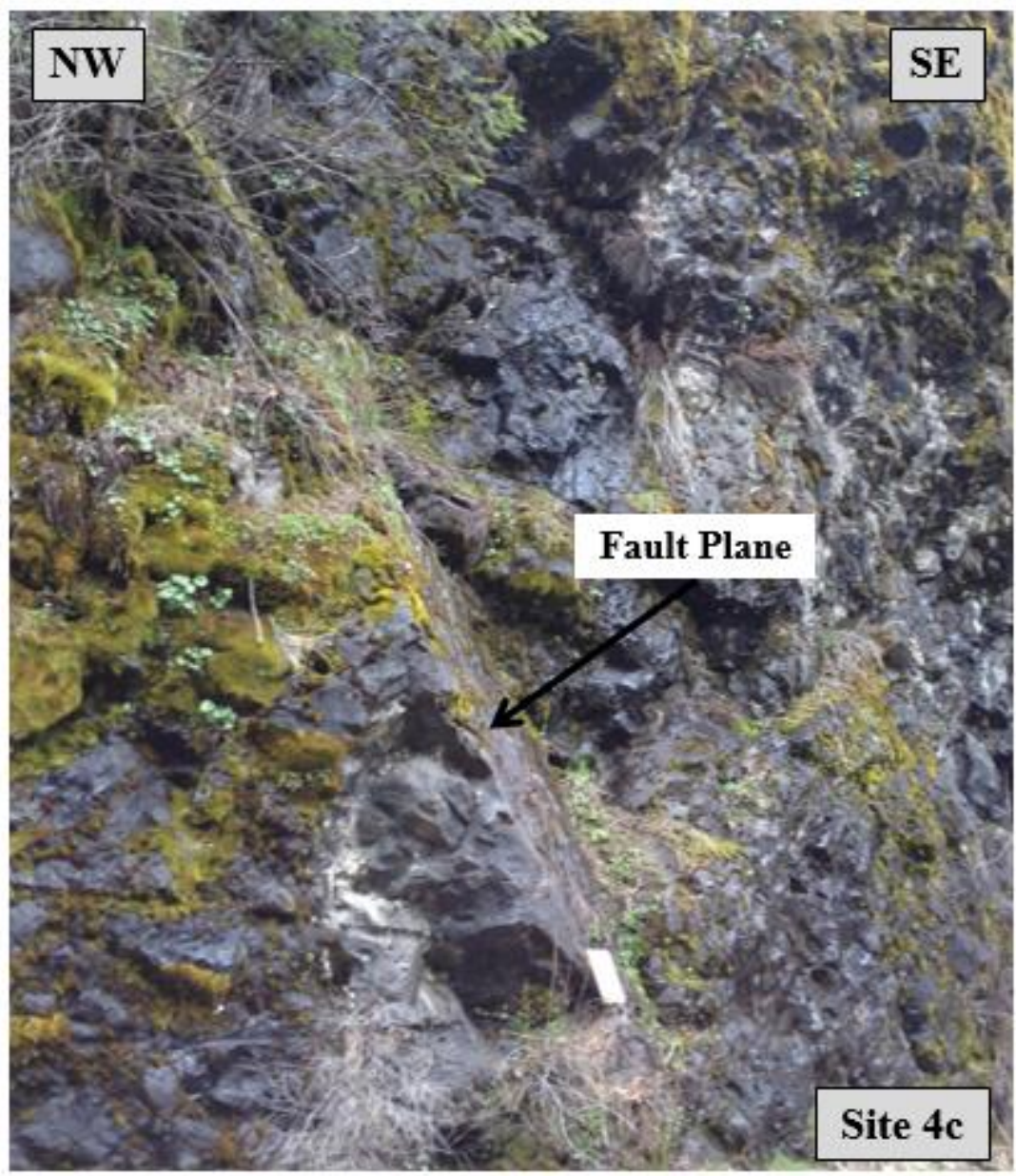

Figure 5.4. Photo of a fault plane at Site $4 \mathrm{c}$. Photo is of a cliff outcrop facing northeast, and the notebook is $30 \mathrm{~cm}$ tall. 

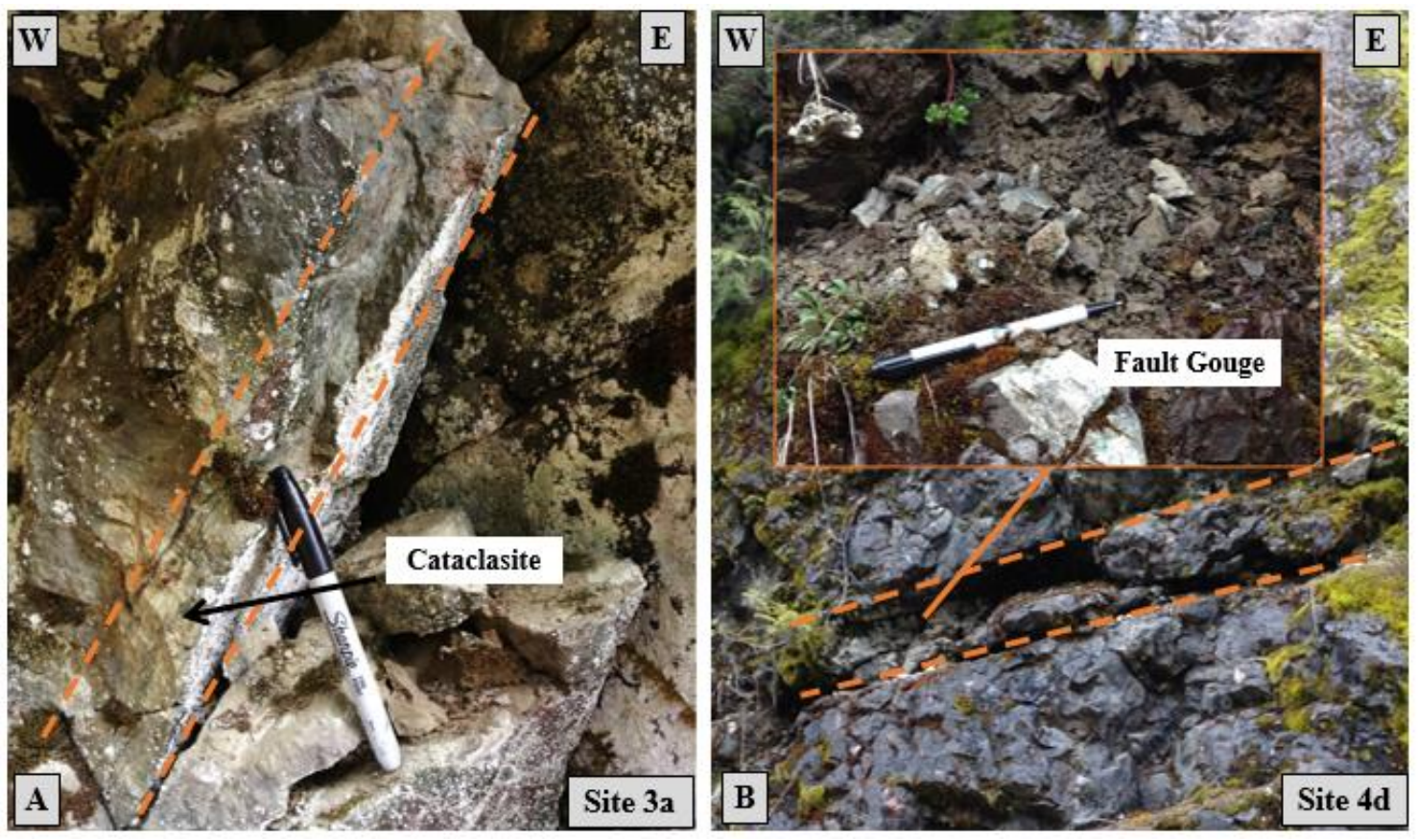

Figure 5.5. Photo of evidence for comminution on some faults. A) A fault at Site 3a shows cataclasite. B) A fault at Site $4 \mathrm{~d}$ shows unlithified fault gouge. Photos are of subvertical outcrops facing north. The pens are $15 \mathrm{~cm}$ long. 


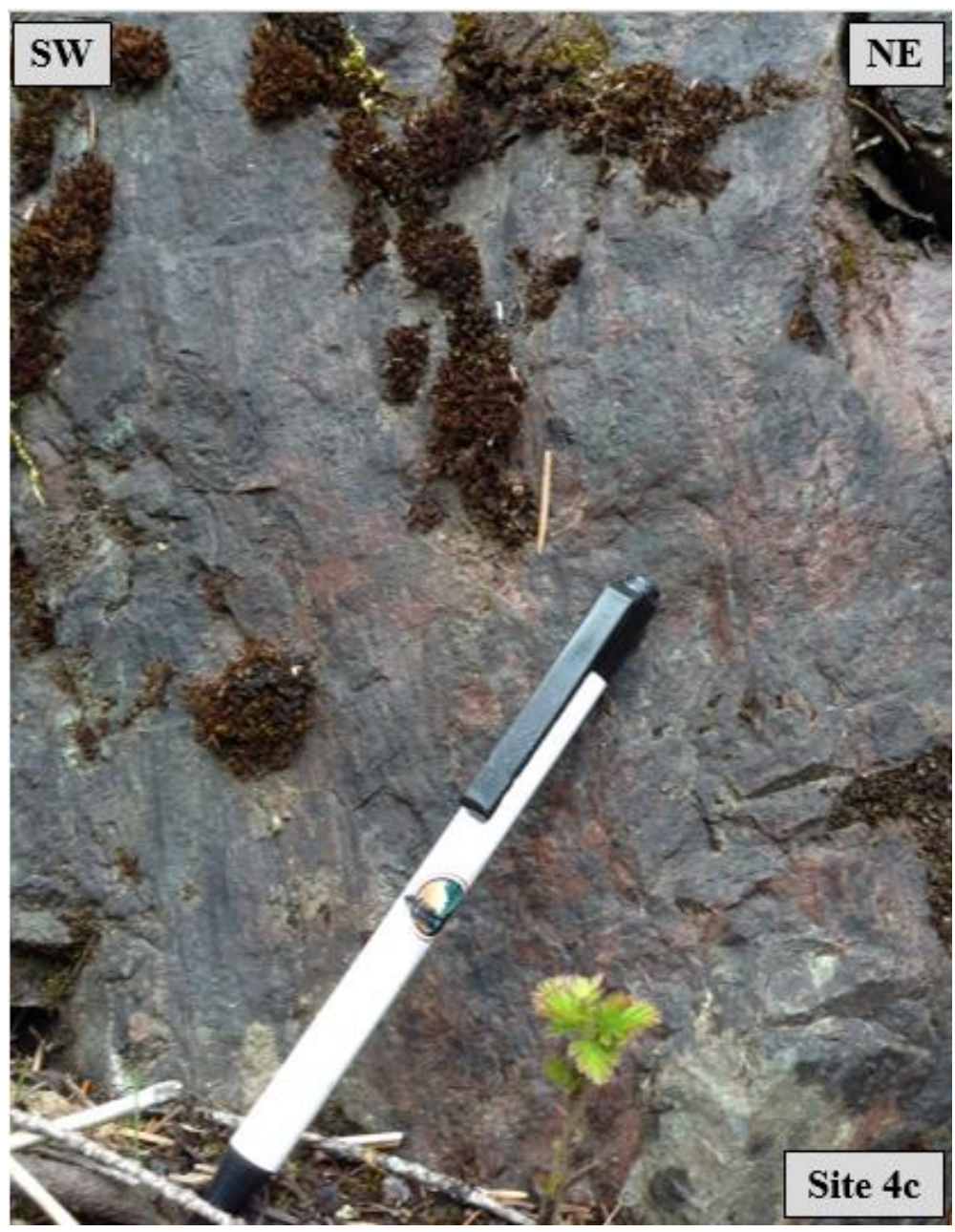

Figure 5.6. Photo of slickenlines on fault planes at Site 4c. Photo was taken facing northwest. Pen is $15 \mathrm{~cm}$ long. 


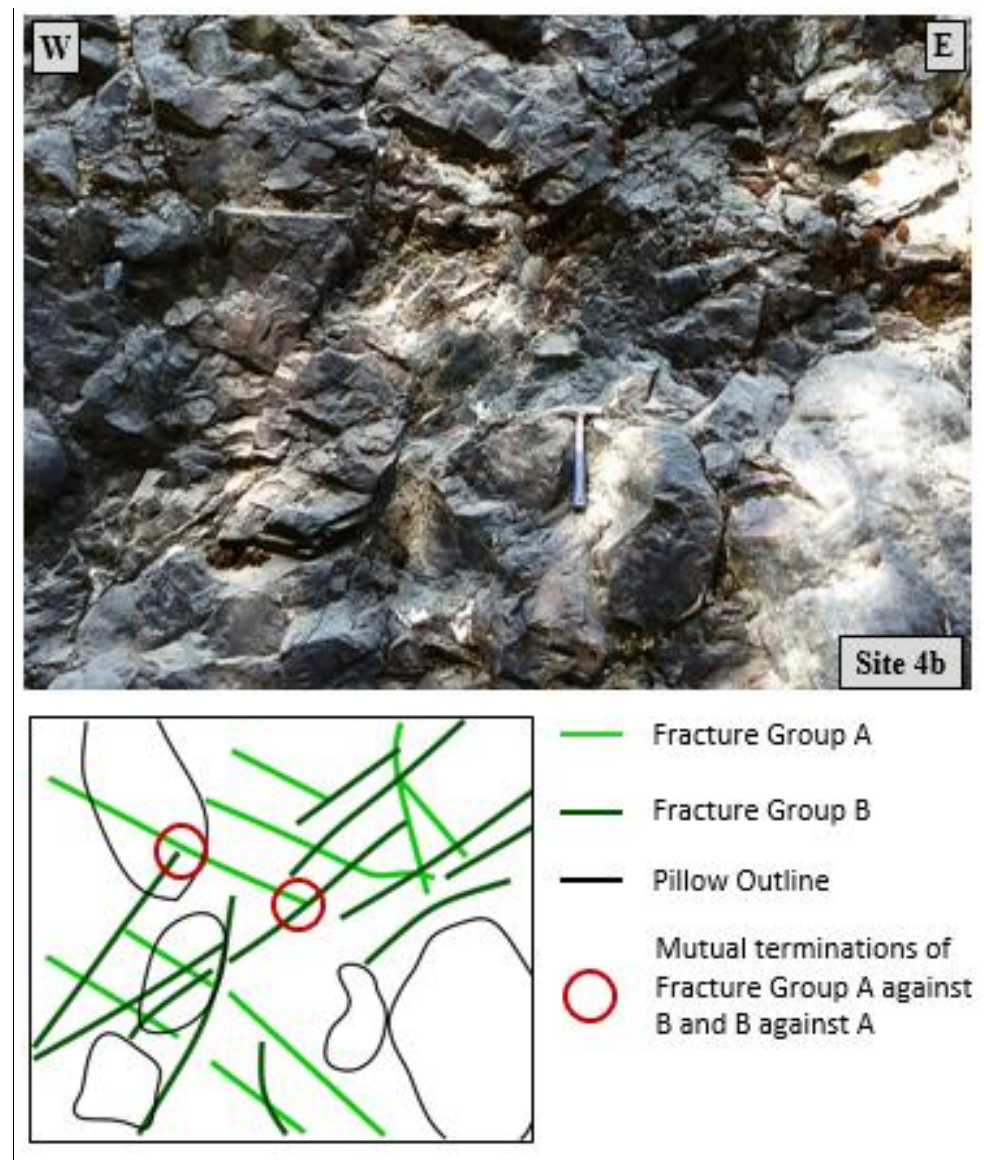

Figure 5.7. Photo and interpretive diagram of fractures cutting through the pillow basalts. Group A dips to the east and Group B dip to the west. The red circles in the diagram highlight examples of where the fractures are mutually cross-cutting. Photo is of a subvertical outcrop from Site $4 \mathrm{~b}$ facing north. The rock hammer is $36 \mathrm{~cm}$ long.
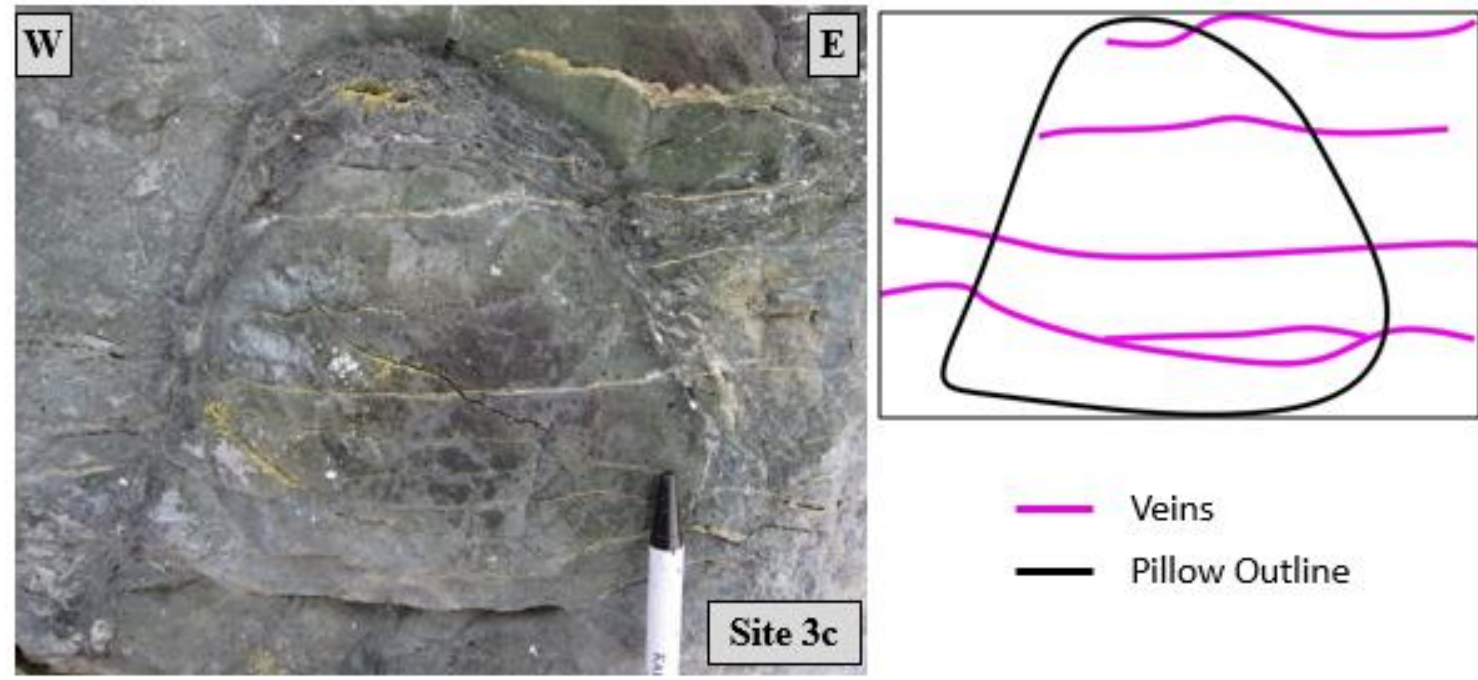

Figure 5.8. Photo and interpretive diagram of veins cutting across an individual pillow. Photo was taken of a subvertical outcrop from Site $3 \mathrm{c}$ facing north. The portion of the pen showing is $5 \mathrm{~cm}$ long. 

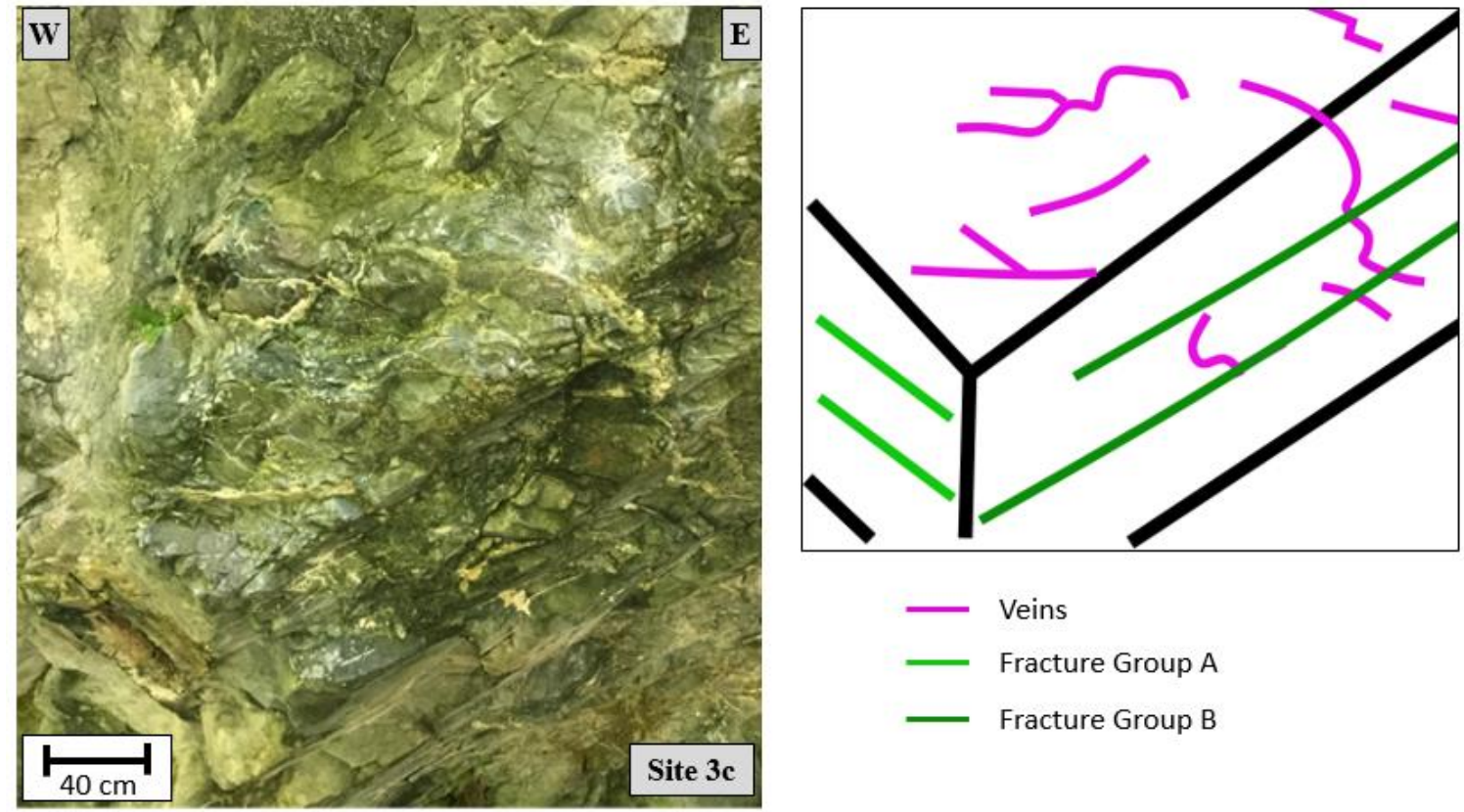

Figure 5.9. Photo and interpretive diagram of a cluster of veins identified at Site $3 \mathrm{c}$. The veins are cut by fractures. Photo is of a subvertical outcrop from Site $3 \mathrm{c}$ facing north.
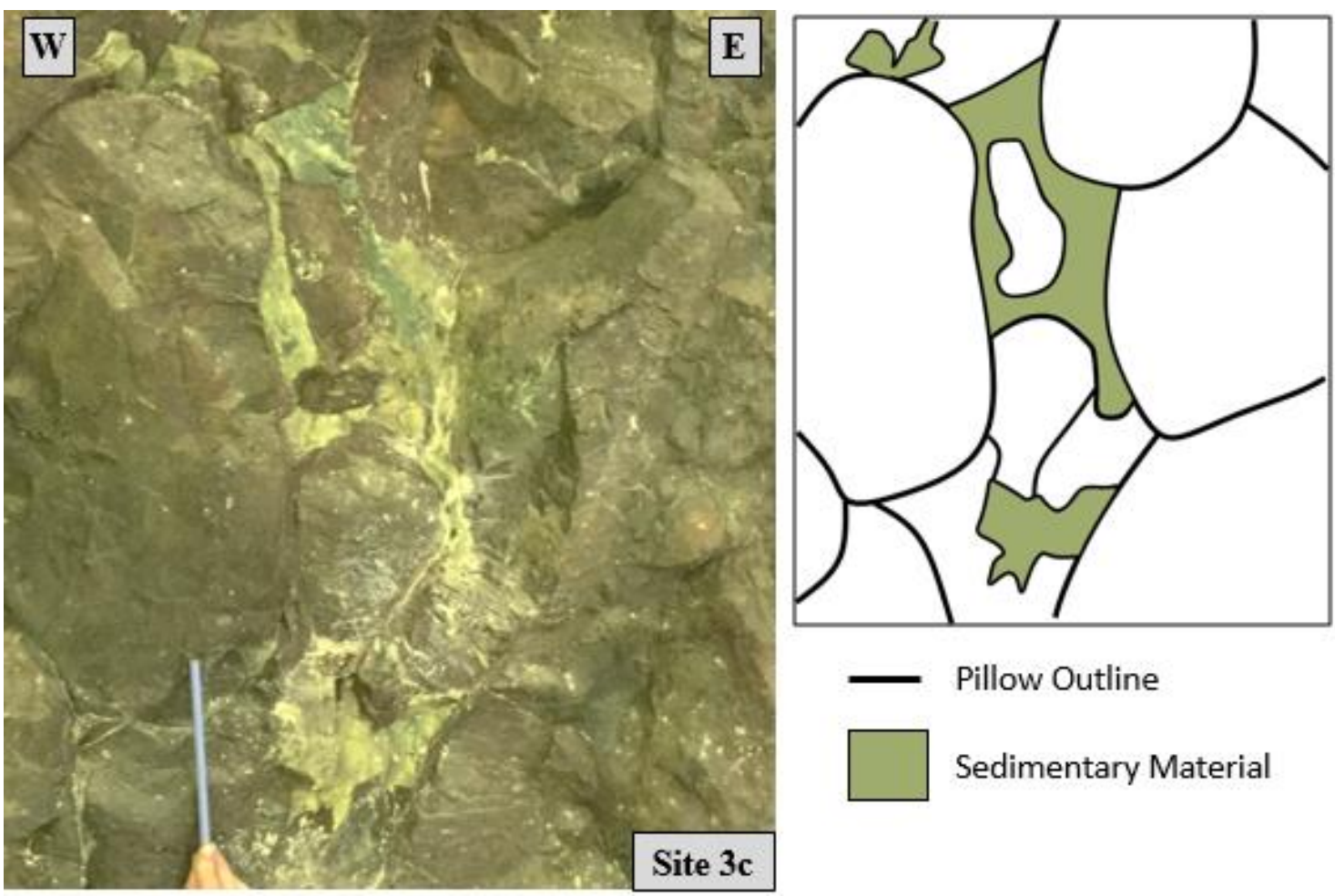

Sedimentary Material

Figure 5.10. Photo and interpretive diagram of meta-sedimentary material between pillow basalt beds. Chunks of pillow basalt appear to be incorporated into this meta-sedimentary material. Photo is of a subvertical outcrop from Site $3 \mathrm{c}$ facing north. The pencil is $15 \mathrm{~cm}$ long. 


\subsubsection{Structural Orientation Data}

Bedding measurements were taken along the most convex side of the pillows (Fig. 5.2). Three-dimensional views present in the outcrops gave confidence that measurements accurately reflect bedding orientations, and measurements are relatively consistent from site to site. Beds are subvertical to vertical and strike north-south (Fig. 5.11). The orientation of sedimentary material between pillows (Fig. 5.10) are also included with the bedding data.

Nine faults of varying orientations were identified across the pillow basalt outcrops. The faults have been divided into four groups based on orientation, geomorphic expression, and confidence in their existence (Table 5.1). All fault orientations and associated slickenline measurements are shown in Figure $\mathbf{5 . 1 2}$ with their respective groups delineated. Two faults were identified with high confidence (5/5) and are oriented similarly, striking NW-SE and dipping to the NE, and are grouped as Fault Group A. Five faults were identified with moderately high confidence (4/5) and strike NE-SW. These faults have been separated into different groups based on their dip direction; Group B dips to the NW whereas Group C dips to the SE. Two faults were identified with moderate confidence (3/5) and are grouped as Fault Group D. These faults strike E-W and dip to the south.

Figure 5.13 shows the orientations and number of faults identified at each subsite. Site 3a has the most faults, one of each group. Of the two faults identified at Site 3b, one is of Group C and one is of Group D. Site 4a has one fault of Group B, Site 4b has one fault Group C, and Site 4d has one fault of Group A. 
The fracture orientations at each subsite are presented in Figure 5.14. When all fracture orientations are plotted together, two main orientations are apparent, which reflect the oppositely dipping Groups A and B observed in outcrop (Fig. 5.15). Fracture Group A strikes NW-SE, dips to the NE, and has a representative orientation of $(303,40)$. Fracture Group B strikes NE-SW, dips to the NW, and has a representative orientation of $(211,39)$.

The veins also show a range in orientations and distribution (Fig. 5.16). Measurements are for those veins that cut across basalt pillows. Orientations range in strike from E-W to NNE-SSW and dip shallowly to the N, NE, and E. The sites that show a greater number of vein measurements indicate that a cluster was found at that site. More clusters were identified at Site 3 than Site 4, and Site 3 has significantly more veins than Site 4. There is no obvious trend in grouping of orientations from site to site.

Figure 5.17 shows all bedding, fault, fracture, and vein data combined. 

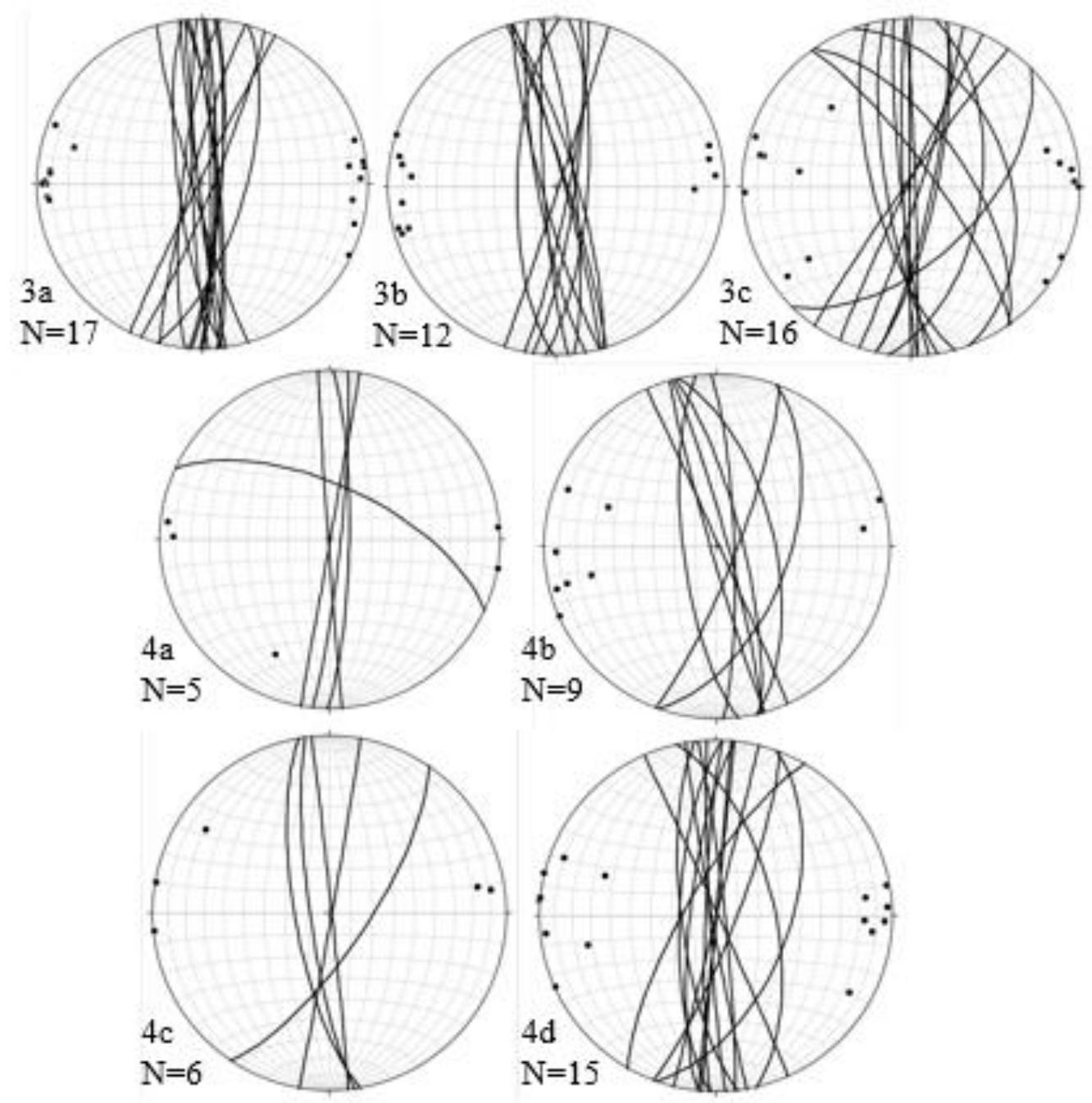

Figure 5.11. Pillow basalt bedding planes and poles for Sites $3 \mathrm{a}-\mathrm{c}$ and $4 \mathrm{a}-\mathrm{d}$. Plots are lower hemisphere, equal area stereographic projections. $\mathrm{N}$ values refer to the number of measurements presented in each stereonet. 
- Fault A Slickenlines, $\mathrm{N}=1$

Fault B Slickenlines, $\mathrm{N}=2$

Fault C Slickenlines, $\mathrm{N}=5$

Fault D Slickenlines, $\mathrm{N}=3$

Fault Planes: $\mathrm{N}=9$

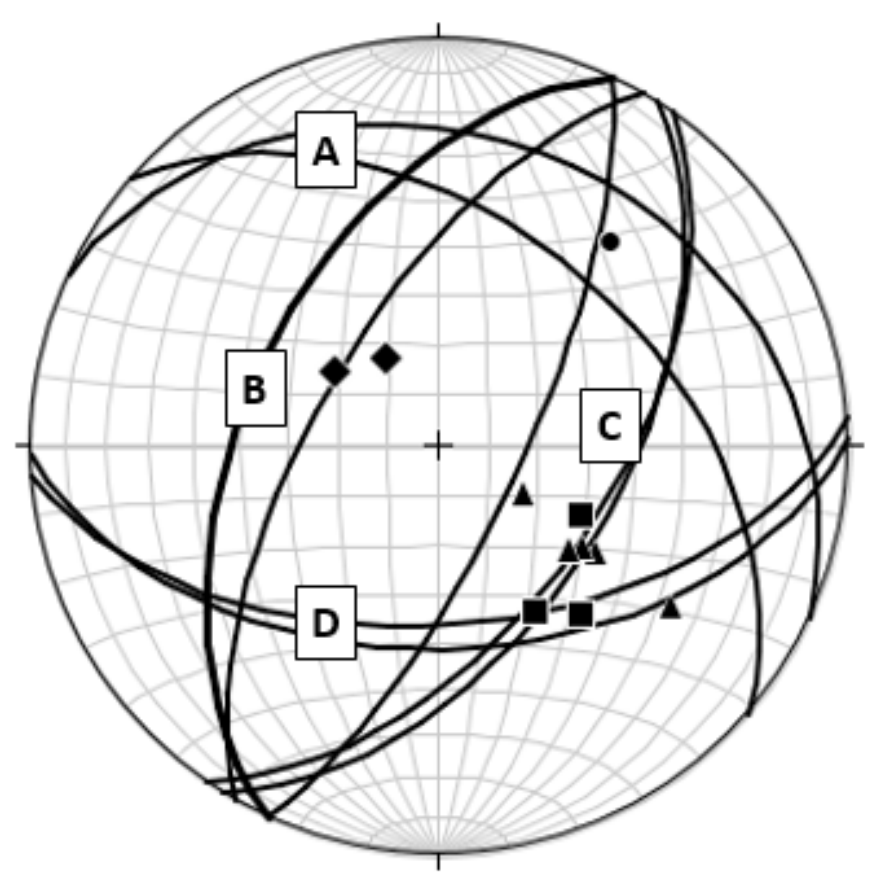

Figure 5.12. Grouping of fault plane measurements and associated slickenline data from the pillow basalt outcrops. Fault groupings were made based on orientation and field expression. All slickenlines indicate a normal sense of motion. Plots are lower hemisphere, equal area stereographic projections. $\mathrm{N}$ values refer to the number of measurements presented in each stereonet.
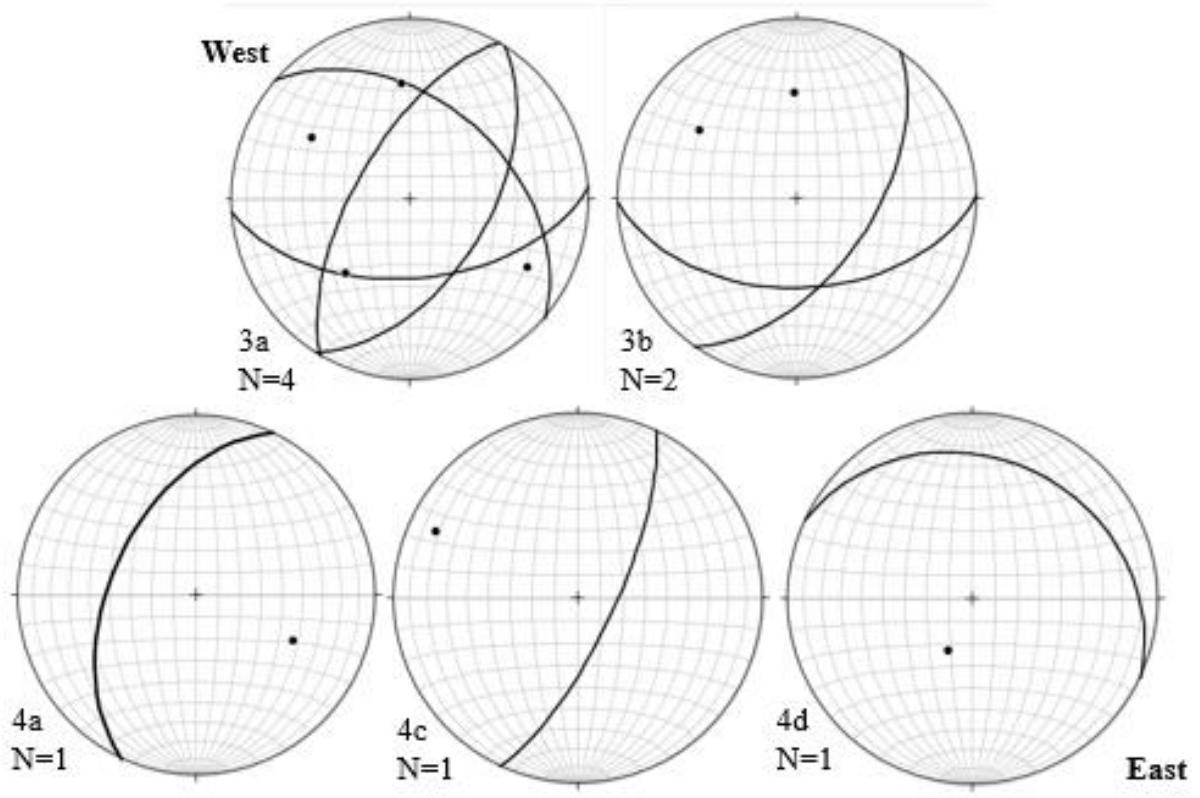

Figure 5.13. Fault planes and poles from the pillow basalt outcrops, Sites 3a-c and 4a-d. Plots are lower hemisphere, equal area stereographic projections. $\mathrm{N}$ values refer to the number of measurements presented in each stereonet. 

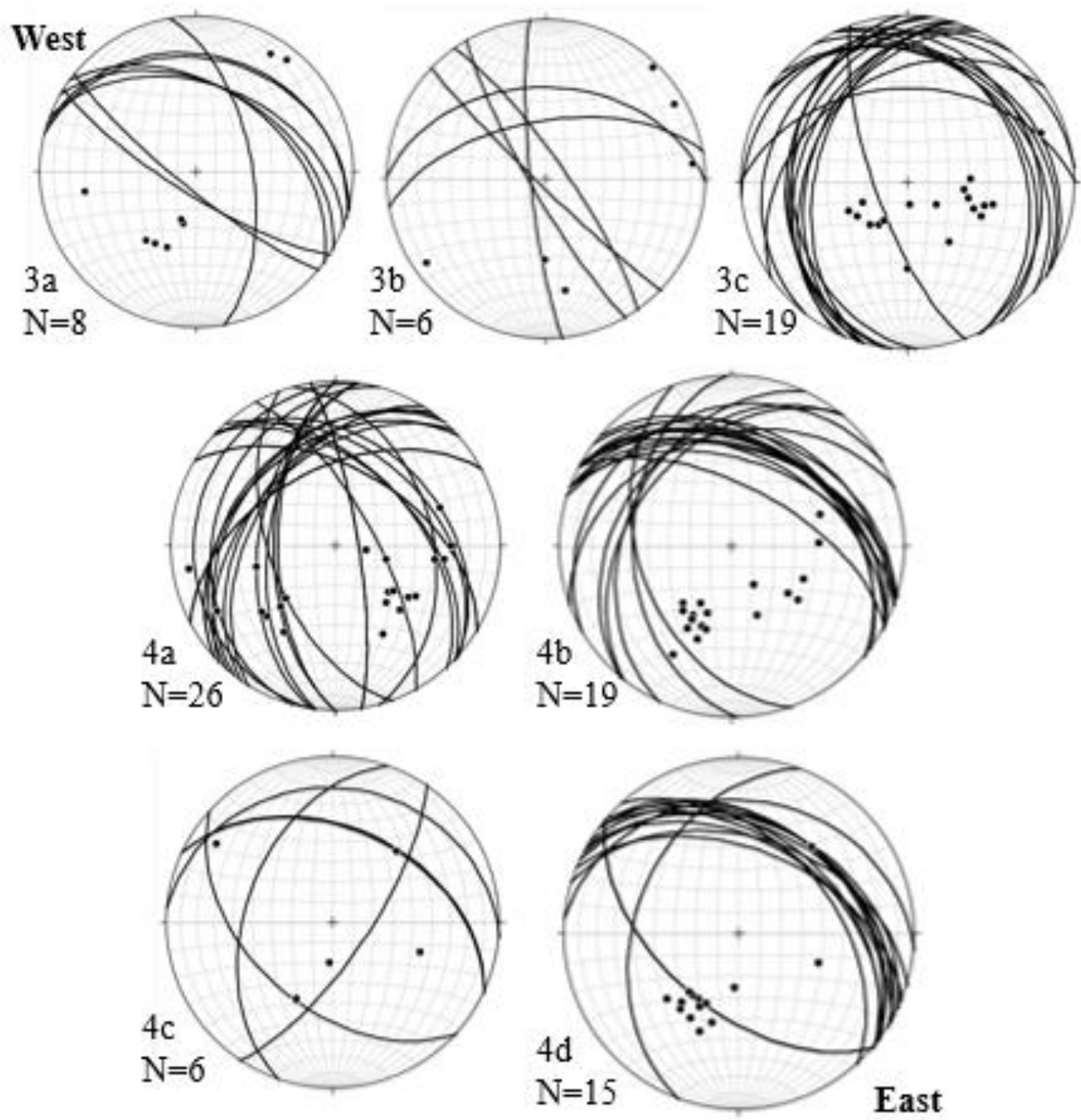

Figure 5.14. Fracture planes and poles from the pillow basalt outcrops, Sites 3a-c and 4a-d. Plots are lower hemisphere, equal area stereographic projections. $\mathrm{N}$ values refer to the number of measurements presented in each stereonet. 


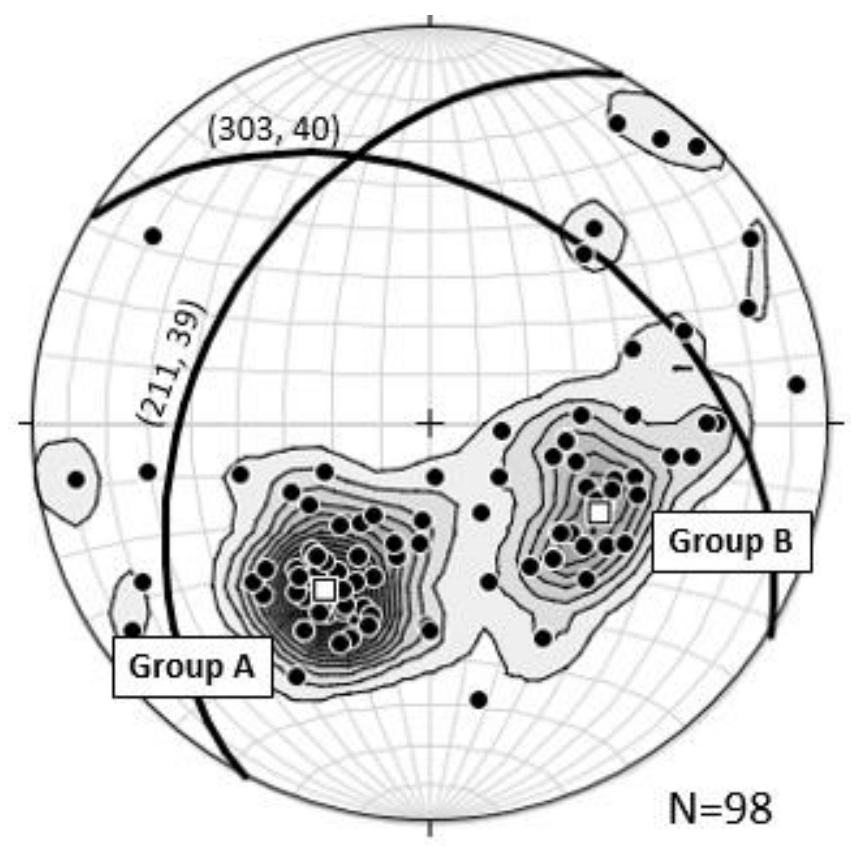

Figure 5.15. Poles to all fracture plane measurements from the pillow basalt outcrops. Group A has a representative orientation of $(303,40)$, and Group B has a representative orientation of $(211,39)$.

Representative orientations are indicated by white squares. The plot is a lower hemisphere, equal area stereograph with $1 \%$ area contours. The $\mathrm{N}$ value refers to the number of poles presented.
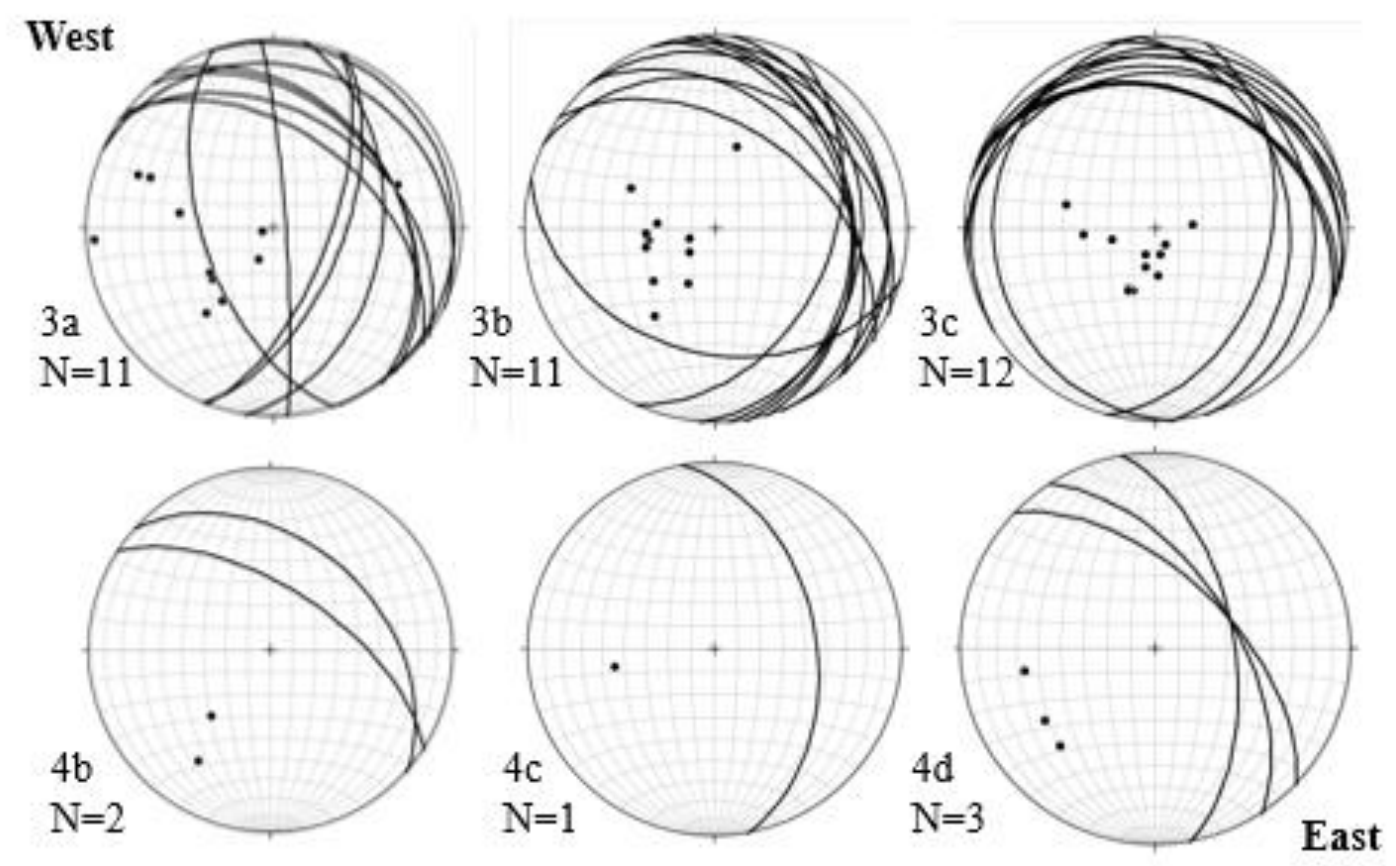

Figure 5.16. Vein planes and poles from the pillow basalt outcrops, Sites $3 a-c$ and $4 a-d$. Plots are lower hemisphere, equal area stereographic projections. $\mathrm{N}$ values refer to the number of measurements presented in each stereonet. 

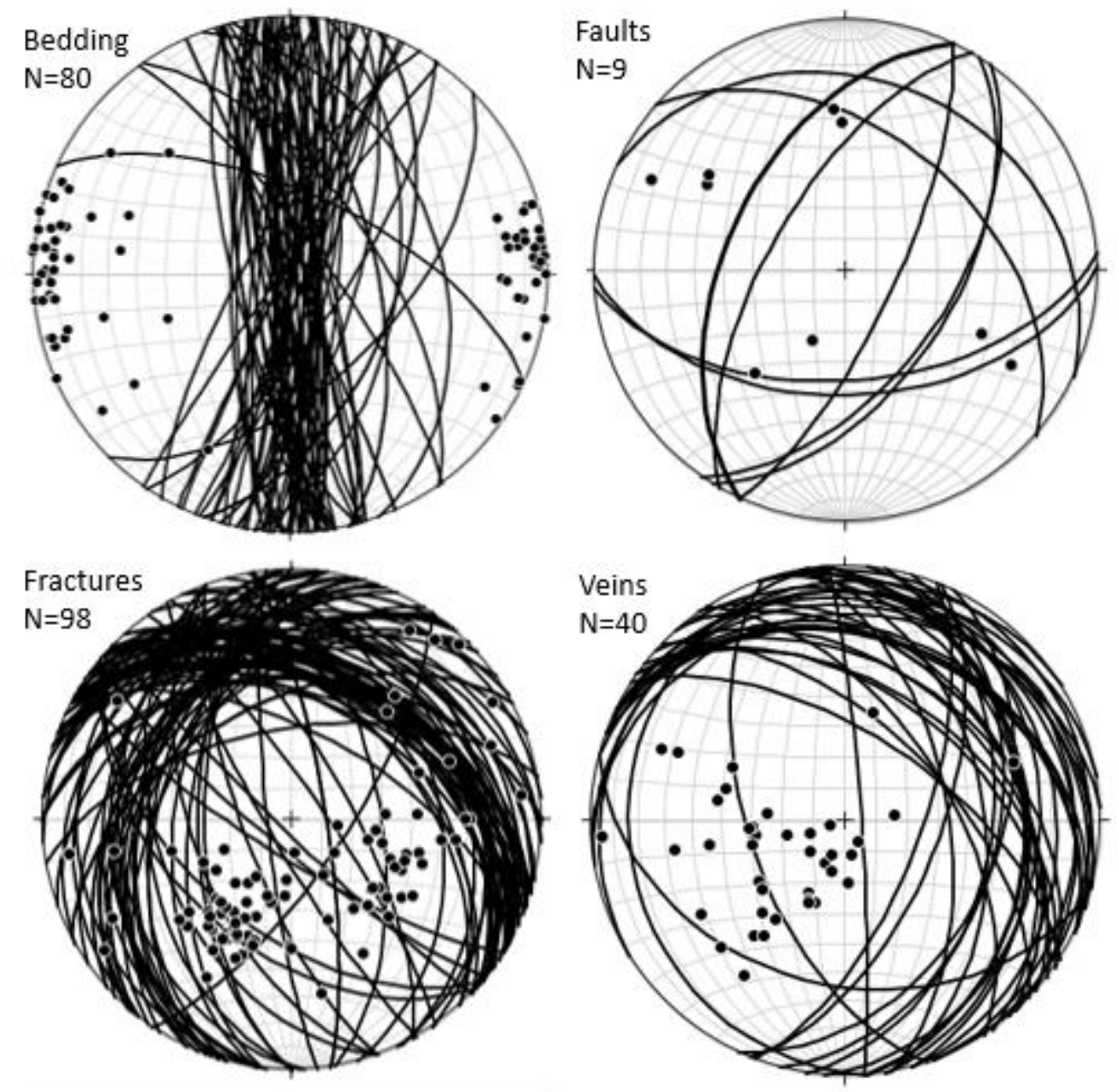

Figure 5.17. Planes and poles of all structures from the pillow basalt outcrops, Sites 3a-c and 4a-d. Plots are lower hemisphere, equal area stereographic projections. $\mathrm{N}$ values refer to the number of measurements presented in each stereonet. 


\subsubsection{Microscale Data and Observations}

Samples were collected to investigate how micro-structures vary throughout the core, rim, and sedimentary material within the pillow basalts. This section looks at three samples: Sample C from Site 4c, Sample D from Site 3a, and Sample E from Site 4a. Samples C and D show the edge of the pillow cores, their rims, and meta-sedimentary material along their margins, referred to here as the matrix (Fig. 5.18). Sample $\mathrm{E}$ is from the center of a pillow core, away from the rim-matrix boundary.

The pillow cores (Sample E) are aphanitic and have an intersertal textured groundmass of plagioclase, clinopyroxene, chlorite, actinolite, and sparse olivine (also described by Lyttle \& Clarke [1975]; Fig. 5.19a). The plagioclase crystals are thin and feathery. The shape of the chlorite and actinolite mineralizations suggests that they are pseudomorphs of clinopyroxene and olivine. Vesicles are present and are filled with calcite, quartz, prehnite, and zeolites. Iron oxides are prevalent (titanomagnetite according to Lyttle \& Clark [1975]) and increase in density towards the pillow rim (Fig. 5.19b), giving the rim a black appearance in thin section.

The pillow rims are composed of discontinuous layers of calcite, devitrified glass, oxides, and other minerals, such as chlorite (Fig 5.20). The rims in Sample C contain more oxide and calcite layers than the rims from Sample D, which contain more devitrified glass and chlorite layers. The boundary between the layered rim and the oxiderich edge of the pillow is not always discrete. For example, the oxide layers in the rim of Sample D are less well developed and grains are more interspersed the closer they are to the pillow side of the rim. 
The meta-sedimentary matrix material originated as micritic, calcareous mud. In general, the material of Sample $\mathrm{C}$ is microcrystalline and contains microfossils (described as coccoliths by Garrison [1972]; Fig. 5.21a). The material of Sample D is devoid of fossils and coarser-grained, with individual grains discernable at the micro-scale (Fig. 5.21b). Oxides are also observed in the matrix and appear as red mineralization in hand sample. This observation is consistent with the presence and distribution of oxides and the overall macro-scale color of the matrix material between sites. Oxides are distributed throughout the matrix in Sample D, giving it a redder overall appearance, whereas the oxides are more localized in Sample C (e.g., red areas near the rims in the otherwise green matrix; Fig. 5.18).

Veins are observed throughout the pillow cores and matrix. Consistent with field observations, some veins are contained within the pillows and terminate at the pillow rim, whereas others cross-cut the pillows and matrix (Sample D, Fig. 5.18). Veins are composed of blocky quartz and calcite crystals that show twinning (Fig. 5.22). The larger veins, and to a lesser extent the smaller veins, in Sample D are oriented similarly to those measured in outcrop (Fig. 5.16). There is no significant offset on the veins, and overall, they are not folded.

Samples $C$ and D show fold structures along the pillow rims (Figs. 5.18, 5.23). Among all the samples collected, fold structures were not common but locally developed in some samples. The folds bend the meta-sedimentary matrix and the layers in the pillow rims. An accumulation of darker material in the meta-sedimentary matrix define subtle linear structures that appear axial planar to the folds (Fig. 5.23a) 
The folds were imaged with the scanning electron microscope (SEM). The pillow rims did not show an alignment of mineral grains consistent with a mineral fabric, although the layering in the rims was locally disrupted. The oxides within the metasedimentary core showed a preferred orientation, parallel to the axial trace of the apparent folds. Where the mineral matrix showed a darker red appearance in hand sample, aligned oxide grains anastomose around calcite grains (Fig. 5.24a\&b). In other areas without an abundance of oxides, the mineral fabric is defined by the elongate shape of calcite grains. The degree of alignment appears to be stronger and more prevalent in Sample D than in Sample C. However, this mineral fabric is variably-developed in and around the folds and is not penetrative. Samples C and D show horizontal cuts of the rock, and the strike orientation of mineral alignment was estimated from north (Fig. 5.25). The orientations are predominantly WNW-ESE in Sample C and range from NE-SW to NW-SE in Sample D, with the strongest grouping oriented WNW-ESE. However, these structures are rare and the sample size is small, so these orientations are not necessarily indicative of a penetrative fabric throughout the sedimentary matrix. 


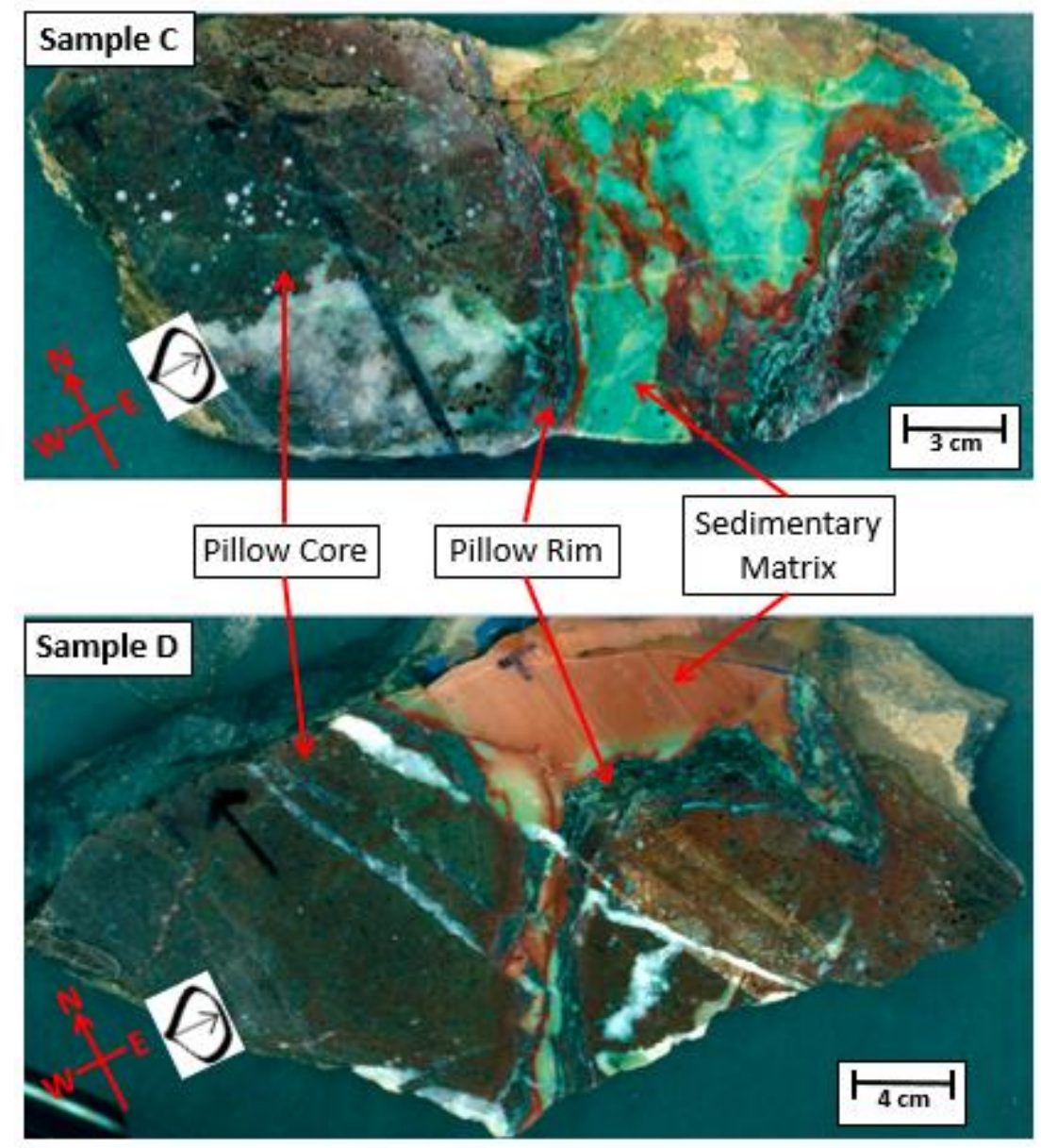

Figure 5.18. Slab scan images of pillow basalt Samples $C$ and D. The pillow core, rim, and metasedimentary matrix material are highlighted. Sample C is from Site 3a; Sample D is from Site 4c. Both slabs are cut in map view (looking down from above). 


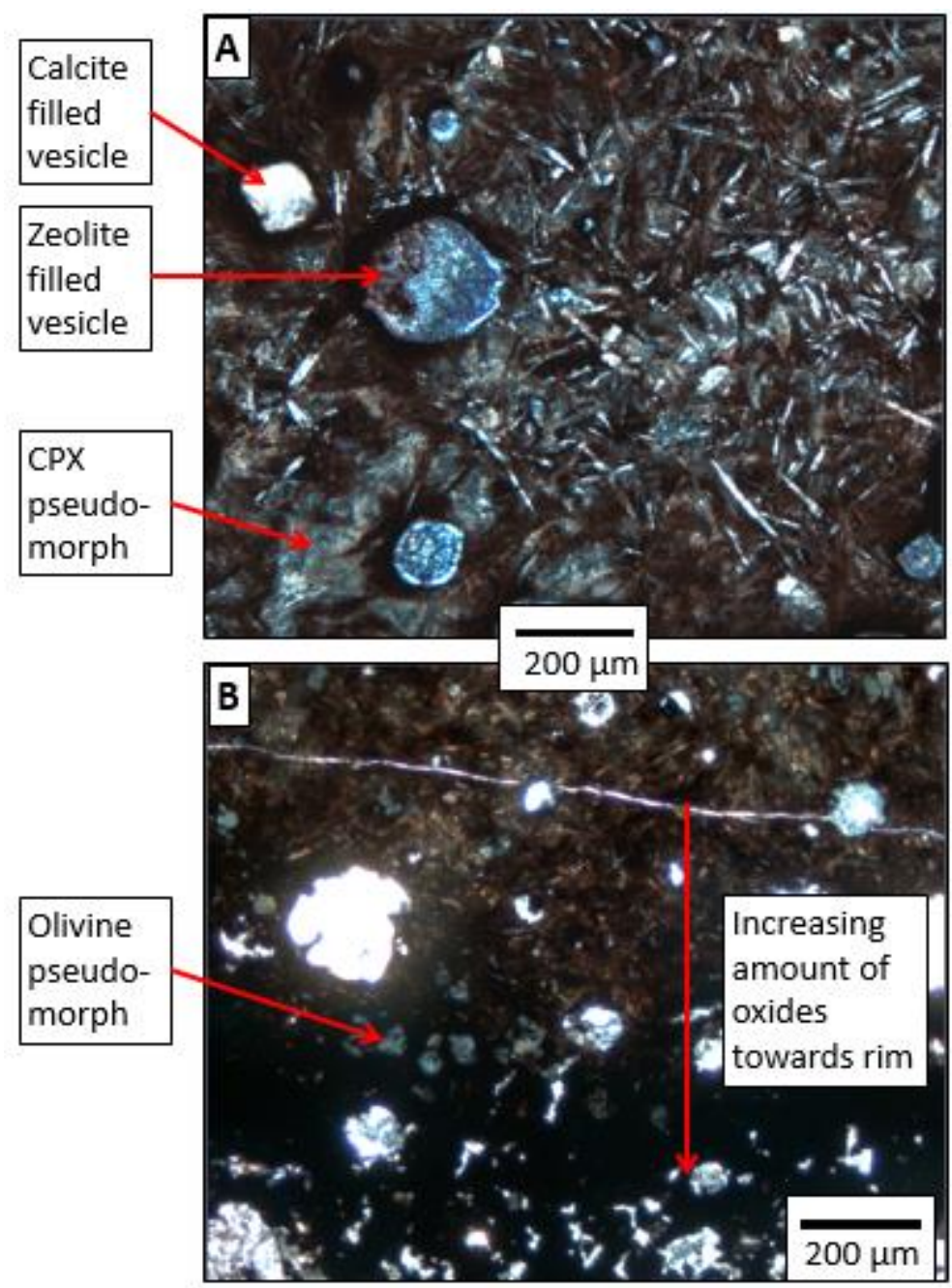

Figure 5.19. Photomicrographs of the pillow basalt ground mass. (a) shows the center of a pillow core and (b) shows the core near the rim of a pillow. The groundmass is composed of plagioclase, clinopyroxene (CPX), and olivine. The CPX and olivine crystals are pseudomorphs and have been replaced by actinolite, chlorite, calcite, and other minerals. Oxides are prevalent throughout and increase in density towards the rims of the pillows (b). Vesicles are filled by zeolites and calcite. Images show cross-polarized light; ASample E; B-Sample D. 


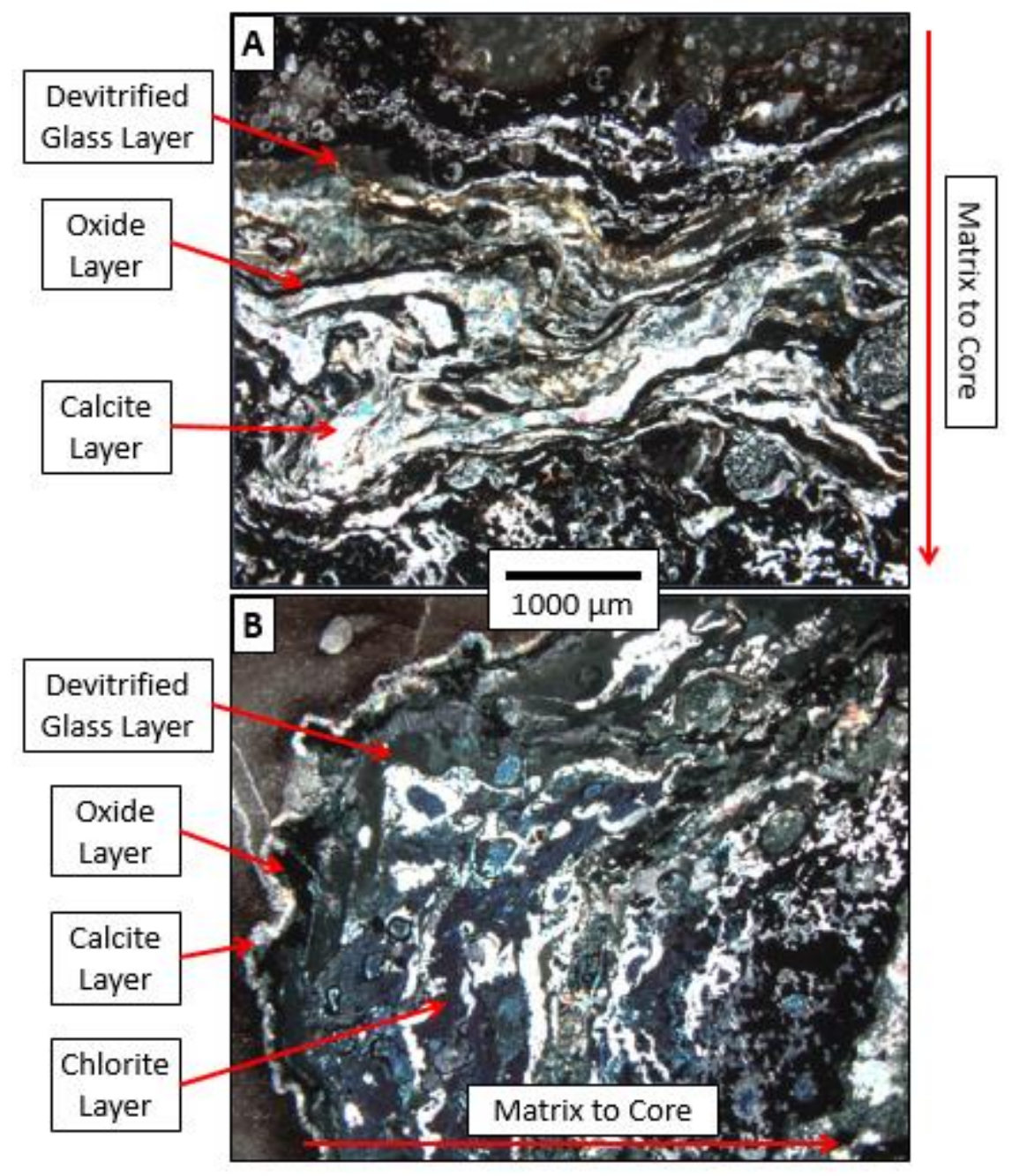

Figure 5.20. Photomicrographs of pillow rims. The rims are composed of varying amounts of discontinuous layers of calcite, devitrified glass, oxides, and chlorite. Sample $\mathrm{C}$ has more calcite and oxide layers whereas Sample D has more devitrified glass and chlorite layers. Images show cross-polarized light; A-Sample C; B-Sample D. 


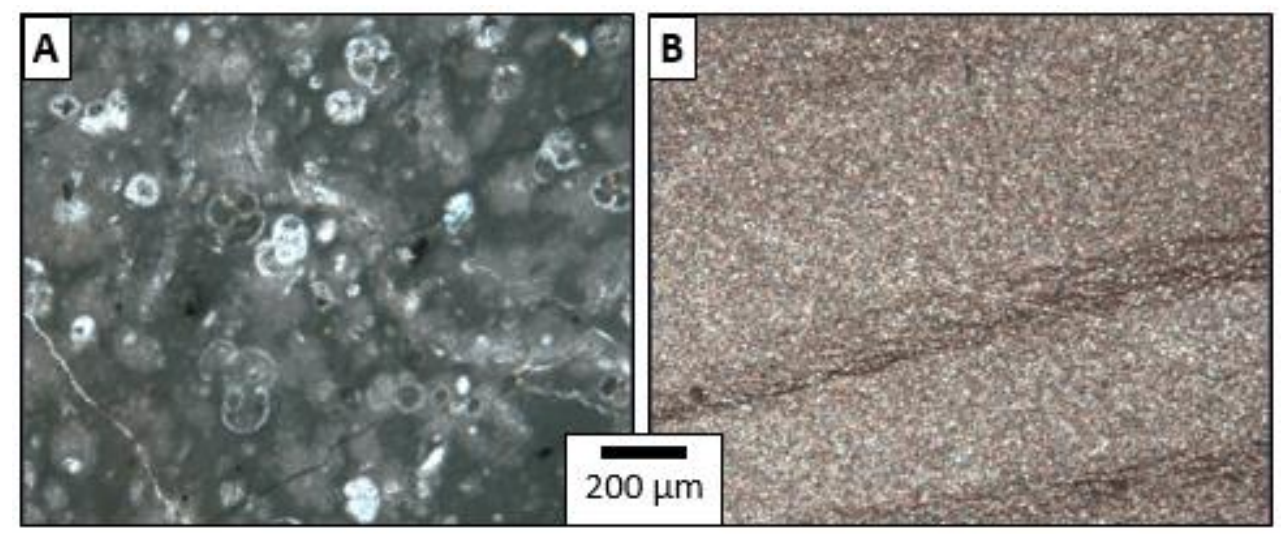

Figure 5.21. Photomicrographs the meta-sedimentary matrix of the pillow basalts. (a) shows the matrix of Sample C which is microcrystalline and contains microfossils. (b) shows the matrix of sample D which is devoid of fossils and coarser grained. Images show plane polarized light.

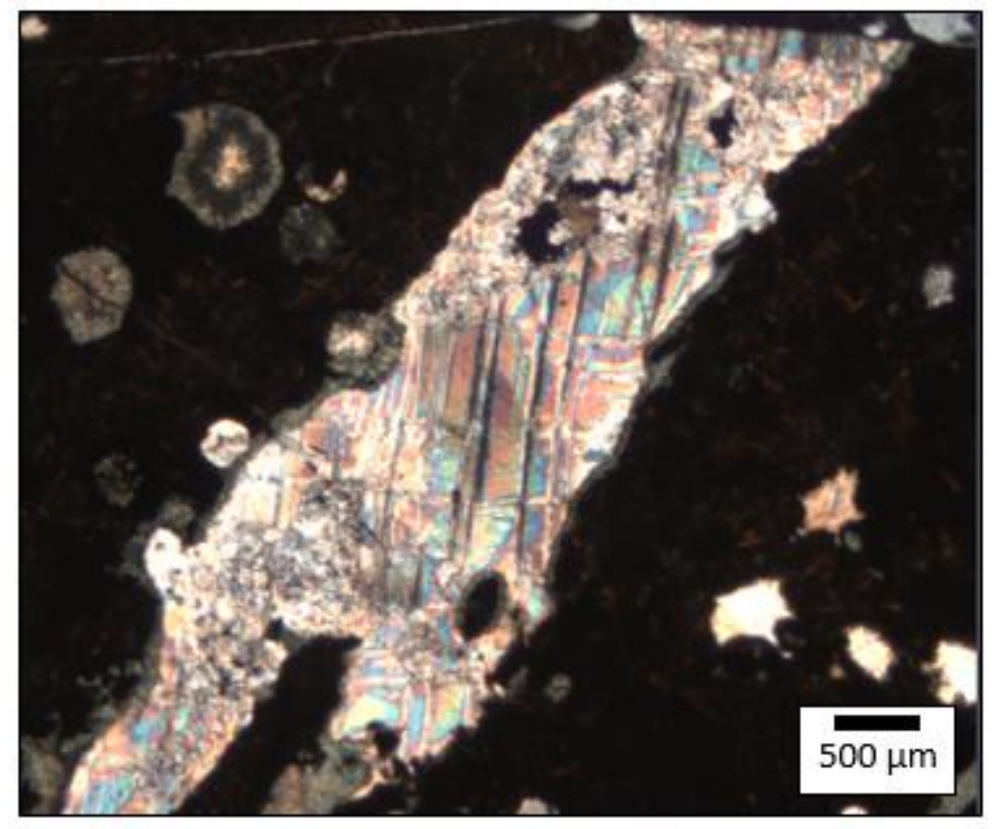

Figure 5.22. Photomicrograph of a calcite vein showing twinning. Image is of Sample D and shows crosspolarized light. 

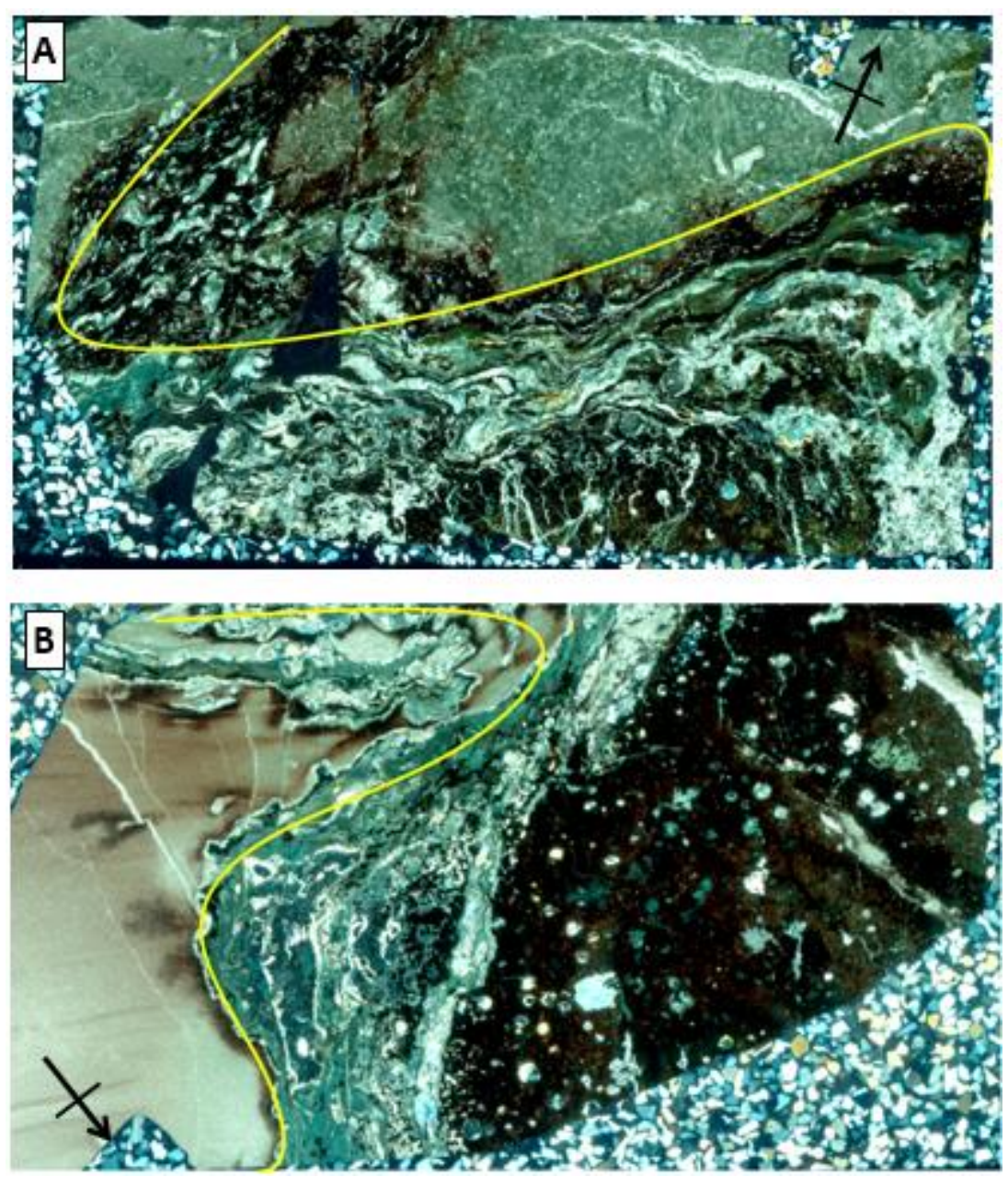

Figure 5.23. Photomicrograph in polarized light of two thin sections made from the rock slabs with the apparent folds outlined as traced by the pillow rims. (a) is from sample $\mathrm{C}$ and (b) is from sample $\mathrm{D}$ and thin sections are in map view (looking down from above) where north is indicated by the black arrows. 


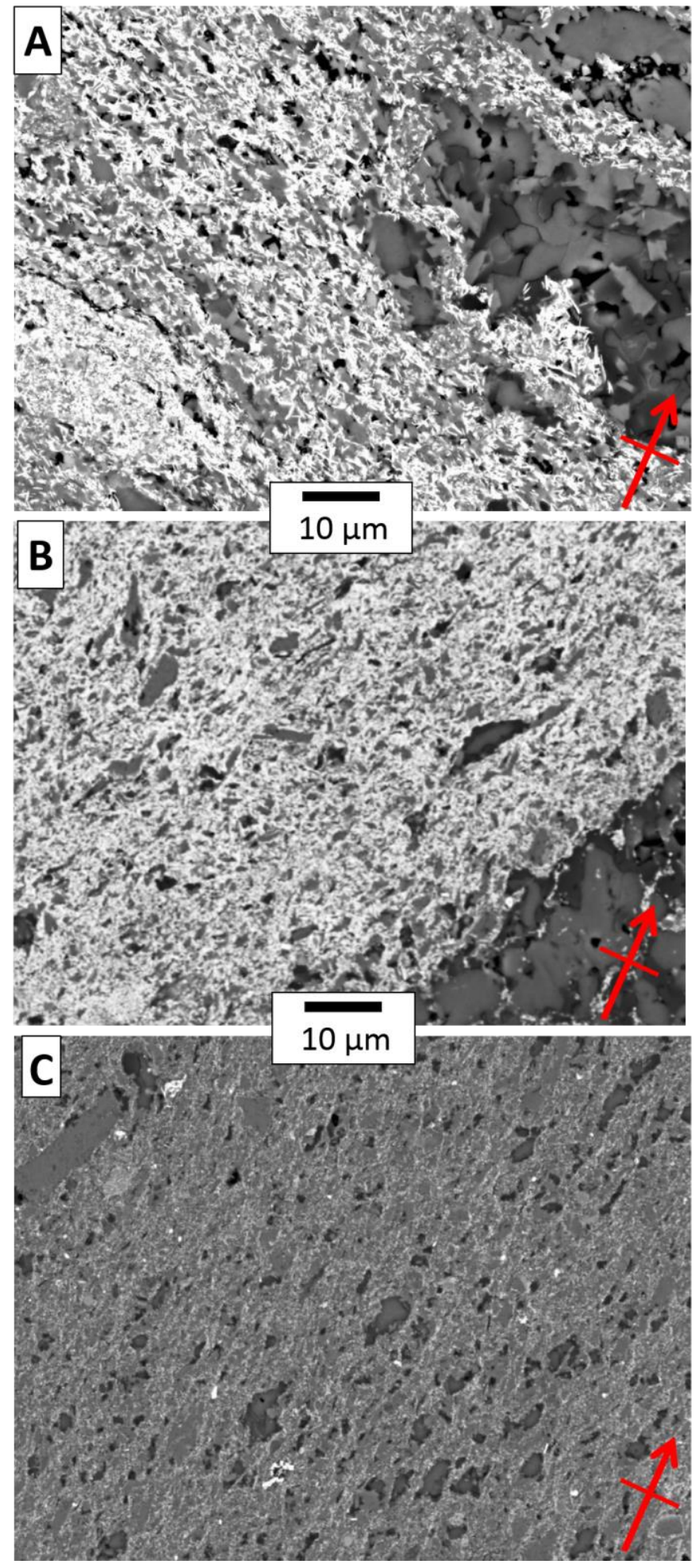

Figure 5.24. Backscattered electron images of mineral fabric locally developed in the meta-sedimentary matrix material. $(\mathrm{a}, \mathrm{b})$ show the aligned lighter oxide grains that anastomose around the darker calcite grains; these are from areas with a high concentration of oxides and appear darker red in hand sample. (c) shows a mineral fabric farther from the red, oxide-rich area of the thin section A-Sample C; B and CSample D. Images are in map view and north is represented by the red arrow. 

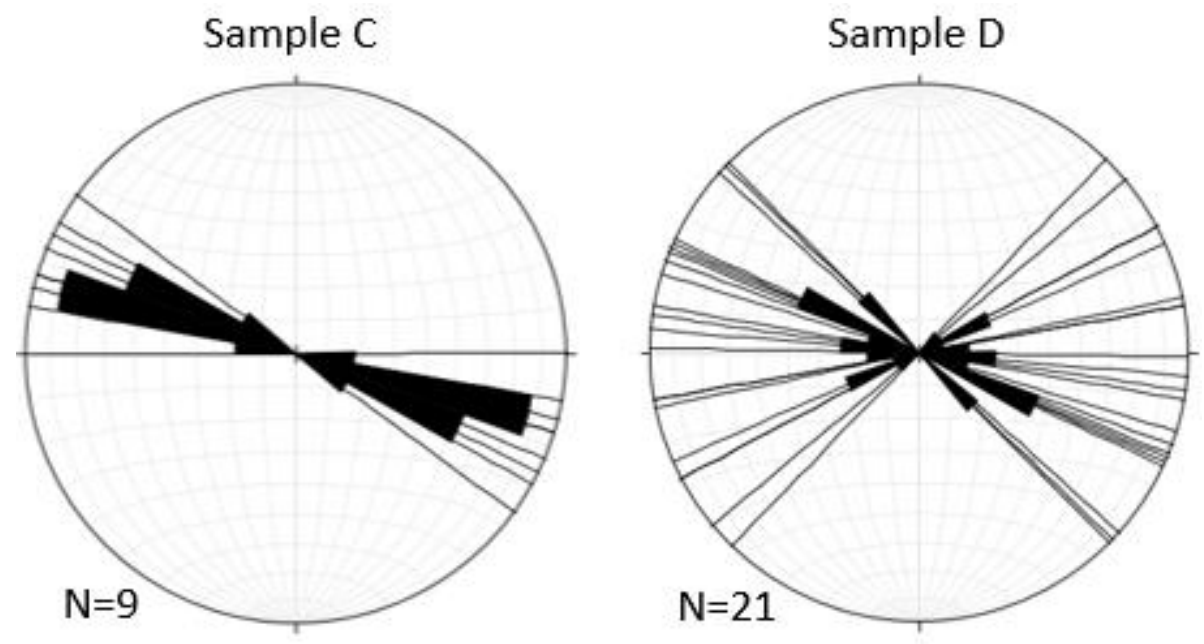

Figure 5.25. Rose diagrams of the average orientation of aligned oxide grains. The orientations are strike estimates as measured from backscattered electron images of thin sections that were cut parallel to the horizontal in "map view".

\subsection{Interpretation}

This section presents interpretations made based on the field observations, structural data, and micro-scale observations from the pillow basalt outcrops, Sites 3 and 4, of the Hamma Hamma Transect. Table 5.2 shows representative orientations of the structures discussed.

The representative orientation for the pillow basalt bedding is $(002,88)$; striking $\mathrm{N}-\mathrm{S}$ and dipping near vertical. Pillow basalts form initially with horizontal bedding, so the present orientation indicates that the beds have been rotated approximately $90^{\circ}$. The pillows top toward the east, so the direction of rotation must be clockwise. The calculated axis of rotation is $(00 \rightarrow 182)$ with a magnitude of $92^{\circ}$, clockwise (Fig. 5.26). The necessary $\sigma 1$ for this rotation is oriented E-W.

When all the fault and fracture data are compared, some similar trends are observed (Fig. 5.17). The first is that Fault Groups A and B are have similar orientations 
to Fracture Groups A and B. This indicates that the respective groups are related; as a fracture network forms, the fractures will interconnect and form faults that accommodate further movement (Fig. 5.27). The presence of cataclasite and fault gouge on the faults in Group A indicate that these faults have accumulated the greatest amount of strain. Since the fracture groups mutually crosscut one another and because of their relative orientations (Fig. 5.7), I interpret Faults A and B as conjugate faults with a $\sigma 1$ of $(12 \rightarrow 265)$. This indicates that the faults formed from horizontal, nearly E-W compressive stresses with a reverse sense of motion (Fig. 5.28). The slickensides, however, indicate that the last motion on the faults' surface was of a normal motion (smooth down dip on footwall side). If the faults formed in their present orientation, then they must have been reactivated as normal faults by a change in the stress regime. The exhumation of the Crescent Fm. created steep mountains relatively quickly. If the erosion rate cannot keep up with the rate of steepening, normal faulting will occur to alleviate vertical stresses. The discrepancy in the slickensides for Fault Groups A and B is interpreted as reactivation of the faults as normal faults from over-steepening.

If Fault Groups A and B did reactivate as normal faults from over-steepening, it is possible that additional faults would have formed in orientations more optimal for normal slip. Based on orientation, Fault Group C stands out as a conjugate to Fault Group B, with $\sigma 1$ oriented $(87 \rightarrow 345)$ (nearly vertical) and a $\sigma 3$ oriented $(00 \rightarrow 119)$ (nearly horizontal and NW-SE) (Fig. 5.29). Slickenline measurements on both Groups B and C are also consistent with normal, dip-slip motion. Therefore, if Faults B and C are conjugates, they have a normal, extensional, geometry. Based on similarities in 
orientation, Fault Group C does not have a fracture group associated with it, but it does crosscut through the fractures that are associated with Fault Groups A and B. This supports the interpretation that Fault Group C formed after Fault Groups A and B. A normal conjugate was not identified for Fault Group A.

Fault Group D was identified in the field with the lowest confidence because the faults strike subparallel to the outcrop and only footwall surfaces could be observed. The orientation of slickenlines measured on these faults were used to determine possible reverse and normal conjugates (Fig. 5.30). The principal stresses, $\sigma 1$ and $\sigma 3$, for each regime do not appear to correlate with any of those calculated for the other faults. Like the other fault groups, the nature of the slickensides suggest that the last motion on the fault was normal. If Fault Group D formed initially as a reverse fault and then reactivated as a normal fault, like Groups A and B, then this would a significant change in the state of stress, from E-W (as calculated for Groups A and B) to N-S (as calculated by the hypothesized reverse conjugate in Fig. 5.30). There are other reverse faults mapped in the vicinity that are oriented similarly to Fault Group D (i.e. the western extent of the Seattle Fault), supporting the interpretation of some component of revers motion on the fault.

The vein orientations can be weakly correlated with the fracture orientations if the fractures represent Mode II structures and the veins are Mode I structures. If the veins are Mode I fractures, then their poles indicate a $\sigma 3$ stress direction. Figure 5.31 shows all of the fracture data plotted as planes and the location of the line of intersection (red circles) of eight selected pair of fractures. The fracture pairs that define these intersections were considered conjugates, and the $\sigma 3$ was calculated for each (red triangles). When 
compared, the contoured range of the poles to veins (i.e., their estimated $\sigma 3$ ) and the range of $\sigma 3$ for the selected fracture pairs overlap, which would indicate that the fractures and the veins formed under the same state of stress. However, there are some vein orientations that do not agree with this correlation and are more similar in orientation to fracture Group B, suggesting that some veins are mineralized Mode II fractures.

Within the pillow basalt outcrops, selected samples show that the metasedimentary matrix and the pillow rims are folded with an associated mineral fabric. The presence of this fabric means that some component of strain was taken up by the matrix and was driven by dissolution-driven or crystal plastic processes. The sample from Site 3 shows the fabric localized to the pillow rim/sediment boundary whereas the sample from Site 4 shows the fabric more distributed throughout the sediment. This indicates that folding and fabric development occurred locally but was not penetratively developed across the outcrops.

Table 5.2. Representative orientations of major structure groups in the pillow basalt outcrops.

\begin{tabular}{|c|c|}
\hline Structure & Representative Orientation(s) \\
\hline Bedding & $(002,88)$ \\
\hline Fault Group A & $(304,37)$ \\
\hline Fault Group B & $(207,59)$ \\
\hline Fault Group C & $(031,61)$ \\
\hline Fault Group D & $(087,50)$ \\
\hline Fracture Group A & $(303,40)$ \\
\hline Fracture Group B & $(211,39)$ \\
\hline
\end{tabular}




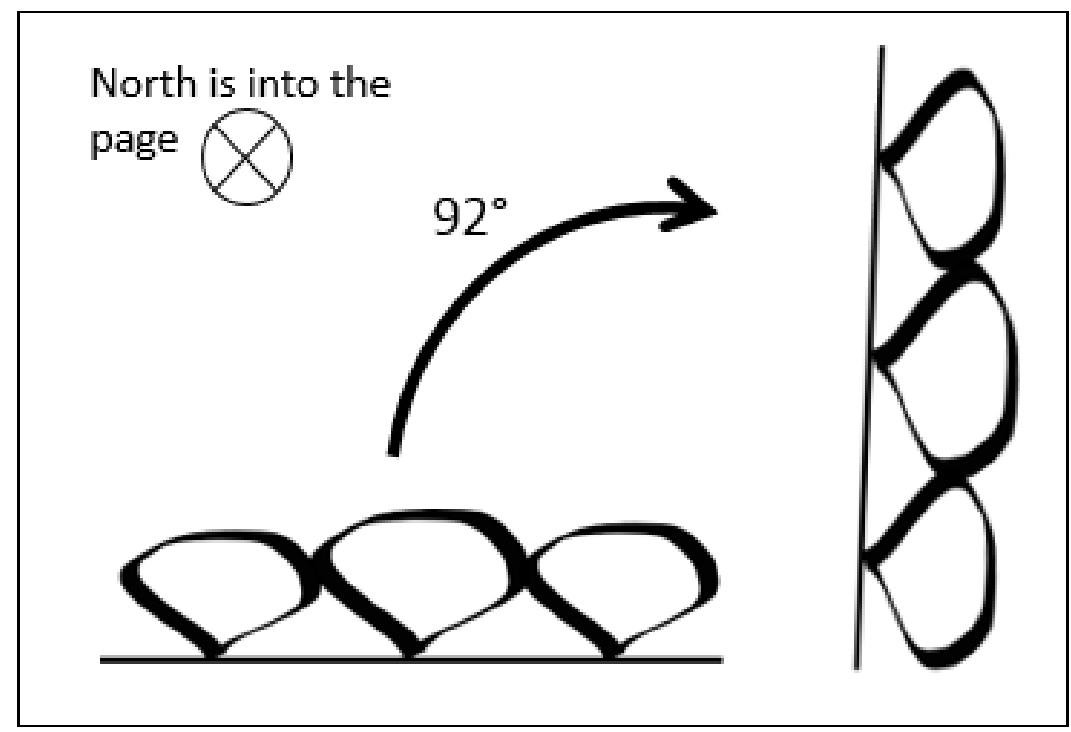

Figure 5.26. Diagram showing the rotation of the pillow basalts. The basalt was rotated $\sim 92^{\circ}$ clockwise from horizontal to near vertical about an estimated axis of rotation of $(00 \rightarrow 182)$. North is into the page.
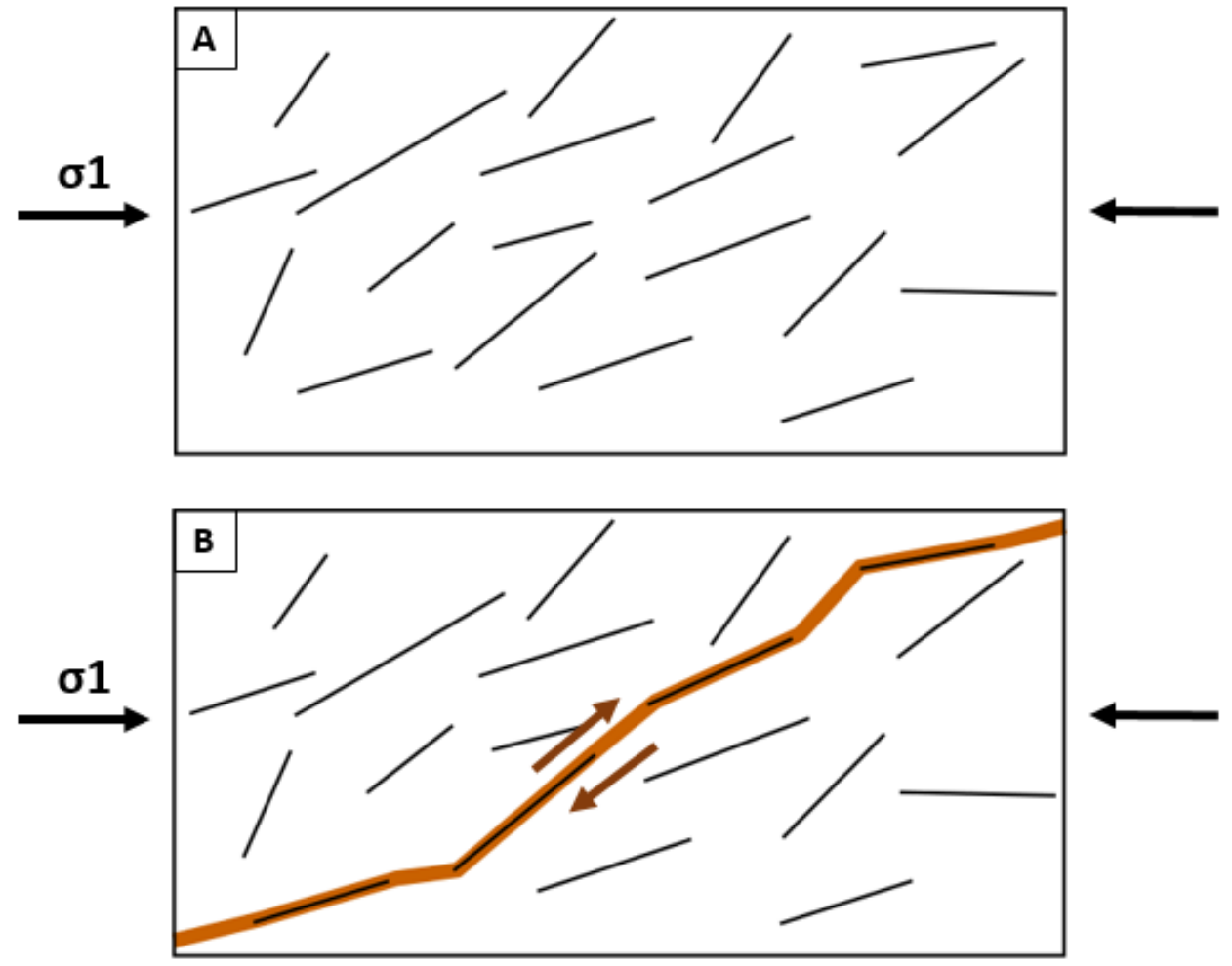

Figure 5.27. Diagram showing how a fault forms from the interconnection of fractures. A) Fractures form in response to a maximum principal stress. B) Fractures link up and form a through-going fault (orange line). 


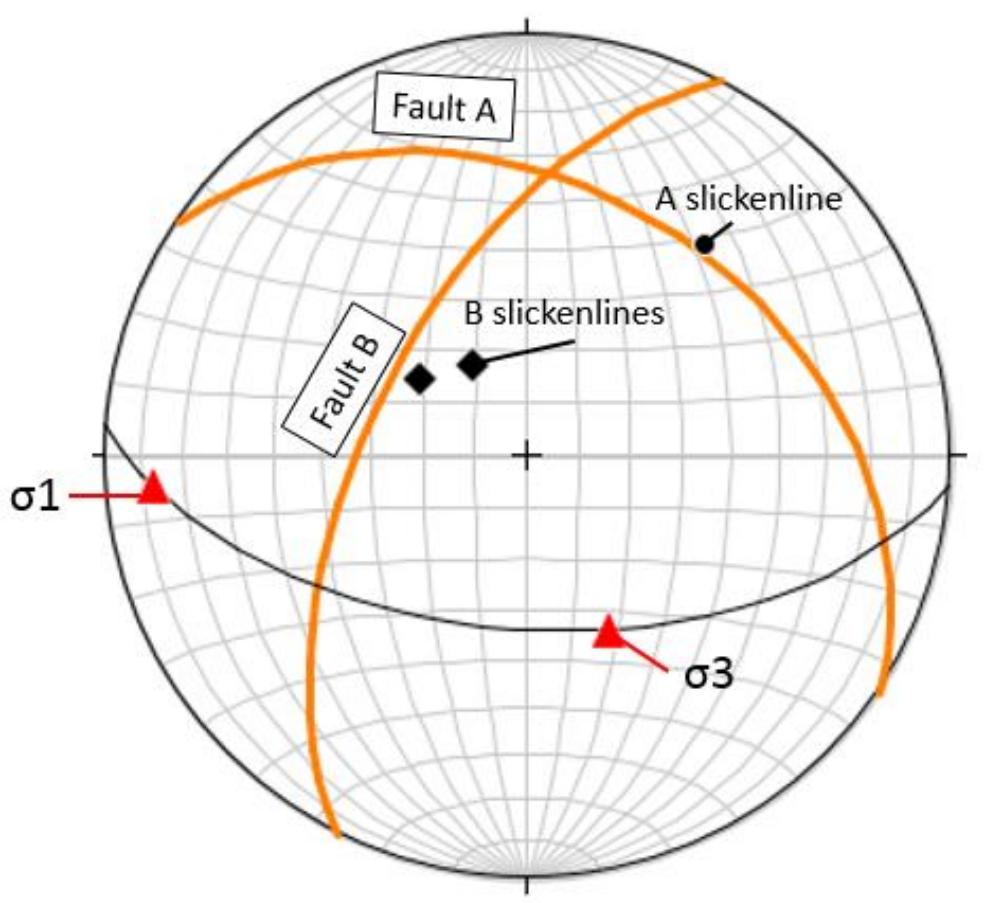

Figure 5.28. Representative orientations and an interpreted state of stress for Fault Groups A and B. If conjugates, $\sigma 1$ is $(12 \rightarrow 265)$ and $\sigma 3$ is $(52 \rightarrow 155)$.

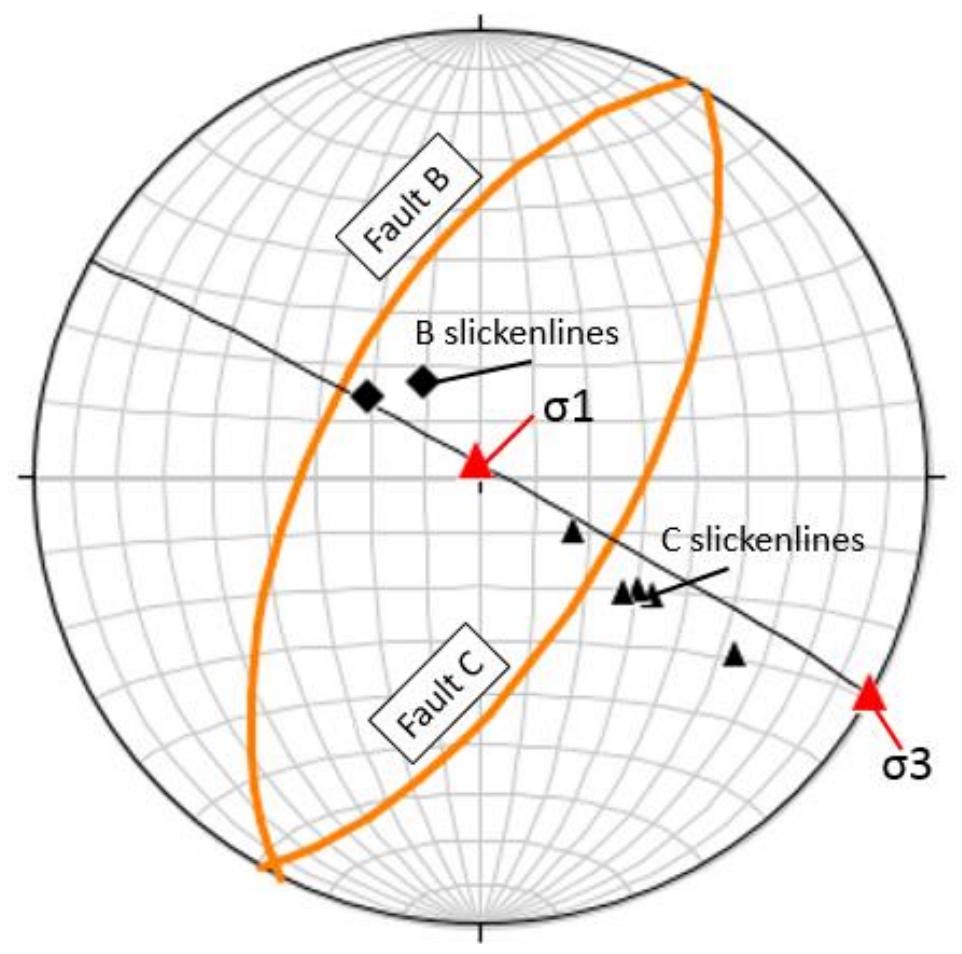

Figure 5.29. Representative orientations and an interpreted state of stress for Fault Groups B and C. If conjugates, $\sigma 1$ is $(87 \rightarrow 345)$ and $\sigma 3$ is $(00 \rightarrow 119)$. 

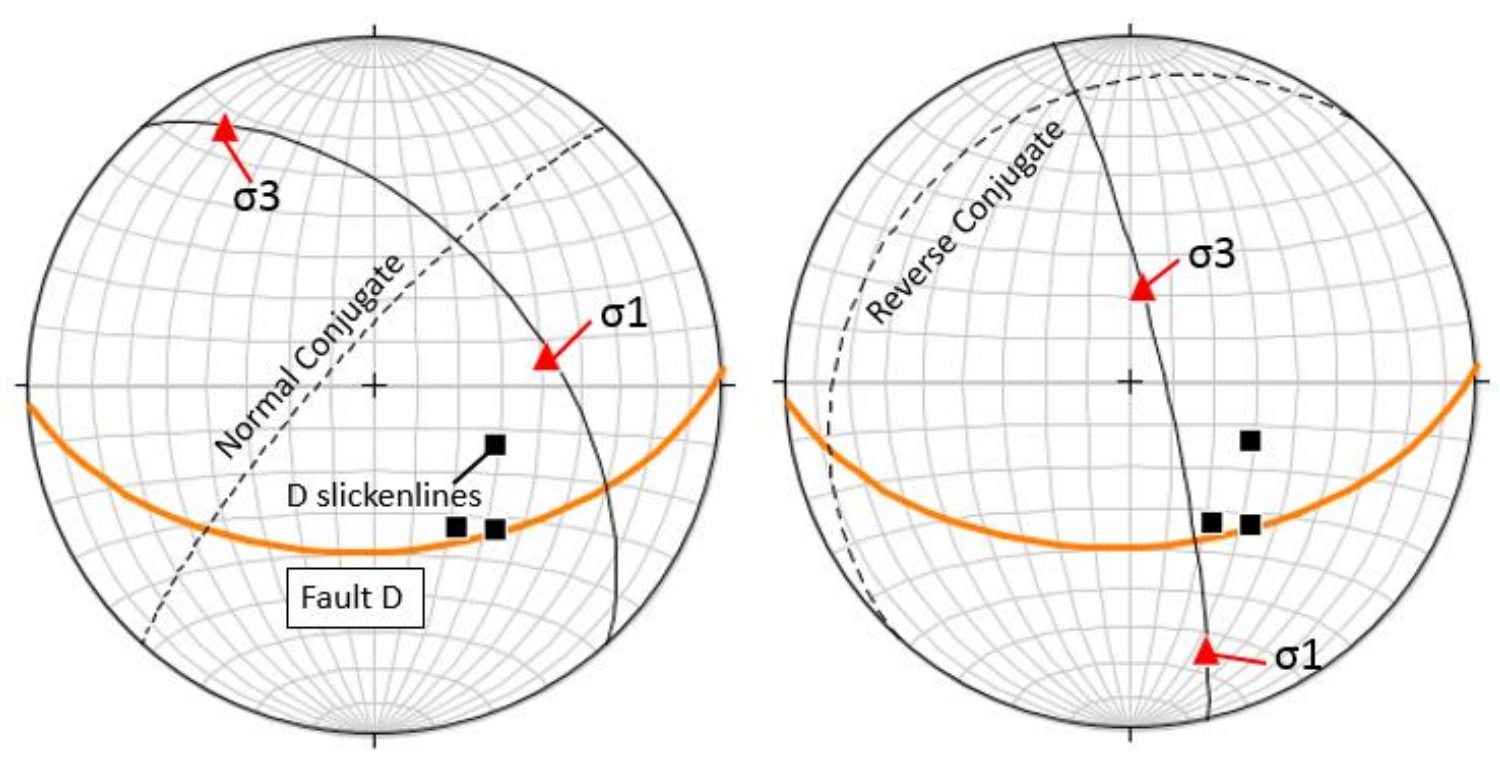

Figure 5.30. Estimated orientations for normal and reverse conjugates to Fault Group D. Conjugate faults were estimated using measured slickenlines (black squares). The principal stresses, $\sigma 1$ and $\sigma 3$, for each are also shown.

- Fracture Planes
- Poles to Vein Planes $(\sigma 3)$
- Fracture Intersections
Calculated $\sigma 3$ for
Fracture Intersections
Contour Lines for Poles
to Vein Planes

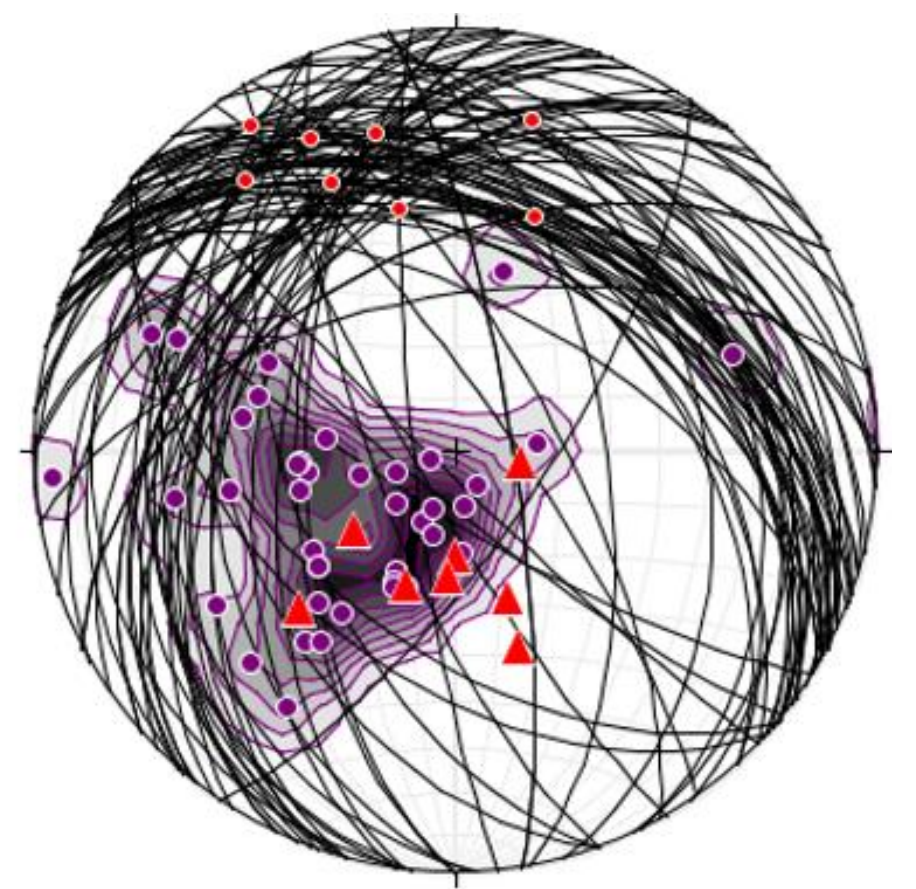

Figure 5.31. A comparison of the estimated minimum principal stress for fractures and veins in the pillow basalts. The poles to veins estimate $\sigma 3$, assuming Mode I fractures (purple circles). Eight fracture intersections are shown for selected conjugate fracture pairs (red circles), and the estimated $\sigma 3$ is shown (red triangles) for each pair. 


\subsection{Model of Deformation}

Based on interpretation of the field observations and structural data from the pillow basalt sites along the Hamma Hamma Transect, the following is one proposed model for the deformational history of the rocks. The stages in the deformational history are denoted by T1-5 and refer to Figure 5.32.

The pillow basalts of the lower Crescent Fm. formed as part of the large oceanic chain, Siletzia. Their initial orientation was with their tops pointing upwards and their most convex edge subparallel to the horizontal, or the ocean floor. The pillows were rotated on end about a N-S oriented rotation axis by E-W compressive stresses associated with the subduction zone and accretion and underplating of the meta-sediments (T1).

Once the rock package was rotated into its current position, it began fracturing under the same E-W oriented state of stress (T2). The veins formed as Mode 1 extensional fractures and along with the fracture Groups A and B as Mode II fractures. The fractures connected to form conjugate Fault Groups A and B that slipped through reverse motion (T3).

If Fault Group D formed as a reverse fault as speculated, then it would have formed by a N-S oriented state of stress. Because of a lack of crosscutting relationships, it is not clear when it formed in relation to the other faults. However, the meta-sedimentary interpretations suggest E-W compression followed by $\mathrm{N}-\mathrm{S}$ compression. If the pillow basalts experience a similar history, then Fault Group D would have formed after Groups A and B (T4). 
The mountains steepened as the rock body was exhuming. If the erosion rate could not keep up with the rate of steepening, then gravity would become the maximum principal stress and normal faulting would have occurred. The slickensides on Fault Groups A, B, and D indicate that the last motion on their planes was normal, so these faults may have reactivated as normal faults from over-steepening of the rock body (T5). Fault Group C may have also formed as a normal conjugate to Fault Group B. 


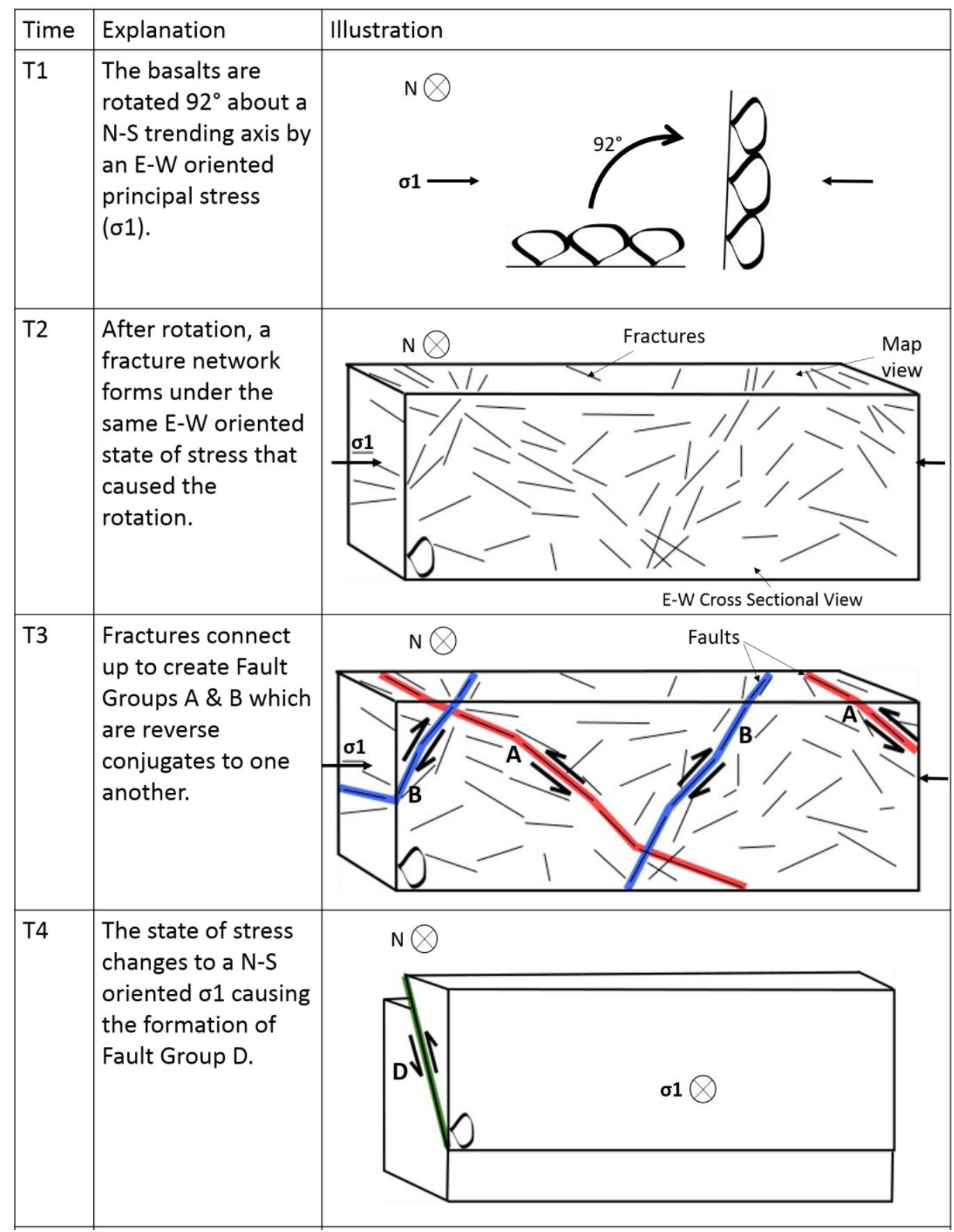

(continued on next page) 


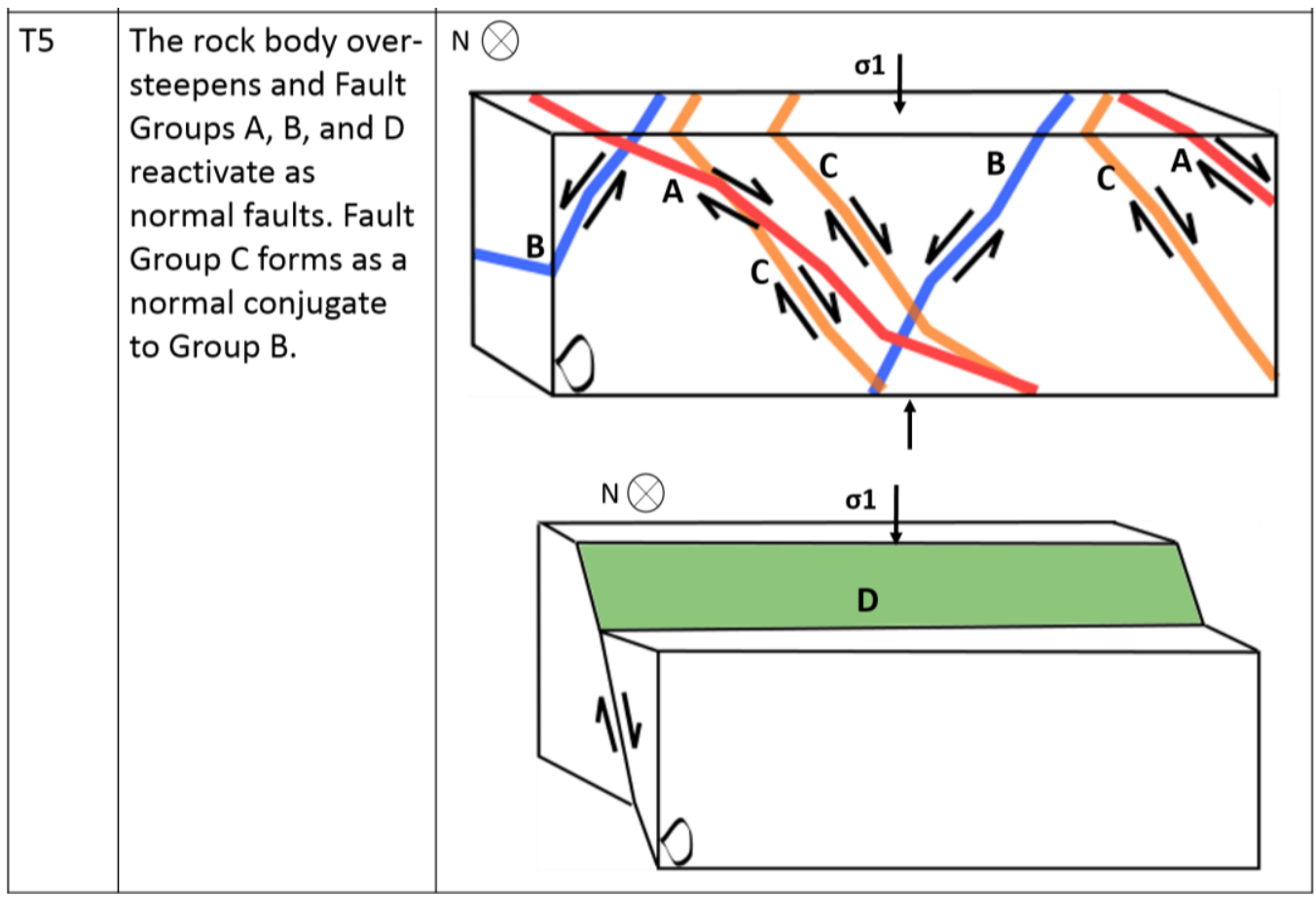

Figure 5.32. Stages in the deformational history of the pillow basalts from the Hamma Hamma Transect Sites 3 and 4. Diagrams are not to scale. 


\section{Comparison of Meta-Sediments and Pillow Basalts from the Hamma Hamma Transect}

This chapter presents a unified model for deformation of the pillow basalts and the meta-sediments within the vicinity of the Hurricane Ridge Fault (HRF) across the Hamma Hamma Transect based on data from all four sites of this study and from the literature. Figure 6.1 shows the main steps of the model locally within the Hamma Hamma Transect, and Figure 6.2 shows the main steps in this model regionally for the Olympic Peninsula, as interpreted from the literature.

The pillow basalts formed between 65 and $55 \mathrm{Ma}$ as part of the large, oceanic island chain, Siletzia (Duncan, 1982). Subsequent to its formation, Siletzia was accreted to the North American continent and accretion was complete by $50 \mathrm{Ma}$ (Fig. 6.1, T1) (Fig. 6.2a) (Wells et al., 2014). The accretion of Siletzia overstuffed the subduction complex, and for the next 10-14 million years, the subduction zone jumped west-ward to where the Cascadia subduction zone currently lies (Schmandt \& Humphreys, 2011).

Around $36 \mathrm{Ma}$, underplating, frontal accretion, and deformation of sedimentary material from the Juan de Fuca slab caused the wedge to thicken beneath the Crescent Fm. (Fig. 6.2b) (Brandon \& Vance, 1992). Wedge thickening started to steepen the HRF and caused the rotation of the pillow basalts about the N-S oriented horizontal axis (Fig. 6.1, T2) (Tabor \& Cady, 1978). This is also when the meta-sediments of Sites 1 and 2 of the Hamma Hamma Transect may have experienced folding at depth (Fig. 6.1, T2). The folds would have formed initially with their axial planes subparallel to the subducting margin, as in the classic fold and thrust structures of the accretionary wedge (Davis, Suppe, \& Dahlen, 1983). The mountain range was not exhuming at this point, (Batt, 
Brandon, Farley, \& Roden-Tice, 2001; Brandon, Roden-Tice, \& Carver, 1998), so the wedge would had to have been thickening downwards.

As wedge thickening progressed, the HRF continued to rotate into its current, near vertical position, putting the pillow basalts on end, facing the east (Fig. 6.1, T3). The Crescent Fm. acted as a backstop to the meta-sediments, so the folds of the Hamma Hamma Transect would have steepened along with the HRF into an upright orientation. Once the HRF was vertical and perpendicular to the regional E-W oriented subduction zone stresses, it could no longer accommodate these stresses through slip on the fault. At this point, Fault and Fracture Groups A and B, observed at Sites 3 and 4, formed to accommodate strain from continued E-W oriented compression (Fig. 5.28).

At $17 \mathrm{Ma}$, the exhumation of the metamorphic core began (Fig. 6.2c) (Brandon \& Vance, 1992). It is unclear whether the HRF was already vertical at the beginning of exhumation, or if the exhumation process played a role in its steepening. If the fractures that cut the folds formed at lower temperatures where more brittle processes dominate, then the folded meta-sediments of Sites 1 and 2 of the Hamma Hamma Transect may have moved to shallower depths during exhumation and were fractured (Fig. 6.1, T4). If these fractures formed by N-S oriented compression (Fig. 4.28), this would indicate a change in the state of stress, at least locally. The presence and initial formation of Fault Group D is not well-defined; however if, as speculated, it formed initially as a reverse fault, then it would have also formed under this NNW-SSE oriented compression.

The folds of the meta-sediments are steeply-plunging, suggesting a period of rotation from an original upright orientation. This rotation of the folded meta-sediments 
may have been driven by NNW-SSE oriented compression (Fig. 4.25) during the exhumation process but after fracturing (Fig. 6.1, T5). One of the models for Olympic exhumation suggests that the mountain range was uplifted by N-S oriented shortening of Siletzia against the Canadian Buttress (Wells et al., 1998; Blakely et al., 2009, 2011; Brocher, Wells, Lamb, \& Weaver, 2017; McCaffrey et al., 2007; Wells et al., 2014; Wells \& McCaffrey, 2013). If the meta-sediment fractures, rotation of the metasediments, and Fault Group D in the pillow basalts did result from near N-S shortening as interpreted here, then these structures would support this model. However, the study area is small compared to the whole mountain range, and the inferred change in the state of stress from E-W to N-S/NNW-SSE compression may only reflect local conditions.

As the meta-sedimentary core was exhumed, the state of stress may have shifted to gravity as the maximum principal stress. Fault Groups A, B and D may have reactivated as normal faults during this time, and Fault Group C may have formed as a conjugate to Fault Group B (Fig. 5.29) (Fig. 6.1, T6). 


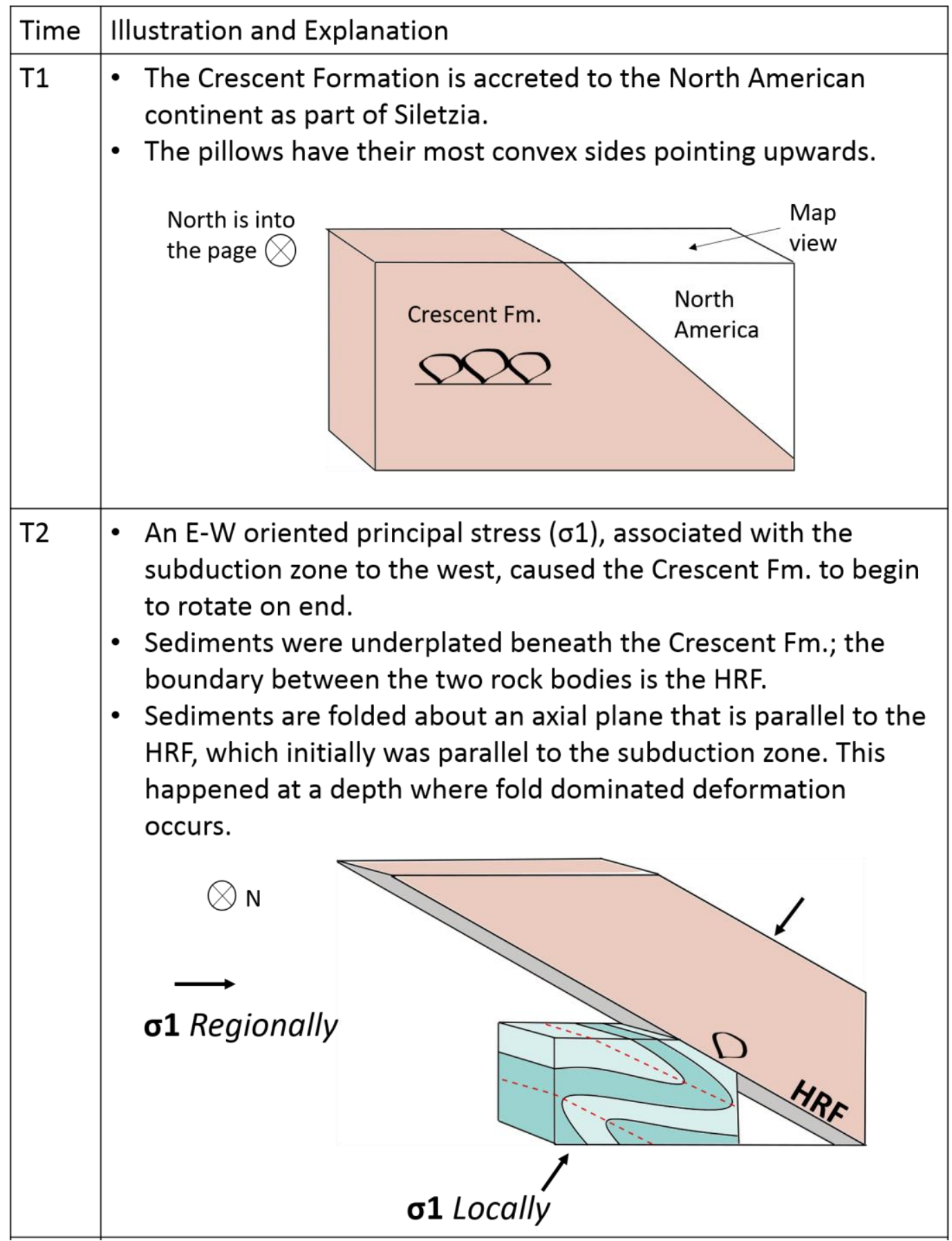

(continued on next page) 


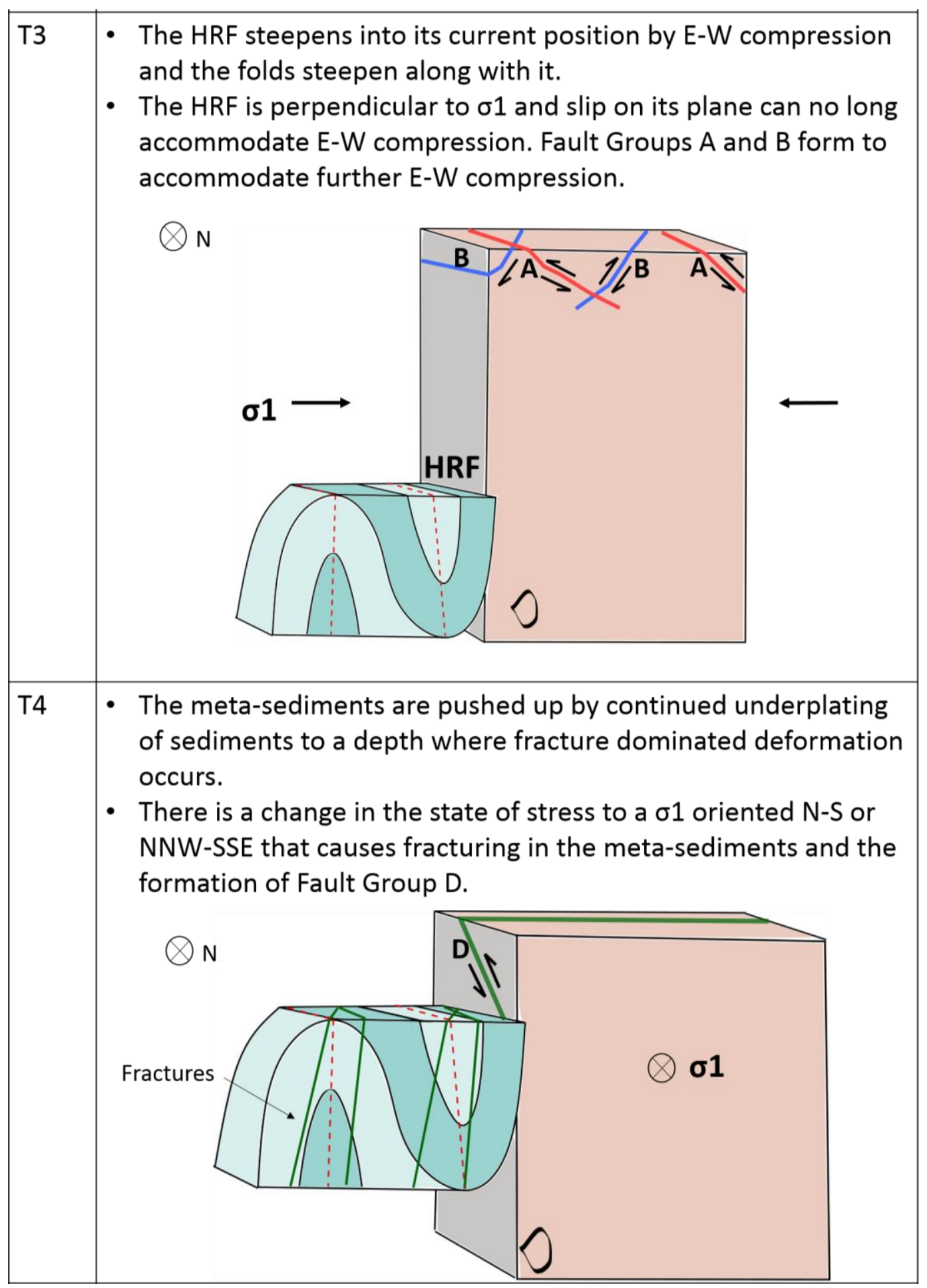

(continued on next page) 


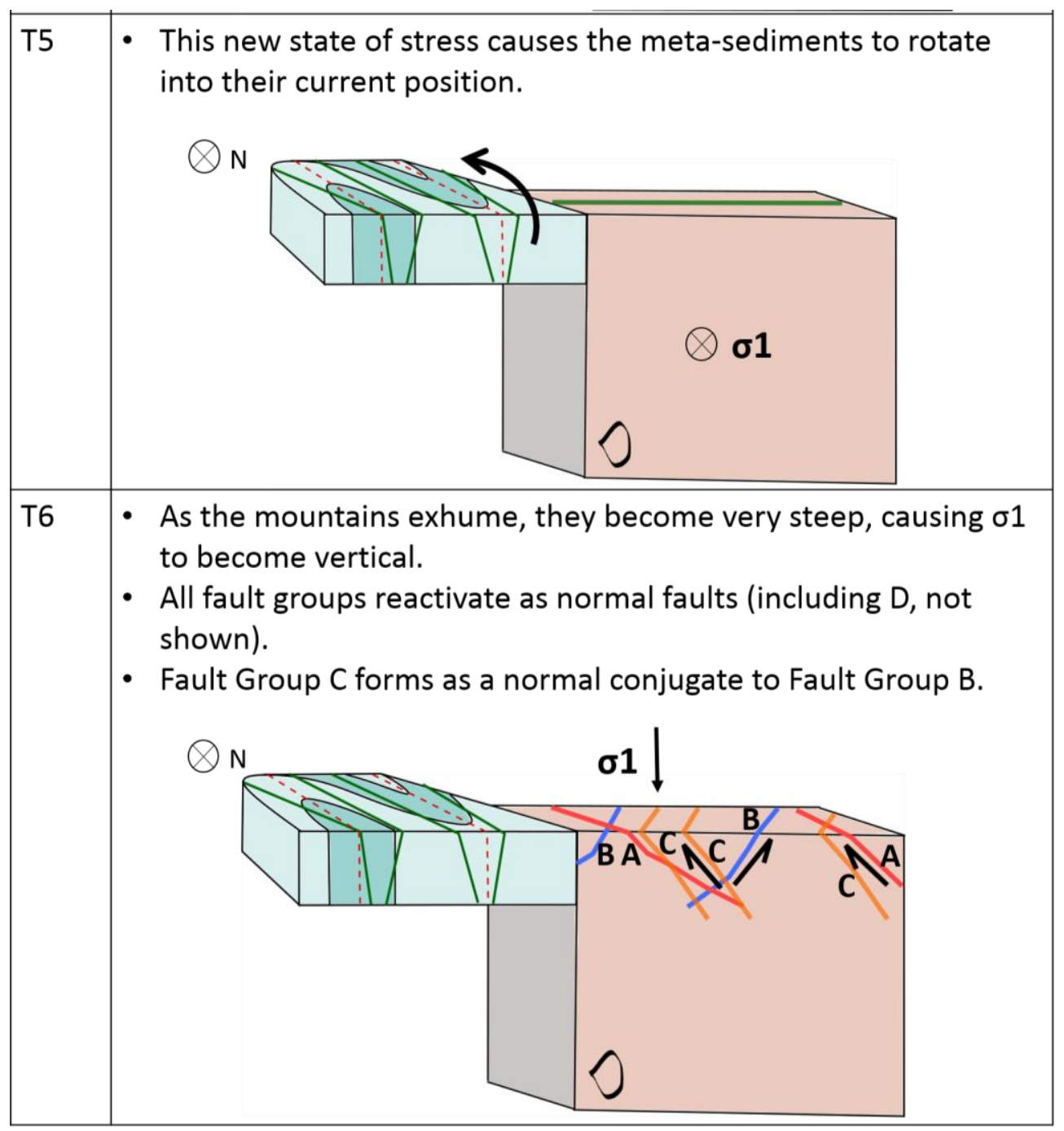

Figure 6.1. Series of events in the model of deformation for the Hamma Hamma Transect. Diagrams are not to scale. 


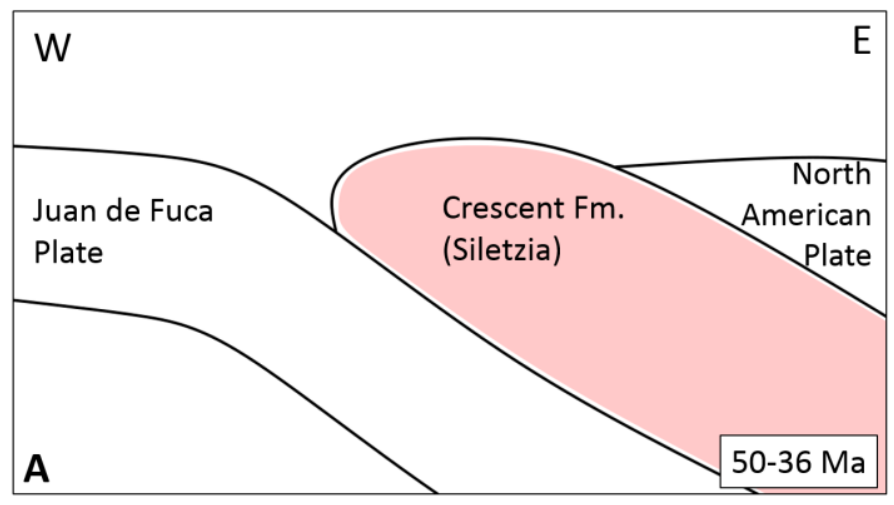

Time
Periods
from

Fig. 6.1

$\mathrm{T} 1$
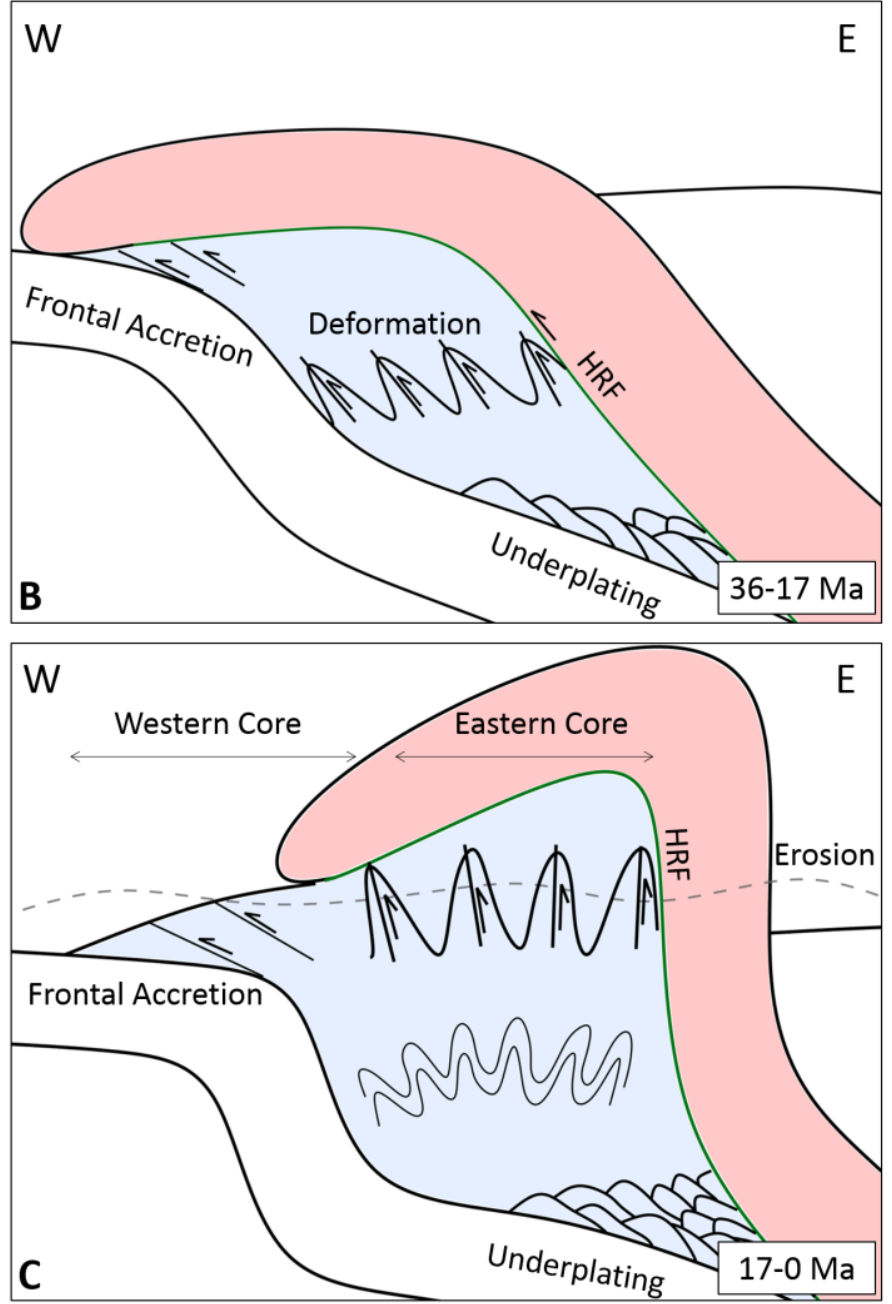

T2

T3?

T4, T5,

\& T6

Figure 6.2. Diagrams showing the steps in deformation of the Olympic Peninsula. The relative timing of the events (T1-T6) relate to Figure 6.1. A) The Crescent Fm. is accreted to the North American Continent

by $50 \mathrm{Ma}$ and the subduction zone is established on the west side of the Siletzia terrane. B) The accretionary wedge thickens as sediments are accreted, underplated, and deformed. C) Exhumation begins and the HRF is rotated into its current, vertical position. The dotted line in (c) represents the current erosional surface. Diagrams are not to scale. The model is based on Batt et al. (2001), Tabor \& Cady (1978), and Brandon \& Vance (1992). 


\section{Implications for the Interpretation of Regional Structure \& Geologic History}

\subsection{Comparison of the Hamma Hamma Transect to Regional Structures}

\subsubsection{Meta-Sediments of the Eastern Core}

Tabor and Cady (1978) give the most robust structural dataset for the eastern core of the Olympic Mountains. The structures of interest in their study were bedding, cleavages, and pencil features. Figure 7.1 shows a map of their data with the data from this study added in; the Hamma Hamma Transect falls spatially into the Outer Edge Domains. For many of their structural domains, they describe their bedding data as acting as a proxy for fold axial planes due to the isoclinal nature of the folds. The bedding data in Tabor \& Cady's Domain 12 and the data from this study are not parallel to the axial plane and the folds are more open with a northwest plunge. Unlike Domain 12, the foliation in the Hamma Hamma Transect follows a similar trend to the bedding and foliation of the Outer Edge Domains, striking subparallel to the HRF. This study shows that the fold axial plane is not parallel to the dominant cleavage (or S2), suggesting that additional factors affected the formation of the foliation, such as shear folding.

Although Tabor and Cady (1978) describe cleavages as fabric planes that disrupt and offset bedding, they do not document fractures like those described at the sites in this study. Tabor and Cady may have grouped the cleavages and fractures together because of their similar appearance in the field. The micro-scale observations in this study demonstrate that they are different features that formed at different times. The fracture groups identified in this study do strike similarly to the axial plane, but other than this correlation, it is unclear how the fractures from the Hamma Hamma Transect compare to 
Tabor \& Cady's data. Similarly, there were no pencil structures identified in this study, so it is unclear how the data presented here related to the pencil orientations identified elsewhere in the meta-sedimentary core.

The deformation model for the data collected across the Hamma Hamma Transect suggests two stages of deformation with two states of stress: folds and foliations that formed first under an E-W oriented $\sigma 1$ that were rotated and fractured by a N-S/NNWSSE oriented $\sigma 1$. Tabor \& Cady's Domain 12 share similar fold structures, suggesting similarities in the deformation history, but foliation orientations are different and there is no fracture data to compare. Therefore, it is unclear to what degree Domain 12 and other areas in the Outer Edge Domains share the same deformational history or the same inferred states of stress through time. Since the cleavages, axial planes, and bedding are subparallel to the HRF, it may be that the HRF was folded into place and the structures were rotated along with it (as suggested by Tabor \& Cady [1978]) by local states of stress different from the Hamma Hamma Transect. This would allow for different states of stress but a similar two stage history as proposed in this study. This theory is discussed in more detail in the following section. 


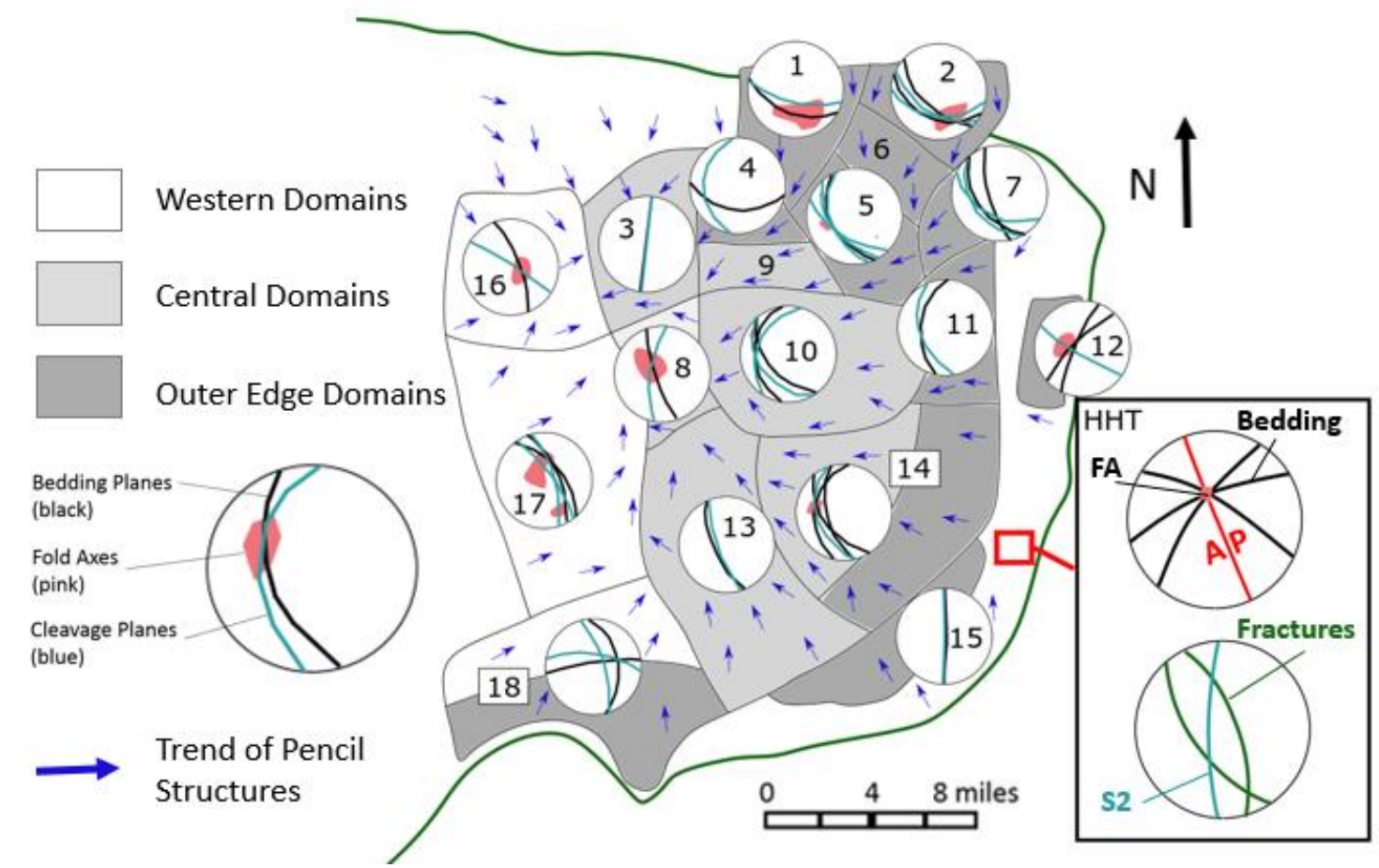

Figure 7.1. The Hamma Hamma Transect (HHT) structural data for the meta-sedimentary Sites 1 and 2 compared to the data from Tabor \& Cady (1978). FA=Fold Axis, AP=Axial Plane.

\subsubsection{The Crescent Formation of the Peripheral Rocks}

The bedding data from the Hamma Hamma Transect is consistent with the bedding data for the rest of the Crescent Formation (Fig. 7.2). The beds are steeply dipping, which indicates that the rest of the Crescent Fm. has also been turned on end from its initial orientation of deposition. The general trend in the bedding in the region is that it strikes subparallel to the HRF, and wraps around the eastern core (Gerstel \& Lingley, 2003; Tabor \& Cady, 1978).

There is no detailed study of the fracture orientation at the outcrop scale in the Crescent Fm. so the data from this study are limited to comparisons with structures 
mapped at the regional scale or proposed from the literature (Fig. 7.2). Map-scale faults in the area include the Saddle Mountain Fault (SMF), the Frigid Creek Fault (FCF), the Canyon River Fault (CRF), and the proposed western extent of the Seattle Fault (SF) (Blakely et al., 2009). Fault Groups B and C strike subparallel to the Saddle Mountain Fault, with Group $\mathrm{C}$ having the same dip direction. The Saddle Mountain Fault is a reverse fault with sinistral component, so although the orientation is similar, the slickenline data from Fault Groups B and C do not match this style of motion. Fault Group D strikes and dips similarly to the Seattle Fault, and the slickenlines of Fault Group D agree with the dip-slip motion of the Seattle Fault. The map-scale faults of the Crescent Formation have been interpreted as playing a role in accommodating N-S shortening from regional rotation of the Siletzia block (Blakely et al., 2009).

Eddy, Clark, \& Polenz (2017) propose that there is a fault separating the Blue Mountain Unit and the rest of the Crescent Fm. that runs parallel to the HRF throughout the peninsula. Of the faults identified in this study, none of the fault groups are subparallel to the HRF or bedding, so it is unlikely these faults represent the fault proposed by Eddy, Clark, \& Polenz (2017). 

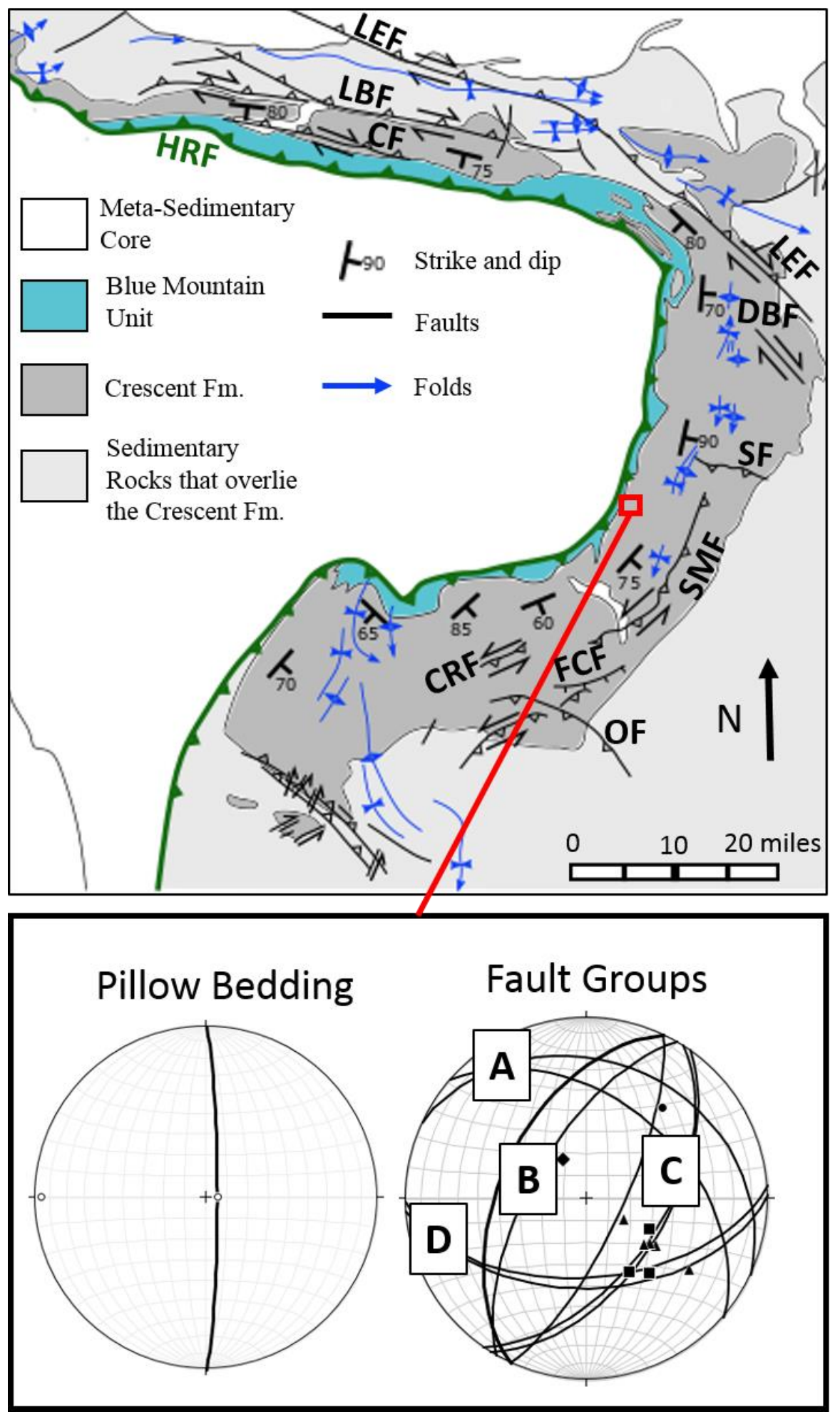

Figure 7.2. The Hamma Hamma Transect structural data for the pillow basalt outcrops, Sites 3 and 4, compared to regional structures of the Crescent Fm. 
7.2 Analysis of Regional Structures Relative to the Models for Exhumation

In a classic accretionary complex, imbricate faults and moderately plunging folds form parallel to and dip towards the subduction margin (Davis, Suppe, \& Dahlen, 1983). The Crescent Fm. has an arcuate shape, which Tabor \& Cady (1978) state is either inherited from the shape of the accreted terrane or was established by deformation after accretion. Some researchers argue that this shape is a product of exhumational doming alone (Warnock, Burmester, \& Engebretson, 1993) from the uneven E-W accretion of sediments along the orogen. The data from this study suggests E-W compression, which supports the accretionary model. However, other researchers cite N-S oriented shortening in the formation of the arcuate shape of the Crescent Fm. and as a driver of exhumation. The structural data presented from the Hamma Hamma Transect may also form from a N-S maximum stress. Therefore, it may be that the structures began as what would be expected for a normal accretionary wedge and were subsequently folded about a vertical axis as the rock packages were pushed against the Canadian Buttress (Fig. 7.3).

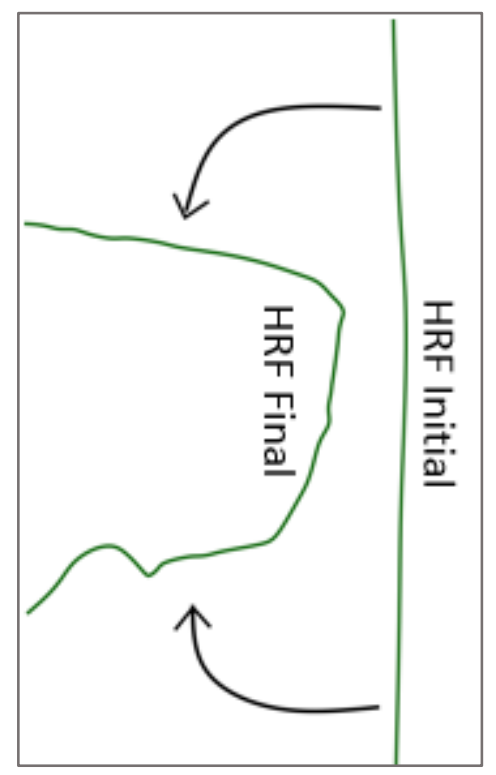

Figure 7.3. Hypothesis for the folding of the HRF by N-S shortening showing the proposed initial and final positions of the fault. 
To address this hypothesis, the bedding and fault data for the Outer Edge Domains in the eastern core and the Crescent were 'unfolded' in the same way as expected for the HRF if the orogen originally had a straight subduction margin (Fig. 7.4). The result is that faults and folds with orientations subparallel to the edge of the peripheral rocks and the HRF have similar orientations along the strike of the orogen, which is what is expected in a normal accretionary wedge. The rocks of the Hamma Hamma Transect would not have been rotated in this model, so this would need to be taken into account when comparing the Hamma Hamma Transect data with other localities elsewhere in the Crescent Formation. 


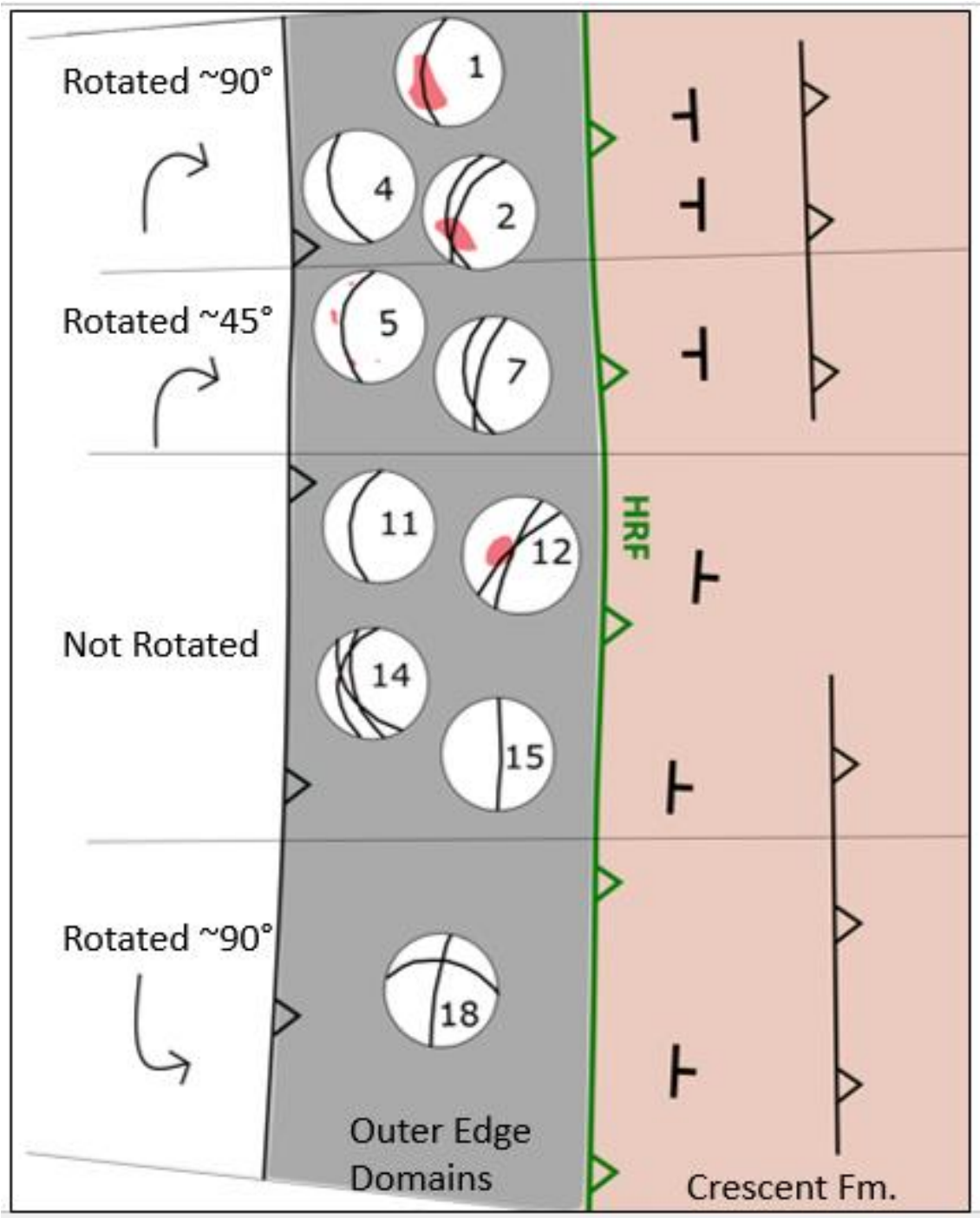

Figure 7.4. A schematic of how the bedding and fault data for the Outer Edge Domains and the Crescent Fm. would look if it were unfolded along with the HRF as depicted in Figure 7.3. 


\section{Conclusion}

The purpose of this work was to characterize the structures at the meso-scale on both sides of the Hurricane Ridge Fault along the Hamma Hamma River Transect and then to interpret structures to create a model of deformation for the study area. This was accomplished by field mapping of structures, analysis of structural orientations in stereographic projection, and microscale analysis of samples collected from the sites.

Strain was accommodated in the meta-sedimentary rocks through folding, foliation development, fracturing, and rotation of the rock package. Strain was accommodated in the basalt by faulting, fracturing, rotation of beds, and foliation development in metasedimentary material along some bedding planes.

In the meta-sediments, two main periods of deformation are identified: one where the rocks deformed by folding and fabric formation under E-W or ENE-WSW oriented compression followed by another period in which the rocks were fractured and rotated by $\mathrm{N}-\mathrm{S}$ or NNW-SSE oriented compression. In the pillow basalts, two or possibly three periods of deformation are identified: first a period of E-W compression that rotated and faulted the rocks, followed by further faulting from N-S or NNW-SSE oriented compression, and then finally, reactivation of the faults by vertical compression. The second step in the pillow basalts is speculative because the evidence for it is weaker than that for the other periods of deformation.

The interpretation of the data presented in this work supports the N-S oriented regional shortening of Siletzia model for Olympic exhumation (as described by 
McCaffrey et al., 2007 and Wells et al., 2014). The fracturing and rotation of the folds in the meta-sediments and Fault Group D in the pillow basalts suggest deformation by a N-S or NNW-SSE oriented principal stress. However, the study area is small and the states of stress detected may be local phenomena. In order to truly test this model, more mesoscale structural studies would need to be performed in other areas of the peninsula. 


\section{References}

Allmendinger, R. W., Cardozo, N. C., \& Fisher, D. (2013) Structural Geology Algorithms: Vectors \& Tensors. Cambridge, England: Cambridge University Press.

Anderson, E. M. (1905). The dynamics of faulting. Edinburgh Geological Society Transactions, 8, pp. 393-402.

Batt, G. E., Brandon, M. T., Farley, K. A., \& Roden-Tice, M. (2001). Tectonic synthesis of the Olympic Mountains segment of the Cascadia wedge, using twodimensional thermal and kinematic modeling of thermochronological ages. Journal of Geophysical Research, 106(B11), pp. 26731-26746.

Blakely, R. J., Sherrod, B. L., Hughes, J. F., Anderson, M. L., Wells, R. E., \& Weaver, C. S. (2009). Saddle Mountain fault deformation zone, Olympic Peninsula, Washington: Western boundary of the Seattle uplift. Geosphere, 5(2), pp. 105125.

Blakely, R. J., Sherrod, B. L., Weaver, C. S., Wells, R. E., Rohay, A. C., Barnett, E. A., \& Knepprath, N. E. (2011). Connecting the Yakima fold and thrust belt to active faults in the Puget Lowland, Washington. Journal of Geophysical Research, 116(B07105), pp. 1-33.

Brandon, M. T., Roden-Tice, M. K., \& Garver, J. I. (1998). Late Cenozoic exhumation of the Cascadia accretionary wedge in the Olympic Mountains, northwest Washington State. Bulletin of the Geological Society of America, 110(8), pp. 9851009.

Brandon, M. T., \& Vance, J. A. (1992). Tectonic evolution of the Cenozoic Olympic subduction complex, Washington State, as deduced from fission track ages for detrital zircons. American Journal of Science, 292, pp. 565-636.

Brocher, T. M., Wells, R. E., Lamb, A. P., \& Weaver, C. S. (2017). Evidence for distributed clockwise rotation of the crust in the northwestern United States from fault geometries and focal mechanisms. Tectonics, 36, 787-818.

Cardozo, N. \& Allmendinger, R. W. (2013). Spherical projections with OSXStereonet: Computers \& Geosciences, 51, pp. 193-205.

Davis, D., Suppe, J., \& Dahlen, F. A. (1983). Mechanics of fold-and-thrust belts and accretionary wedges. Journal of Geophysical Research, 88(B2), pp. 1153-1172.

Duncan, R. A. (1982). A captured island chain in the Coast Range of Oregon and Washington. Journal of Geophysical Research, 87(B13), pp. 10,827-10,837. 
Eddy, M. P., Clark, K. P., \& Polenz, M. (2017). Age and volcanic stratigraphy of the Eocene Siletzia oceanic plateau in Washington and on Vancouver Island. Lithosphere, 9(4), pp. 652-664.

Garrison R. E. (1972). Inter- and intrapillow limestones of the Olympic Peninsula, Washington. The Journal of Geology, 80(3), pp. 310-322.

Gerstel, W. J. \& Lingley, W. S. Jr. (2000). Geologic Map of the Forks Quadrangle, Washington [map]. (1:100,000). Olympia, WA: Washington State Department of Natural Resources.

Gerstel, W. J. \& Lingley, W. S. Jr. (2003). Geologic Map of the Mount Olympus Quadrangle, Washington [map]. (1:100,000). Olympia, WA: Washington State Department of Natural Resources.

Glassley, W. (1974). Geochemistry and tectonics of the Crescent Volcanic Rocks, Olympic Peninsula, Washington. Geological Society of America Bulletin, 85, pp. 785-794.

Healy, D. Blenkinsop, T. G., Timms, N. E., Meredith, P. G., Mitchell, T. M., Cooke, M. L. (2015). Polymodal faulting: Time for a new angle on shear failure. Journal of Structural Geology, 80, pp. 57-71.

Hirsch, D. M., \& Babcock, R. S. (2009). Spatially heterogeneous burial and high-P/T metamorphism in the crescent formation, Olympic Peninsula, Washington. American Mineralogist, 94, pp.1103-1110.

Joyner, C. N. (2016). Lacustrine Megaturbidites and Displacement Waves: The Holocene Earthquake History of the Lake Creek-Boundary Creek Fault at Lake Crescent, Washington, USA. Thesis. Retrieved from https://repository.lib.ncsu.edu/handle/1840.20/33332.

Lamb, A. P., Liberty, L. M., Blakely, R. J., Pratt, T. L., Sherrod, B. L., \& van Wijk, K. (2012). Western limits of the Seattle fault zone and its interaction with the Olympic Peninsula, Washington. Geosphere, 8(4), pp. 915-930.

Logan, R. L. (2003). Geologic Map of the Shelton 1:100,000 Quadrangle, Washington [map]. (1:100,000). Olympia, WA: Washington State Department of Natural Resources.

Lyttle N. A. \& Clark D. B. (1975). New Analyses of Eocene basalt from the Olympic Peninsula, Washington. Geological Society of America Bulletin, 86, pp. 421-427.

McCaffrey, R., Qamar, A. I., King, R. W., Wells, R., Khazaradze, G., Williams, C. A., Stevens, C. W., Vollick, J. J., \& Zwick, P. C. (2007). Fault locking, block rotation 
and crustal deformation in the Pacific Northwest. Geophysical Journal International, 169(3), pp. 1315-1340.

Nelson, A. R., Personius, S. F., Wells, R. E., Schermer, E. R., Bradley, L., Buck, J., \& Reitman, N. (2017). Holocene earthquakes of magnitude 7 during westward escape of the Olympic Mountains, Washington. Bulletin of the Seismological Society of America, 107 (5), pp. 2394-2415.

Orange, D. L., Geddes, D. S., \& Moore, J. C. (1993). Structural and fluid evolution of a young accretionary complex: the Hoh rock assemblage of the western Olympic Peninsula, Washington. Geological Society of America Bulletin, 105(8), pp. 1053-1075.

Pazzaglia, F. J., \& Brandon, M. T. (2001). A fluvial record of long-term steady-state uplift and erosion across the Cascadia forearc high, Western Washington State. American Journal of Science, 301, pp. 385-431.

Schasse, H. W. (2003)a. Geologic Map of the Washington portion of the Cape Flattery 1:100,000 Quadrangle [map]. (1:100,000). Olympia, WA: Washington State Department of Natural Resources.

Schasse, H. W. (2003)b. Geologic Map of the Washington portion of the Port Angeles 1:100,000 Quadrangle [map]. (1:100,000). Olympia, WA: Washington State Department of Natural Resources.

Schmandt, B., \& Humphreys, E. (2011). Seismically imaged relict slab from the $55 \mathrm{Ma}$ Siletzia accretion to the northwest United States. Geology, 39(2), pp. 175-178.

Stipp, M., Stunitz, H., Heilbronner, R., \& Schmid, S. M. (2002). The eastern Tonale fault zone: a 'natural laboratory' for crystal plastic deformation of quartz over a temperature range from 250 to $700^{\circ} \mathrm{C}$. Journal of Structural Geology, 24, pp. 1861-1884.

Tabor, R. W. \& Cady, W. M. (1978). The structure of the Olympic Mountains, Washington; analysis of a subduction zone. U. S. Geological Survey Professional Paper, 1033.

Walsh, T. J. and Logan, R. L. (2007). Results of trenching the Canyon River Fault, southeast Olympic Mountains, Washington [abstract for GSA presentation]. Presented at GSA Cordilleran Section Meeting on 6 May 2007. Retrieved from: https://gsa.confex.com/gsa/2007CD/finalprogram/abstract_121357.htm.

Warnock, A. C., Burmester, R. F., \& Engebretson, D. C. (1993). Paleomagnetism and tectonics of the Crescent Formation, northern Olympic Mountains, Washington. Journal of Geophysical Research, 98(B7), 11,729-11,741. 
Wells, R., Bukry, D., Friedman, R., Pyle, D., Duncan, R., Haeussler, P., \& Wooden, J. (2014). Geologic history of Siletzia, a large igneous province in the Oregon and Washington Coast Range: Correlation to the geomagnetic polarity time scale and implications for a long-lived Yellowstone hotspot. Geosphere, 10(4), 692-719.

Wells, R. E., \& McCaffrey, R. (2013). Steady rotation of the Cascade arc. Geology, 41(9), pp. 1027-1030.

Wells, R. E., Weaver, C. S., \& Blakely, R. J. (1998). Fore-arc migration in Cascadia and its neotectonic significance. Geology, 26(8), 759-762. 


\section{Appendix: Spatial and Structural Data}

Table A1. GPS locations of each site from the Hamma Hamma Transect.

\begin{tabular}{|c|c|c|c|c|}
\hline \multirow{2}{*}{ Site } & \multicolumn{2}{|c|}{ Starting Point } & \multicolumn{2}{c|}{ Ending Point } \\
\hline & Latitude & Longitude & Latitude & Longitude \\
\hline 1 & 47.575218 & -123.261287 & 47.575818 & -123.259652 \\
\hline 2 & 47.580019 & -123.251279 & 47.580186 & -123.250621 \\
\hline 3 & 47.582472 & -123.228886 & 47.582588 & -123.227200 \\
\hline 4 & 47.582154 & -123.223441 & 47.582376 & -123.222123 \\
\hline
\end{tabular}

Table A2. Strike and dip measurements of bedding planes from the meta-sedimentary outcrops along the Hamma Hamma Transect.

\begin{tabular}{|c|c|c|c|c|c|c|c|c|c|c|c|}
\hline Site & Strike & Dip & Site & Strike & Dip & Site & Strike & Dip & Site & Strike & Dip \\
\hline $1 \mathrm{a}$ & 190 & 78 & $1 b$ & 193 & 80 & $1 d$ & 131 & 85 & $1 \mathrm{f}$ & 276 & 70 \\
\hline $1 a$ & 189 & 81 & $1 c$ & 219 & 81 & $1 \mathrm{e}$ & 172 & 61 & $1 \mathrm{f}$ & 296 & 63 \\
\hline $1 a$ & 156 & 81 & $1 c$ & 199 & 70 & $1 \mathrm{e}$ & 176 & 60 & $1 \mathrm{f}$ & 301 & 71 \\
\hline $1 a$ & 173 & 75 & $1 c$ & 184 & 70 & $1 \mathrm{e}$ & 261 & 78 & $1 \mathrm{f}$ & 244 & 61 \\
\hline $1 a$ & 191 & 84 & $1 c$ & 214 & 86 & $1 e$ & 269 & 69 & $1 \mathrm{f}$ & 325 & 72 \\
\hline $1 a$ & 196 & 81 & $1 c$ & 212 & 83 & $1 e$ & 247 & 72 & 1f & 328 & 66 \\
\hline $1 a$ & 186 & 80 & $1 c$ & 189 & 76 & $1 e$ & 252 & 73 & $2 a$ & 197 & 70 \\
\hline $1 a$ & 183 & 75 & $1 c$ & 186 & 76 & $1 e$ & 258 & 75 & $2 a$ & 202 & 60 \\
\hline $1 a$ & 188 & 75 & $1 c$ & 198 & 80 & $1 \mathrm{e}$ & 1 & 89 & $2 a$ & 204 & 70 \\
\hline $1 \mathrm{a}$ & 166 & 76 & $1 c$ & 219 & 85 & $1 e$ & 174 & 81 & $2 a$ & 206 & 70 \\
\hline $1 a$ & 180 & 75 & $1 c$ & 55 & 86 & $1 \mathrm{e}$ & 265 & 80 & $2 a$ & 208 & 75 \\
\hline $1 \mathrm{a}$ & 172 & 79 & $1 c$ & 39 & 84 & $1 \mathrm{e}$ & 268 & 58 & $2 a$ & 211 & 69 \\
\hline $1 a$ & 175 & 79 & $1 c$ & 47 & 81 & $1 e$ & 272 & 69 & $2 a$ & 212 & 80 \\
\hline
\end{tabular}




\begin{tabular}{|c|c|c|c|c|c|c|c|c|c|c|c|}
\hline $1 b$ & 208 & 68 & $1 c$ & 219 & 48 & $1 e$ & 250 & 64 & $2 a$ & 213 & 65 \\
\hline $1 b$ & 208 & 66 & $1 c$ & 48 & 72 & $1 e$ & 242 & 76 & $2 a$ & 220 & 68 \\
\hline $1 b$ & 206 & 61 & $1 c$ & 66 & 78 & $1 \mathrm{e}$ & 273 & 70 & $2 a$ & 224 & 71 \\
\hline $1 b$ & 220 & 65 & $1 c$ & 35 & 75 & $1 e$ & 268 & 68 & $2 a$ & 226 & 60 \\
\hline $1 b$ & 215 & 76 & $1 c$ & 36 & 78 & $1 e$ & 273 & 57 & $2 b$ & 256 & 68 \\
\hline $1 b$ & 215 & 68 & $1 c$ & 200 & 80 & $1 e$ & 270 & 64 & $2 b$ & 260 & 70 \\
\hline $1 b$ & 218 & 70 & $1 d$ & 222 & 63 & $1 \mathrm{f}$ & 271 & 54 & $2 b$ & 285 & 55 \\
\hline $1 b$ & 214 & 65 & $1 d$ & 240 & 70 & $1 f$ & 263 & 60 & $2 b$ & 290 & 62 \\
\hline $1 b$ & 213 & 80 & $1 d$ & 240 & 80 & $1 \mathrm{f}$ & 270 & 56 & $2 b$ & 290 & 59 \\
\hline $1 b$ & 214 & 81 & $1 d$ & 239 & 73 & $1 \mathrm{f}$ & 294 & 70 & $2 b$ & 229 & 67 \\
\hline $1 b$ & 211 & 76 & $1 d$ & 241 & 73 & $1 \mathrm{f}$ & 298 & 65 & $2 b$ & 255 & 63 \\
\hline $1 b$ & 214 & 73 & $1 d$ & 234 & 75 & $1 \mathrm{f}$ & 312 & 79 & $2 c$ & 182 & 65 \\
\hline $1 b$ & 206 & 70 & $1 d$ & 236 & 74 & $1 \mathrm{f}$ & 324 & 74 & $2 c$ & 197 & 75 \\
\hline $1 b$ & 210 & 76 & $1 d$ & 242 & 65 & $1 \mathrm{f}$ & 306 & 82 & $2 c$ & 255 & 84 \\
\hline $1 b$ & 204 & 71 & $1 d$ & 250 & 76 & $1 \mathrm{f}$ & 311 & 70 & $2 c$ & 291 & 69 \\
\hline \multirow[t]{2}{*}{$1 b$} & 206 & 84 & $1 d$ & 306 & 80 & $1 \mathrm{f}$ & 306 & 75 & $2 c$ & 35 & 79 \\
\hline & & & & & & & & & $2 c$ & 85 & 61 \\
\hline
\end{tabular}


Table A3. Strike and dip measurements of mineralizes fractures (veins) from the meta-sedimentary outcrops along the Hamma Hamma Transect.

\begin{tabular}{|l|r|r|l|r|r|r|r|r|r|r|r|}
\hline Site & Strike & Dip & Site & Strike & Dip & Site & Strike & Dip & Site & Strike & Dip \\
\hline 1c & 113 & 55 & $1 \mathrm{c}$ & 128 & 67 & $1 \mathrm{c}$ & 336 & 46 & $2 \mathrm{~b}$ & 315 & 69 \\
\hline 1c & 116 & 68 & $1 \mathrm{c}$ & 120 & 59 & $1 \mathrm{e}$ & 159 & 61 & $2 \mathrm{~b}$ & 110 & 85 \\
\hline 1c & 113 & 61 & $1 \mathrm{c}$ & 116 & 66 & $1 \mathrm{e}$ & 150 & 65 & $2 \mathrm{~b}$ & 320 & 89 \\
\hline 1c & 117 & 59 & $1 \mathrm{c}$ & 123 & 71 & $1 \mathrm{f}$ & 300 & 71 & $2 \mathrm{~b}$ & 305 & 81 \\
\hline 1c & 104 & 71 & $1 \mathrm{c}$ & 313 & 35 & $1 \mathrm{f}$ & 216 & 54 & $2 \mathrm{~b}$ & 301 & 90 \\
\hline & & & & & & & & & $2 \mathrm{~b}$ & 131 & 54 \\
\hline
\end{tabular}

Table A4. Strike and dip measurements of foliation planes from the meta-sedimentary outcrops along the Hamma Hamma Transect.

\begin{tabular}{|c|c|c|c|c|c|c|c|c|}
\hline Site & Strike & Dip & Site & Strike & Dip & Site & Strike & Dip \\
\hline $1 a$ & 136 & 61 & $1 c$ & 356 & 72 & $1 \mathrm{f}$ & 331 & 80 \\
\hline $1 a$ & 155 & 74 & $1 c$ & 359 & 74 & $1 f$ & 337 & 81 \\
\hline $1 a$ & 167 & 72 & $1 c$ & 3 & 81 & $1 f$ & 356 & 80 \\
\hline $1 b$ & 183 & 58 & $1 c$ & 184 & 82 & 1f & 202 & 69 \\
\hline $1 b$ & 178 & 70 & $1 \mathrm{c}$ & 182 & 75 & If & 330 & 80 \\
\hline $1 b$ & 183 & 71 & $1 c$ & 172 & 68 & $2 a$ & 18 & 85 \\
\hline $1 b$ & 189 & 72 & $1 d$ & 350 & 69 & $2 a$ & 350 & 80 \\
\hline $1 b$ & 180 & 76 & $1 d$ & 1 & 85 & $2 a$ & 135 & 48 \\
\hline $1 b$ & 174 & 71 & $1 e$ & 195 & 78 & $2 b$ & 181 & 69 \\
\hline $1 b$ & 170 & 80 & $1 e$ & 175 & 74 & $2 b$ & 185 & 76 \\
\hline $1 b$ & 175 & 73 & $1 \mathrm{e}$ & 187 & 77 & $2 b$ & 189 & 66 \\
\hline $1 b$ & 171 & 78 & $1 \mathrm{e}$ & 189 & 90 & $2 b$ & 350 & 85 \\
\hline $1 b$ & 165 & 65 & $1 e$ & 204 & 63 & $2 b$ & 177 & 61 \\
\hline
\end{tabular}




\begin{tabular}{|l|r|r|l|r|r|r|r|r|}
\hline $1 c$ & 180 & 76 & $1 \mathrm{e}$ & 345 & 77 & $2 \mathrm{~b}$ & 215 & 71 \\
\hline $1 \mathrm{c}$ & 184 & 84 & $1 \mathrm{e}$ & 325 & 80 & $2 \mathrm{~b}$ & 176 & 65 \\
\hline $1 \mathrm{c}$ & 182 & 79 & $1 \mathrm{f}$ & 332 & 80 & $2 \mathrm{c}$ & 189 & 60 \\
\hline $1 \mathrm{c}$ & 179 & 81 & $1 \mathrm{f}$ & 335 & 75 & $2 \mathrm{c}$ & 193 & 65 \\
\hline $1 \mathrm{c}$ & 173 & 75 & & & & & & \\
\hline
\end{tabular}

Table A5. Strike and dip measurements of fracture planes and trend and plunge measurements of associated slickenlines from the meta-sediment outcrops along the Hamma Hamma Transect.

\begin{tabular}{|c|c|c|c|c|c|c|c|c|c|}
\hline Site & Fracture & lanes & Slicke & lines & Site & Fracture & anes & Slicke & lines \\
\hline & Strike & Dip & Plunge & Trend & & Strike & Dip & Plunge & Trend \\
\hline $1 a$ & 82 & 40 & 40 & 165 & $1 d$ & 125 & 65 & 50 & 290 \\
\hline $1 a$ & 100 & 55 & 54 & 178 & $1 d$ & 136 & 85 & 85 & 198 \\
\hline $1 a$ & 75 & 45 & 45 & 180 & $1 d$ & 135 & 65 & 65 & 80 \\
\hline $1 \mathrm{a}$ & 96 & 55 & 55 & 295 & $1 e$ & 160 & 78 & 58 & 175 \\
\hline $1 b$ & 125 & 45 & & & $1 \mathrm{e}$ & 139 & 76 & 80 & 72 \\
\hline $1 b$ & 130 & 51 & & & $1 e$ & 150 & 65 & & \\
\hline $1 b$ & 95 & 36 & & & $1 \mathrm{e}$ & 135 & 35 & & \\
\hline $1 b$ & 75 & 35 & & & $1 e$ & 130 & 80 & & \\
\hline $1 b$ & 138 & 40 & 40 & 220 & $1 \mathrm{e}$ & 148 & 40 & & \\
\hline $1 b$ & 141 & 36 & 35 & 208 & $1 \mathrm{e}$ & 140 & 64 & & \\
\hline $1 b$ & 132 & 37 & 35 & 195 & $1 \mathrm{f}$ & 300 & 79 & & \\
\hline $1 b$ & 96 & 48 & 45 & 215 & $1 \mathrm{f}$ & 151 & 69 & & \\
\hline $1 b$ & 115 & 65 & 60 & 226 & $1 \mathrm{f}$ & 141 & 53 & & \\
\hline $1 b$ & 156 & 58 & & & $1 \mathrm{f}$ & 136 & 42 & & \\
\hline
\end{tabular}




\begin{tabular}{|c|c|c|c|c|c|c|c|c|c|}
\hline $1 b$ & 135 & 72 & & & if & 165 & 80 & & \\
\hline $1 b$ & 278 & 74 & & & $1 f$ & 260 & 51 & & \\
\hline $1 b$ & 144 & 65 & & & $2 a$ & 142 & 57 & 80 & 290 \\
\hline $1 c$ & 108 & 66 & & & $2 a$ & 332 & 64 & 55 & 126 \\
\hline $1 c$ & 131 & 59 & & & $2 a$ & 334 & 70 & 60 & 120 \\
\hline $1 c$ & 114 & 60 & & & $2 a$ & 135 & 65 & & \\
\hline $1 c$ & 162 & 65 & 20 & 155 & $2 a$ & 126 & 85 & & \\
\hline $1 c$ & 325 & 72 & 69 & 60 & $2 a$ & 105 & 75 & & \\
\hline $1 c$ & 158 & 70 & & & $2 b$ & 305 & 77 & & \\
\hline 1c & 120 & 70 & & & $2 b$ & 275 & 66 & & \\
\hline $1 c$ & 65 & 36 & & & $2 b$ & 274 & 60 & & \\
\hline $1 c$ & 75 & 64 & & & $2 b$ & 285 & 68 & & \\
\hline $1 c$ & 141 & 56 & & & $2 b$ & 304 & 80 & & \\
\hline $1 c$ & 340 & 53 & & & $2 b$ & 135 & 69 & & \\
\hline $1 c$ & 317 & 43 & & & $2 c$ & 290 & 68 & & \\
\hline $1 c$ & 110 & 60 & & & $2 c$ & 293 & 78 & & \\
\hline $1 c$ & 104 & 69 & & & $2 c$ & 291 & 67 & & \\
\hline $1 d$ & 130 & 85 & & & $2 c$ & 328 & 71 & & \\
\hline
\end{tabular}


Table A6. Strike and dip measurements of bedding planes from the pillow basalt outcrops along the Hamma Hamma Transect.

\begin{tabular}{|c|c|c|c|c|c|c|c|c|c|c|c|}
\hline Site & Strike & Dip & Site & Strike & Dip & Site & Strike & Dip & Site & Strike & Dip \\
\hline 3а & 5 & 81 & $3 b$ & 176 & 84 & $3 c$ & 12 & 80 & $4 c$ & 170 & 74 \\
\hline 3а & 4 & 81 & $3 b$ & 165 & 83 & $3 c$ & 215 & 87 & $4 c$ & 125 & 86 \\
\hline 3а & 164 & 85 & $3 b$ & 344 & 80 & $3 c$ & 174 & 85 & $4 c$ & 172 & 81 \\
\hline $3 a$ & 0 & 83 & $3 b$ & 11 & 84 & $3 c$ & 205 & 88 & $4 c$ & 354 & 89 \\
\hline 3а & 174 & 88 & $3 b$ & 18 & 89 & $3 c$ & 45 & 56 & $4 c$ & 10 & 89 \\
\hline $3 a$ & 206 & 88 & $3 b$ & 354 & 81 & $4 a$ & 295 & 64 & $4 d$ & 177 & 87 \\
\hline $3 a$ & 22 & 85 & $3 b$ & 181 & 71 & $4 a$ & 6 & 85 & $4 d$ & 14 & 90 \\
\hline 3a & 1 & 84 & $3 b$ & 4 & 75 & $4 a$ & 190 & 90 & $4 d$ & 130 & 54 \\
\hline $3 a$ & 178 & 85 & $3 b$ & 170 & 81 & $4 a$ & 176 & 89 & $4 d$ & 21 & 81 \\
\hline $3 a$ & 186 & 80 & $3 c$ & 180 & 89 & $4 a$ & 1 & 81 & $4 d$ & 5 & 90 \\
\hline 3а & 195 & 84 & $3 c$ & 8 & 56 & $4 b$ & 21 & 81 & $4 d$ & 170 & 88 \\
\hline $3 a$ & 0 & 86 & $3 c$ & 165 & 72 & $4 b$ & 345 & 85 & $4 d$ & 354 & 86 \\
\hline 3а & 355 & 83 & $3 c$ & 340 & 42 & $4 b$ & 164 & 87 & $4 d$ & 186 & 78 \\
\hline 3а & 172 & 88 & $3 c$ & 12 & 78 & $4 b$ & 173 & 74 & $4 d$ & 182 & 85 \\
\hline $3 a$ & 354 & 82 & $3 c$ & 358 & 88 & $4 b$ & 336 & 89 & $4 d$ & 6 & 90 \\
\hline $3 a$ & 16 & 69 & $3 c$ & 324 & 79 & $4 b$ & 20 & 56 & $4 d$ & 182 & 73 \\
\hline $3 a$ & 173 & 78 & $3 c$ & 325 & 63 & $4 b$ & 347 & 63 & $4 d$ & 210 & 76 \\
\hline $3 b$ & 343 & 85 & $3 c$ & 171 & 78 & $4 b$ & 358 & 82 & $4 d$ & 173 & 74 \\
\hline $3 b$ & 345 & 86 & $3 c$ & 178 & 86 & $4 b$ & 346 & 78 & $4 d$ & 336 & 89 \\
\hline \multirow[t]{2}{*}{$3 b$} & 8 & 81 & $3 c$ & 18 & 86 & $4 c$ & 34 & 73 & $4 d$ & 20 & 56 \\
\hline & & & & & & & & & $4 d$ & 347 & 63 \\
\hline
\end{tabular}


Table A7. Strike and dip measurements of fault planes and trend and plunge measurements of associated slickenlines from the pillow basalt outcrops along the Hamma Hamma Transect.

\begin{tabular}{|c|c|c|c|c|}
\hline \multirow[t]{2}{*}{ Site } & \multicolumn{2}{|c|}{ Fault Plane } & \multicolumn{2}{|c|}{ Slickenlines } \\
\hline & Strike & Dip & Plunge & Trend \\
\hline \multirow[t]{3}{*}{$3 a$} & 86 & 54 & 45 & 140 \\
\hline & 32 & 54 & 51 & 125 \\
\hline & & & 31 & 125 \\
\hline $3 a$ & 210 & 65 & 65 & 305 \\
\hline \multirow[t]{2}{*}{$3 a$} & 311 & 45 & 35 & 40 \\
\hline & & & 65 & 265 \\
\hline \multirow[t]{2}{*}{$3 b$} & 89 & 49 & 51 & 150 \\
\hline & & & 58 & 116 \\
\hline \multirow[t]{2}{*}{$3 b$} & 35 & 56 & 54 & 126 \\
\hline & & & 56 & 129 \\
\hline $4 a$ & 205 & 50 & & \\
\hline $4 c$ & 25 & 74 & 70 & 120 \\
\hline \multirow[t]{2}{*}{$4 d$} & 295 & 25 & 45 & 315 \\
\hline & & & 18 & 198 \\
\hline
\end{tabular}


Table A8. Strike and dip measurements of mineralized fracture (vein) planes from the pillow basalt outcrops along the Hamma Hamma Transect.

\begin{tabular}{|l|r|r|l|r|r|r|r|r|r|r|r|}
\hline Site & Strike & Dip & Site & Strike & Dip & Site & Strike & Dip & Site & Strike & Dip \\
\hline $3 a$ & 9 & 42 & $3 a$ & 340 & 5 & $3 b$ & 105 & 36 & $3 c$ & 285 & 17 \\
\hline $3 a$ & 161 & 59 & $3 b$ & 305 & 46 & $3 b$ & 320 & 35 & $3 c$ & 345 & 19 \\
\hline $3 a$ & 21 & 66 & $3 b$ & 351 & 29 & $3 c$ & 267 & 20 & $3 c$ & 355 & 31 \\
\hline $3 a$ & 308 & 48 & $3 b$ & 345 & 31 & $3 c$ & 15 & 40 & $3 c$ & 290 & 12 \\
\hline $3 a$ & 320 & 35 & $3 b$ & 356 & 30 & $3 c$ & 175 & 16 & $4 a$ & 303 & 62 \\
\hline $3 a$ & 305 & 39 & $3 b$ & 318 & 15 & $3 c$ & 238 & 8 & $4 a$ & 312 & 40 \\
\hline $3 a$ & 325 & 34 & $3 b$ & 296 & 26 & $3 c$ & 260 & 11 & $4 c$ & 350 & 45 \\
\hline $3 a$ & 22 & 60 & $3 b$ & 25 & 40 & $3 c$ & 295 & 28 & $4 d$ & 327 & 57 \\
\hline $3 a$ & 356 & 85 & $3 b$ & 340 & 12 & $3 c$ & 290 & 28 & $4 d$ & 314 & 59 \\
\hline $3 a$ & 295 & 15 & $3 b$ & 5 & 25 & $3 c$ & 294 & 29 & $4 d$ & 350 & 57 \\
\hline
\end{tabular}


Table A9. Strike and dip measurements of fracture planes from the pillow basalt outcrops along the Hamma Hamma Transect.

\begin{tabular}{|c|c|c|c|c|c|c|c|c|c|c|c|}
\hline Site & Strike & Dip & Site & Strike & Dip & Site & Strike & Dip & Site & Strike & Dip \\
\hline 3а & 122 & 78 & $3 b$ & 335 & 24 & $4 a$ & 195 & 26 & $4 b$ & 205 & 38 \\
\hline 3а & 129 & 81 & $3 b$ & 326 & 30 & $4 a$ & 187 & 15 & $4 b$ & 290 & 34 \\
\hline 3а & 300 & 44 & $3 b$ & 205 & 40 & $4 a$ & 313 & 36 & $4 b$ & 287 & 42 \\
\hline $3 a$ & 284 & 28 & $3 b$ & 311 & 28 & $4 a$ & 312 & 41 & $4 b$ & 290 & 48 \\
\hline $3 a$ & 287 & 26 & $3 b$ & 195 & 44 & $4 a$ & 212 & 48 & $4 b$ & 160 & 45 \\
\hline $3 a$ & 306 & 45 & $3 b$ & 197 & 40 & $4 a$ & 160 & 57 & $4 c$ & 34 & 73 \\
\hline $3 a$ & 291 & 43 & $3 b$ & 304 & 25 & $4 a$ & 188 & 51 & $4 c$ & 132 & 48 \\
\hline 3a & 350 & 61 & $3 b$ & 301 & 22 & $4 a$ & 242 & 51 & $4 c$ & 275 & 20 \\
\hline $3 b$ & 174 & 82 & $3 b$ & 195 & 31 & $4 a$ & 228 & 38 & $4 c$ & 295 & 43 \\
\hline $3 b$ & 134 & 86 & $4 a$ & 180 & 61 & $4 a$ & 301 & 51 & $4 c$ & 199 & 46 \\
\hline $3 b$ & 260 & 60 & $4 a$ & 314 & 50 & $4 a$ & 351 & 79 & $4 c$ & 295 & 42 \\
\hline $3 b$ & 271 & 42 & $4 a$ & 225 & 46 & $4 b$ & 298 & 61 & $4 d$ & 295 & 36 \\
\hline $3 b$ & 325 & 80 & $4 a$ & 215 & 45 & $4 b$ & 219 & 41 & $4 d$ & 200 & 40 \\
\hline $3 b$ & 150 & 82 & $4 a$ & 318 & 50 & $4 b$ & 178 & 42 & $4 d$ & 275 & 25 \\
\hline $3 c$ & 218 & 18 & $4 a$ & 242 & 51 & $4 b$ & 290 & 41 & $4 d$ & 308 & 45 \\
\hline $3 c$ & 160 & 74 & $4 a$ & 228 & 38 & $4 b$ & 310 & 36 & $4 d$ & 310 & 42 \\
\hline $3 c$ & 235 & 36 & $4 a$ & 301 & 51 & $4 b$ & 298 & 39 & $4 d$ & 130 & 54 \\
\hline $3 c$ & 177 & 31 & $4 a$ & 351 & 79 & $4 b$ & 298 & 31 & $4 d$ & 300 & 46 \\
\hline $3 c$ & 186 & 28 & $4 a$ & 345 & 41 & $4 b$ & 240 & 21 & $4 d$ & 292 & 50 \\
\hline $3 c$ & 188 & 28 & $4 a$ & 180 & 59 & $4 b$ & 299 & 38 & $4 d$ & 318 & 46 \\
\hline $3 c$ & 334 & 32 & $4 a$ & 187 & 56 & $4 b$ & 298 & 40 & $4 d$ & 287 & 44 \\
\hline
\end{tabular}




\begin{tabular}{|l|r|r|l|r|r|l|r|r|r|r|r|}
\hline $3 c$ & 270 & 43 & $4 a$ & 331 & 71 & $4 b$ & 250 & 35 & $4 d$ & 302 & 36 \\
\hline $3 c$ & 202 & 35 & $4 a$ & 221 & 35 & $4 b$ & 298 & 45 & $4 d$ & 307 & 36 \\
\hline $3 c$ & 265 & 11 & $4 a$ & 218 & 37 & $4 b$ & 307 & 39 & $4 d$ & 310 & 36 \\
\hline & & & & & & $4 b$ & 220 & 35 & $4 d$ & 298 & 39 \\
\hline
\end{tabular}

